\title{
Effects of the emphasis on achieving adequate yearly progress on teachers and administrators at schools under the constraints of No Child Left Behind
}

\author{
Cathy Ann Burnett Fisher \\ West Virginia University
}

Follow this and additional works at: https://researchrepository.wvu.edu/etd

\section{Recommended Citation}

Fisher, Cathy Ann Burnett, "Effects of the emphasis on achieving adequate yearly progress on teachers and administrators at schools under the constraints of No Child Left Behind" (2010). Graduate Theses, Dissertations, and Problem Reports. 2946.

https://researchrepository.wvu.edu/etd/2946

This Dissertation is protected by copyright and/or related rights. It has been brought to you by the The Research Repository @ WVU with permission from the rights-holder(s). You are free to use this Dissertation in any way that is permitted by the copyright and related rights legislation that applies to your use. For other uses you must obtain permission from the rights-holder(s) directly, unless additional rights are indicated by a Creative Commons license in the record and/ or on the work itself. This Dissertation has been accepted for inclusion in WVU Graduate Theses, Dissertations, and Problem Reports collection by an authorized administrator of The Research Repository @ WVU.

For more information, please contact researchrepository@mail.wvu.edu. 
Effects of the Emphasis on Achieving

Adequate Yearly Progress on Teachers and Administrators

at Schools under the Constraints of No Child Left Behind

\author{
Cathy Ann Burnett Fisher \\ Dissertation submitted to the \\ College of Human Resources \& Education \\ at West Virginia University \\ in partial fulfillment of the requirements \\ for the degree of
}

Doctor of Education

in

Curriculum and Instruction

\author{
Approved by: \\ Patricia Obenauf, Ed. D., Chairperson \\ Ron Iannone, Ed. D. \\ Joy Faini-Saab, Ed. D. \\ Ernest Goeres, Ph. D. \\ David Callejo Perez. Ed. D. \\ Sharon Brisbin, Ed. D. \\ Department of \\ Curriculum and Instruction \\ Morgantown, WV \\ 2010
}

Keywords: Adequate Yearly Progress; Consultants; Curriculum and Instruction; Inclusion; No Child Left Behind; Special Education Issues;

State Mandated Testing; Stress on Educators

Copyright 2010 Cathy Ann Burnett Fisher 


\section{ABSTRACT \\ Effects of the Emphasis on Achieving Adequate Yearly Progress on Teachers and Administrators at Schools under the Constraints of No Child Left Behind \\ Cathy Ann Burnett Fisher}

The purpose of this research was to study the effects of the emphasis on achieving Adequate Yearly Progress at elementary schools under the regulations of the No Child Left Behind legislation. Qualitative data were gathered through interviews with fifty educators: forty-three teachers and seven administrators. All of the educators worked at six schools that had not achieved Adequate Yearly Progress for one or more years. All of the schools had consultants working with the faculty on the implementation of various new teaching strategies and new mandated curricular programs. Some of the findings included the following: 1 . All of the teachers admitted to different levels of low morale and stress. 2. The administrators recognized the effects of the low morale and stress in their teachers. 3. All of the educators felt the need for more staff at their schools including the following: reading, math, data, technology, and special needs teachers. 4. None of the educators believed that the consultants had much of an effect on their daily teaching strategies. 5. Most of the educators felt the district and state officials needed to show empathy for their concerns and listen to the teachers at the building level for input into the necessary changes. Implications for further study included the following: 1 . Doing pilot studies using the suggestions of the educators at schools that had not achieved Adequate Yearly Progress. 2. Setting up programs at the schools in conjunction with other agencies such as the local Department of Health and Human Resources, the local health clinics, and other community agencies to meet the needs of the students regarding their health and conditions of their home lives. 
Running head: EFFECTS OF THE EMPHASIS ON ACHIEVING

\section{ACKNOWLEDGEMENTS}

The author wishes to extend heartfelt thanks and appreciation to all who have assisted in any way with the completion of this dissertation. The cooperation and understanding that you have given to me were essential as I worked my way to the conclusion of this project.

Dr. Patricia Obenauf, my committee chair, continued her faith in me throughout this endeavor and gave me her spirit, support, and encouragement as I worked through this venture. I cannot express how much her confidence and guidance enabled me to complete this task. To my committee members, Drs. Ronald Iannone, Joy Faini-Saab, Ernest Goeres, David Callejo Perez, and Sharon Brisbin, I express my deepest gratitude for your expressions of professional and personal support.

I express my gratitude to the six superintendents, seven administrators, and most especially, to the forty-three teachers who shared their time and encounters with me. Without their comments, I would not have had the data for this study. I only hope that my writing has conveyed what they have experienced. All of you have my utmost respect and admiration.

To all of my friends and family members who have read, commented, suggested, and lived through this with me, I can only say thank for your encouragement and love.

To Dan, my husband, best friend, supporter, and cheerleader, I cannot begin to express my appreciation for all of your love and encouragement throughout my quest to complete this goal.

Most importantly to my dear parents, the late Florence and William Burnett, they taught me the value of an education even before I attended school. I dedicate this paper to them and hope that as a teacher I have been able to instill that same value in my students. 


\section{Table of Contents}

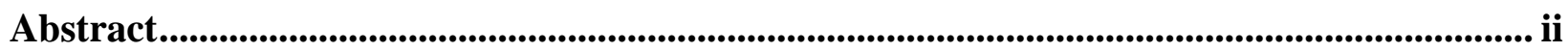

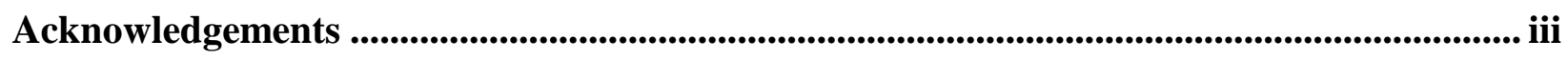

Table of Contents ................................................................................................................... iv

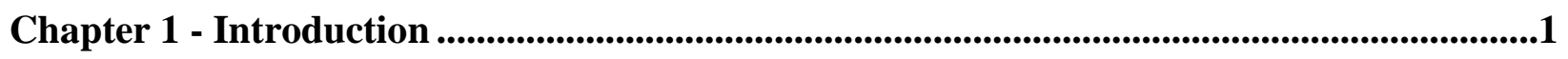

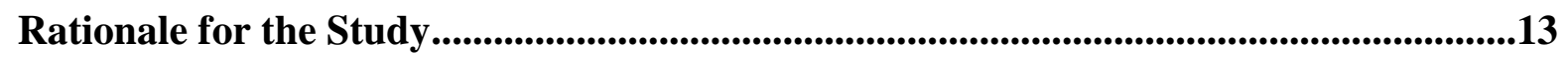

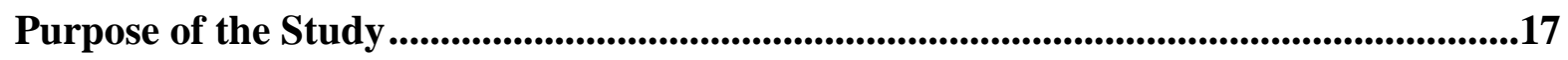

Research Questions ..........................................................................................................18

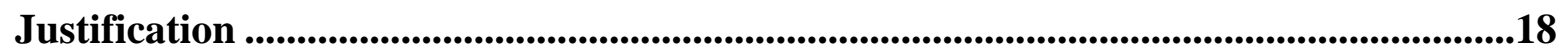

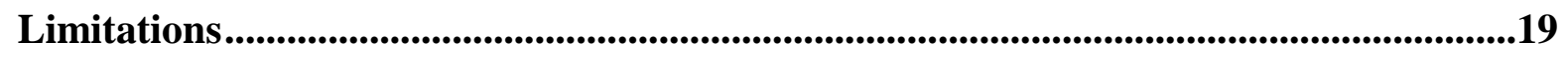

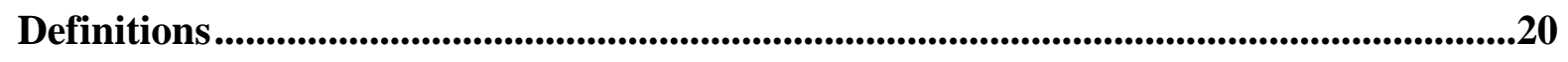

Chapter 2 - Review of the Literature ........................................................................23

Effects of a Consultant's Work at Schools that Did Not Achieve AYP .........................23

Effects of the Emphasis on AYP Achievement on Teachers and Administrators ...........31

Chapter 3 - Methods ........................................................................................................................................441

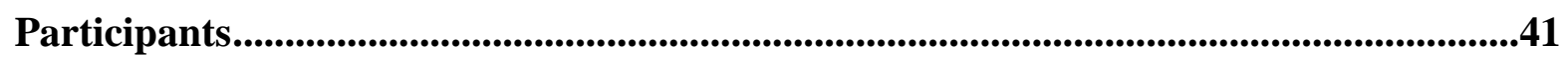

Information about Administrators....................................................................42

Information about the Schools.............................................................................42

Information about School One ...............................................................................................43

Information about School Two ..............................................................................43

Information about School Three ..............................................................................................44

Information about School Four ......................................................................................45

Information about School Five ........................................................................................45

Information about School Six ....................................................................................46

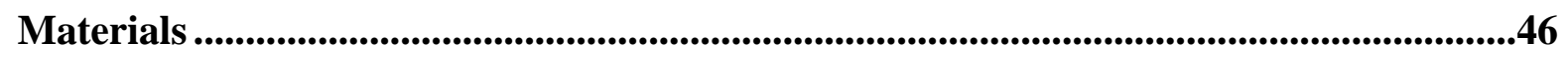

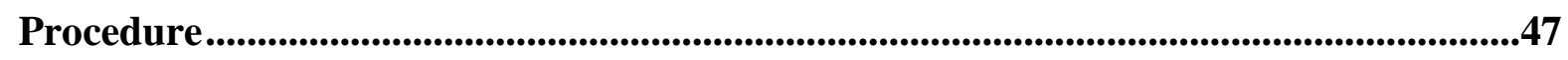


Research Design .50

Chapter 4 - Results of the Teachers' Interviews .58

Theme One - Effects of Consultant on Teachers’ Daily Activities and Work Load......62

Results - Theme One from the Teachers at the Six Schools. .64

Theme Two - Effects of Consultant on Teachers’ Class Management .71

Results - Theme Two from the Teachers at the Six Schools ..........................................72

Theme Three - Effects of Consultant on Changes in Teachers ..........................................79

Results - Theme Three from the Teachers at the Six Schools ..........................................80

Theme Four - Effects of Consultant on Teachers and Most Difficult Aspects ...............85

Results - Theme Four from the Teachers at the Six Schools ..........................................86

Theme Five - Effects of Consultant on Teachers and Empathy from Supervisors........92

Results - Theme Five from the Teachers at the Six Schools ........................................93

Theme Six - Effects of Consultant on Teachers’ Time with Individual Students ..........98

Results - Theme Six from the Teachers at the Six Schools .........................................99

Theme Seven - Effects of Consultants’ Work and Student Home Life .........................104

Results - Theme Seven from the Teachers at the Six Schools ............................................105

Theme Eight -- Effects of AYP Emphasis on Teacher Morale and Motivation...........112

Results - Theme Eight from the Teachers at the Six Schools .......................................114

Theme Nine - Effects of AYP and Teachers' Suggestions for Other Districts .............123

Results - Theme Nine from the Teachers at the Six Schools ........................................125

Theme Ten - Effects of AYP and Empathy from Supervisors for Teachers ................132

Results - Theme Ten from the Teachers at the Six Schools ...........................................133

Theme Eleven - Effects of AYP on Teachers' Training Time.......................................138

Results - Theme Eleven from the Teachers at the Six Schools ...................................139

Theme Twelve - Effects of AYP on Teachers' Staff Changes.............................................142 
Results - Theme Twelve from the Teachers at the Six Schools .143

Theme Thirteen - Effects of AYP on Teachers' Time for Common Planning. 144

Results - Theme Thirteen from the Teachers at the Six Schools 145

Chapter 5 - Results of the Principals' Interviews .148

Theme Fourteen - Effects of Consultant on Principals’ Work Load.

Results - Theme Fourteen from the Principals at the Six Schools

Theme Fifteen - Effects of Consultant on Principals’ Most Difficult Aspects

Results - Theme Fifteen from the Principals at the Six Schools

Theme Sixteen - Effects of Consultant on Principals’ Noticing Teacher Changes.......154

Results - Theme Sixteen from the Principals at the Six Schools .156

Theme Seventeen - Effects of AYP on Principals' Suggestions for Others .158

Results -- Theme Seventeen from the Principals at the Six Schools

Theme Eighteen - Effects of AYP on Principals' Noticing Changes in Staff Morale...162

Results -- Theme Eighteen from the Principals at the Six Schools

Theme Nineteen - Effects of AYP on Principals and Empathy from Supervisors

Results -- Theme Nineteen from the Principals at the Six Schools .166

Theme Twenty - Effects of AYP on Principals as Related to Staff Changes .168

Results -- Theme Twenty from the Principals at the Six Schools .169

Results of Peer Reviews of Transcribed Interviews. .171

Chapter 6 - Summary of Findings .174

Research Question 1 A - Changes in Teachers' Activities and Work Load .176

Research Question 1 A - Changes in Teachers Themselves 179

Research Question 1 A - Teachers' Most Difficult Aspects and Empathy .181

Research Question 1 A - Teachers' Time to Spend with Individual Students .183

Research Question 1 B - Principals’ Work Load and Most Difficult Aspects .186

Research Question 1 B - Principals' Recognition of Changes in Teachers .187 
Research Question 2A - Teachers in Regard to Morale and Motivation ......................188

Research Question 2 A -- Teachers' Need for More Time ............................................190

Research Question 2 A - Teachers' Suggestions, Empathy, and Staff Changes...........191

Research Question 2 B - Principals' Suggestions and Empathy ..................................194

Research Question 2 B - Principals in Regard to Staff Morale and Staff Changes .....196

Limitations .........................................................................................................................196

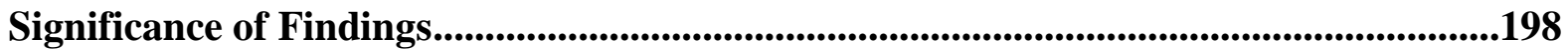

Implications for Future Study .................................................................................201

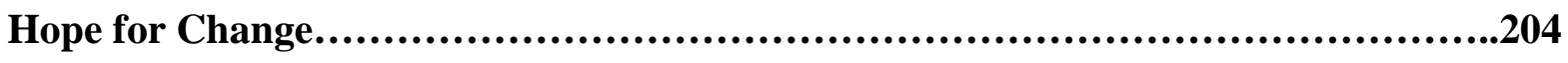

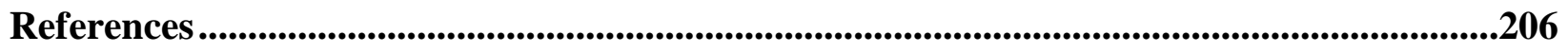

Appendix I - Permission Letter to Superintendents .................................................................213

Appendix II - WVU Internal Review Board Permission ....................................................214

Appendix III- Introductory Letter to Teachers .....................................................................215

Appendix IV - Information about School Administrators ...............................................216

Appendix V - Information about All Participating Schools...................................................217

Appendix VI - School One .............................................................................................................218

Appendix VII - School Two ....................................................................................................219

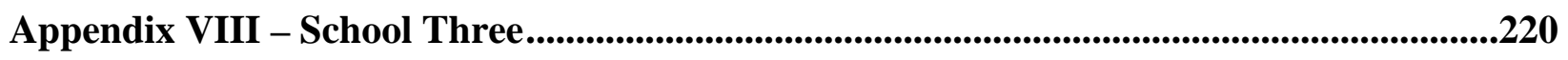

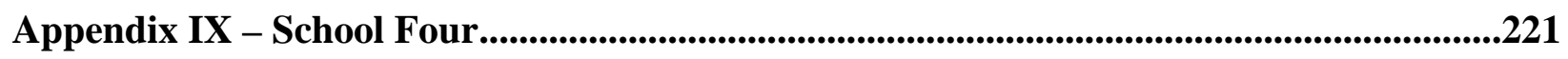

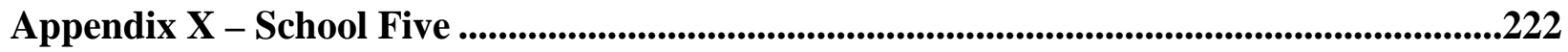

Appendix XI - School Six...............................................................................................................223

Appendix XII - Introductory Script to Begin Interviews ......................................................224

Appendix XIII - Interview Questions (Guide Only) ..................................................225

Appendix XIV - Sample Interview Transcript ......................................................................226

Appendix XV - Background Information of Peer Reviewers ................................................231

Appendix XVI - Development of Themes .......................................................................232 
Running head: EFFECTS OF THE EMPHASIS ON ACHIEVING

\section{CHAPTER 1}

\section{Introduction}

From the very beginning of this nation the founding fathers were concerned with education because they realized that "our democracy was dependent on an educated public" (U. S. Department of Education, 2004, p. 2). It was their belief that "education was not only for the elite, rather for the many” (USDE, 2004, p. 2). It was apparent to the forefathers of this country that "education opens doors to children for a lifetime and leads to their success" (Jorgenson, 2003, p. 7). The crafters of the Constitution of the United States of America truly wanted “education for all” (USDE, 2004, p. 2). John Adams believed that “education for every class and rank of people down to the lowest and the poorest was necessary for the growth and prosperity of the country” (USDE, 2004, p. 2).

Schools of some kind have existed in this country almost since the very first European settlements here. Even prior to that, the Native American Indians had their own pattern of rites, customs, and rituals which were taught to their children and passed down through the generations. When Africans were brought to the colonies, they also brought their traditions and taught them to their children. The teaching of these rituals and traditions was the early rudiments of schooling in the colonies. In those early days one culture began to impose its power on the others. According to James Fraser (2001, p.2) most of the American colonies were founded on a model of a mix of institutions:

- Family - had the responsibility for educating youth in literacy and work skills (farming).

- Church - preached to the youth so they could understand the true faith.

- Community - shared basic values, punished deviance, and organized apprenticeships. 
Running head: EFFECTS OF THE EMPHASIS ON ACHIEVING

- School - provided literacy and math skills and prepared select males for college. (Fraser, 200l, p.2)

The English colonists imposed their religion, education, and culture on the American Indians. They debated what was appropriate for the African-American slaves. They feared that “education and religion might make the slaves eligible for freedom” (Fraser, 2001, p. 2), they continued to educate them in some cases.

In New England, the emphasis on schooling was much greater. As early as 1635, the Boston Latin School was founded. In 1647, it was legislated that any town with fifty households must appoint someone to teach the children. After a town had one hundred households, a school had to be developed for the instruction of the youth. Fraser (200l, p. 3) points out that there were no rules at that time about attendance, especially for girls. The family held the main responsibility for education of the children. The school only served as an option. These schools, along with apprenticeship training, were the prevalent types of education available until the early to mid 1700s.

Although he did not usually include women as citizens and he was a slaveholder, Thomas Jefferson, in 1779, called for the “development of schools throughout the nation” (Fraser, 2001, p. 17). Through this era, Jefferson, John Adams, and Noah Webster were active voices in the design of the early education system of the United States. In 1786, Benjamin Rush, an educated citizen of Pennsylvania, wrote, “it was proper use of tax money to support schools” (Fraser, 2001, p. 21). This novel idea was perhaps the foundation of not only Pennsylvania's educational plan, also that of the American Public School System. Rush was also considered to have a very "liberal approach to the education of women in the new nation" (Fraser, 2001, p. 31). As Rush brought the education of women to another level, Noah Webster was working to shape the 
Running head: EFFECTS OF THE EMPHASIS ON ACHIEVING

“American version of the English language, to add schoolbooks to the classrooms, and to develop an appropriate education for the nation's youth” (Fraser, 2001, p. 35).

These schools of Jefferson, John Adams, Rush, and Webster were still the only options that supported the skills that could not be taught at home. However, in the years before the Civil War the schools began to change into a form similar to what we have today. At this time during the early 1800 s to about 1860, the voice of education became Horace Mann, who served Massachusetts as its first Secretary of the State Board of Education. Mann was a most articulate proponent of "the common school movement” which entailed two goals:

- The school was becoming universal and common to all.

- The school reached the youth when they were young and able to be molded into good Americans.

(Fraser, 2001, p. 49)

These schools became more structured and usually replaced the salaried male schoolmaster with a much lower-paid female teacher. One advocate of the transformation of the male teaching profession to female was Catharine Beecher. As the common schools became more structured, the process of grading the school system became more prevalent. Grading in its earliest form was “a large group of students at all levels together in a large room under the guidance of a single teacher. Instruction was done in small groups led by student monitors” (Labaree, 1997, p. 62). Various prizes were used to encourage the students to compete and eventually they went through a progression of academic levels. “As time passed, the curriculum became classified as: primary, secondary or middle, grammar, and high school. Eventually, grades were established within each level. By the early 1870s, the graded school was accepted as the norm for educational organization” (Labaree, 1997, p. 67). 
Running head: EFFECTS OF THE EMPHASIS ON ACHIEVING

Also, at this time, a variety of educational reforms such as, "longer school terms, better daily attendance, school consolidation, professional training of teachers, and a host of other changes yielded success in the following decades” (Reese, 2005, p. 12). Horace Mann believed that "education could provide social stability and economic mobility for individuals and some others were beginning to think that schools could do this and more” (Reese, 2005, p. 28). As early as 1855, even though Massachusetts did not limit attendance to any public school because of race, color, or religion, the state passed an amendment in regard to ending the practice of segregated schools.

As the country and schools expanded westward from 1835 through the 1860s Catherine Beecher founded the "Board of National Popular Education” (Fraser, 2001, p. 90). This group offered adventure to many young female teachers. Also, published in 1836 in Cincinnati was the first McGuffey Reader. According to Joel Spring (1986, p. 141) the McGuffey Readers were “prepared specifically for use in the development of the common school systems.” References to girls were obviously omitted from the Reader, and the major emphasis was on moral lessons. This made the Readers “an ideal companion for the growth of the industrial society” (Spring, 1986, p. 146). According to Spring, between 1836 and 1922 more than one hundred twenty-two million copies of the Reader were sold to the schools across America. In many ways this little Reader encouraged the ties between America’s public school system and capitalism which continues to this day.

While education and the country continued westward expansion, the Civil War spread throughout the eastern half of the country. During this time there was a young slave, Frederick Douglass, who had been educated somewhat by "his owner's wife and his little white friends", according to Fraser (2001, p. 113). As he learned, he realized that he could not remain a slave 
Running head: EFFECTS OF THE EMPHASIS ON ACHIEVING

for his entire life. He became one of the most respected African-American leaders after the Civil War. Another advocate for the African-Americans was Booker T. Washington, who believed that "the proper education for African-Americans was industrial education and must precede education for high culture” (Fraser, 2001, p. 123). In opposition to this was W.E.B. DuBois, who believed that “African-Americans needed a larger vision and a wider dream if liberation was to be found” (Fraser, 2001, p. 129).

As schools held the promise of economic mobility, many young people were moving to Chicago in the late 1800s because it was becoming a large, industrialized city. John Dewey also found Chicago a place for “engaging life and its problems” (Reese, 2005, p. 137). In his Lab School, children were "engaged in real life experiences, worked together in projects, learned academics, and also social cooperation” (Reese, 2005, p. 139). Dewey though did not believe that the public schools should prepare students for any particular trade. He only sought to teach simultaneously methods of earning a living and various academic subjects. "He opposed those who tried to stream working-class children into vocational high schools” (Reese, 2005, p. 141). He spoke out equally against the shortcomings of the old and new methods of education:

- $\quad$ Fixed rows of desks.

- $\quad$ Rote memorization.

- Undisciplined freedom.

- Aimless activities.

- Childish impulse. (Reese, 2005, p. 142)

However, he never did lose sight of the thought that "schools were vital to social progress and to American Democracy” (Reese, 2005, p. 142). 
Running head: EFFECTS OF THE EMPHASIS ON ACHIEVING

When Dewey first came to Chicago in the late 1880s, common schools and high schools were becoming more firmly, and in some cases, more elaborately established throughout the country. Therefore, a need for teachers was increasing. Even though, "according to many accounts the first normal school had opened in 1839 in Massachusetts, there was still a general teacher shortage” (Labaree, 2004, p. 21). Many large cities were developing their own normal schools to prepare teachers for the local elementary schools. Since there were not yet any provisions that required attendance at a normal school in order to teach, early normal school founders were faced with a problem. As a result of trying to "fill empty seats at the normal schools in the late 1800s and early 1900s, the content and the status of teacher education programs were changed” (Labaree, 2004, p. 24).

As the development of normal schools for teacher preparation continued to rapidly increase, thus began the public views of education:

- Teachers as mere technicians, instead of intellectuals and moral leaders.

- Students as future participants in the industrial-military order instead of as critical thinkers and future citizens.

- Schools as merely training sites for occupational positions in the corporate order instead of centers of critical literacy and civic courage.

(Aronowitz \& Giroux, 1993, p. 220)

Initially, and for many decades, individual states and local governments were left with the task of determining the methods used to deliver the process of education to the citizens. Many more individuals have been noted throughout the history of the American Public School System as champions and contributors to the superior quality of education that has been available across the U.S. Eventually, the federal government began to take a larger role in the public 
Running head: EFFECTS OF THE EMPHASIS ON ACHIEVING

school system of the U.S. By 1918, all states were required to have "compulsory education laws through elementary school” (Thattai, 2001, p. 1). Emphasis on compulsory education further encouraged the shaping of U.S. public school system. This new emphasis centered on science and social efficiency. "The administrative progressives still wanted a one best system, it was to be a more complex, differentiated organization adapted to new social and economic conditions” (Tyack, 1974, p. 188). These individuals wanted to adapt schools to the existing social structure. At this time more junior high schools, high schools, and vocational schools were established. Even the American Federation of Labor (AFL) joined this movement and helped to secure federal funds through the Smith-Hughes Act in 1918” (Tyack, 1974, p. 189).

Then, "in 1958 Congress passed the National Defense Education Act (NDEA) in response to Russia's launch of Sputnik” (Flattau, 2006, p. ES-1). The passage of the NDEA began the "intertwining of the federal government and public school policy and curriculum" (Flynn, 1995, p. 1). Schools were allocated funds to enhance their science and math curricula. This curriculum enrichment effort was just the beginning of the interlocking of the federal government and the educational systems of the individual states. The supporting reason for the NDEA was in regard to national security needs. In 1965, when Congress passed the Elementary and Secondary Education Act (ESEA) as part of President Johnson’s War on Poverty, (Thattai, 2001, p. 3) little did those legislators realize the scope of what ESEA would accomplish. In the 1977 - 1978 congressional hearings for ESEA's reauthorization, the accomplishments of the Act were made clear. It was apparent that ESEA's Title I funds were "being used to provide special services to eligible students in programs that actually were making true contributions to the educational experiences of children." Congress recognized that the "goals of the program were sound and the need for federal commitment to children had not diminished” (Halperin, 1979, p. 
Running head: EFFECTS OF THE EMPHASIS ON ACHIEVING

350). During the reauthorization proceedings, the legislators made sure that federal control would remain at a minimal level. Programs under ESEA’s Title I and Title III were to be “devised locally within a broad range of permissible limits. The states would only give written assurances to the U.S. Commissioner of Education that the requirements were being met” (Halperin, 1979, p. 352). Nationwide, ESEA was “perceived as a vast energizing Act that enabled local authorities and state administrators to plan and conduct an extremely wide array of educational offerings that had been stalled for lack of resources or public support and encouragement” (Halperin, 1979, p. 353).

In 1965, President Johnson and Congress clearly had placed education "at the top of the domestic priority list” (Halperin, 1979, p. 353). The initial passing of ESEA in 1965 was done under bitter contesting. It was then that President Lyndon Johnson decided to work toward getting the largest money authorization ever proposed for the nation's schools. His tireless efforts accomplished the task of breaking the one-hundred-year history of frustrated legislative attempts to approve an act that had the funds to allow local districts to offer truly effective programs to the children of this country. The general citizenry was proud of the passage of the ESEA Act of 1965. The progress of ESEA's programs and their accomplishments were so evident during the 1978 hearings that the bill was reauthorized for another five years with little adjustments or changes, (Halperin, 1979, p. 353).

This legislation was actually the precursor of the No Child Left Behind (NCLB) Act of 2002. Even though the U.S. government was attempting to focus funding on educating those large numbers of school-age children who were living in poverty, in 1973 the U.S. Supreme Court "held that public education was not a fundamental interest under the U.S. Constitution and therefore, the inequitable public school funding scheme in Texas, at that time, was not a violation 
Running head: EFFECTS OF THE EMPHASIS ON ACHIEVING

of the Equal Protection Clause” (Cornell University Law School, 1973, p. 2). As a continuation of the federal government's goal of educating all children, in 1975, Congress ordered all public schools to provide education to all disabled children with the passage of the Education for all Handicapped Children Act. "With the passage of this Act, there was an enormous shift in identified problems, from speech to specific learning disabilities, because the definitions were so vague, those children who got labeled depended partly on where a child lived” (Lewis, 2002, p. 343).

Leaders in Congress were passing legislation which should have enabled officials at the state and local levels to keep the promises made by the founding fathers of this country that stated, "all, regardless of race or class or economic status, are entitled to a fair chance and to the tools for developing their individual powers of mind and spirit to the utmost” (Jorgenson, 2003, p. 2), in April of 1983, President Ronald Reagan received from the members of the National Commission on Excellence in Education their controversial report entitled, A Nation at Risk, which implied that the public education system of this country was becoming second-rate. This was due to the lack of clear goals according to Goldman (1983, p. 26), "We have mindlessly avoided setting clear priorities over these last twenty-eight years. We have been all things to all students, and by doing nothing well we have become A Nation at Risk." Some of the findings of the authors of this divisive report included the following:

- Thirteen percent of U.S. seventeen year-olds could be considered functionally illiterate.

- Scores on the Scholastic Aptitude Test (SAT) were declining in verbal, math, physics and English.

- Forty percent of seventeen year-olds could not draw inferences from written material; only one-fifth could write a persuasive essay; and only one-third could solve a math 
Running head: EFFECTS OF THE EMPHASIS ON ACHIEVING

problem that required several steps.

- Remedial math courses in public four-year colleges had increased by seventy-two percent.

(Jorgenson, 2003, p. 2)

The commission recommended improvements in the following areas:

- Content - graduation requirements should be strengthened.

- Expectations - schools should adopt more rigorous and measurable standards using more challenging materials.

- Time - more emphasis should be placed on using time well, and on more effective use of the existing school day or a longer school day, or a lengthened school year.

- Teaching - improve the preparation, recruitment, and rewarding of teachers. (Jorgenson, 2003, p. 3)

A Nation at Risk implied that all students regardless of their status -- academically or socio-economically -- would be able to achieve at the highest levels. This report started the "reform of achievement testing and standards-based education in the public school system of the United States” (Jorgenson, 2003, p. 3). In an effort to further improve the nation’s public education system, two National Education Summits were held - one in 1989 and one in 1996. These Summits set national education goals which called attention and gave focus to national education standards, hence the passage of the Improving America's Schools Act (IASA) of 1994 and Goals 2000. These Acts continued the new education focus on all students. "Time and research had shown that for all students to learn, the entire school had to focus on the learning of all children” (Jorgenson, 2003, p. 4). This reauthorization of the 1965 ESEA legislation “encouraged states and school districts to connect federal programs with state and local reforms 
Running head: EFFECTS OF THE EMPHASIS ON ACHIEVING

affecting all children, while retaining the focus on educational equity for children with special needs” (Jorgenson, 2003, p. 4). This allowed individual states and local districts to operate their own federally funded education programs. Some of the requirements included the following:

- Development of content and performance standards.

- Assessments aligned with standards.

- Accountability systems to identify schools not achieving standards.

- Non-segregation of students into special classrooms.

- Focus on teaching and learning.

- Resources targeted to areas of greatest need. (Jorgenson, 2003, p. 5)

This legislation caused states to place emphasis on standards-based education and led to the development of individual state achievement tests at a rate that was never before seen in this country. The missing link, then, became the information gathered from the standardized tests that could be used to change the instruction provided to all students in the public schools of America. With this emphasis in mind, in January 2001, President George W. Bush introduced his plan, No Child Left Behind (NCLB), to reform America's public school system. Congress enacted NCLB and it was signed into law on January 8, 2002. This was the largest reform of the 1965 ESEA legislation since its inception and “appeared to promote equality of educational opportunity to a greater extent than the original ESEA legislation” (Kantor, 2006, p. 475).

With the passage of NCLB, funding became tied to accountability expectations. The regulations of the new law, according to the then U. S. Secretary of Education - Rod Paige, were "to see every child in America - regardless of ethnicity, income, or background - achieve high standards" (Jorgenson, 2003, p. 6). Some of the regulations of NCLB included the following: 
Running head: EFFECTS OF THE EMPHASIS ON ACHIEVING

1. States must build assessment systems that track the achievement of all students against a common set of high instructional standards.

2. There must be direct public accountability for individual student learning.

3. Schools and districts work best when allowed to exercise more flexibility and control over teaching methods, while also being held accountable for results.

4. States must test all students annually in the third through and including tenth grades. The tests must be based on challenging state standards.

5. Improvement of all students must be demonstrated under the Adequate Yearly Progress (AYP) provisions of NCLB.

6. Schools not achieving AYP in any subgroup must be provided assistance and may be subject to corrective action.

7. Schools must be encouraged to use funds for teacher retention, professional development, and technology training that best suit their needs without having to obtain separate federal approval.

8. Parents of children in under-performing schools or unsafe schools must be made aware of opportunities for tutoring and transferring to other schools. (Jorgenson, 2003, p.7)

These regulations were designed to reform the U.S. education system so that the educational journey of all children would lead them to success in the global world of the twentyfirst century and beyond. It was believed that these regulations would ensure open doors for all children and truly leave no child behind. According to Labaree (2004, p. 186) there are "two kinds of goals for education: social efficiency and social mobility.” These two goals encouraged the early development of the public education system in this country as far back as the first 
Running head: EFFECTS OF THE EMPHASIS ON ACHIEVING

common schools. In the opinion of this researcher, these goals continued to drive the various regulations, laws, and policies that are currently guiding the schools of this country. These same goals were a foundation for the adoption of the No Child Left Behind Act. The beliefs of political "administrative progressives" are continuing to work on the twenty-first century standards movement. As Tyack (1974, p. 185) wrote, "Problems in the public education system were met, not by changes in its foundations, but by adding fresh stories to its superstructure.” Tyack's beliefs of the 1970s were still applicable now with the implementation of NCLB. Labaree (2004, p. 186) said that the goals of "efficiency and mobility explain both the decline in academic content and the growth in the differentiated form of the curriculum prevalent now.” This researcher believed that these goals continue to shape and determine what is happening in education at the present time.

\section{Rationale for the Study}

As an educator, this researcher was able to observe many of these reform efforts as they trickled down from the federal government - to a local school where this researcher worked as an administrator for five years. This school was located in a high poverty area that also had a large population of special needs students. In regard to the regulations mentioned on the previous page, this researcher observed that this particular school's faculty embraced all of those regulations and worked to ensure that all students were given every possible educational opportunity. With reference to regulations three and seven (as listed on a preceding page) it is noted that these regulations state that "schools should be allowed to exercise control over teaching methods (number three) and that schools would be encouraged to use the funds for teacher retention and professional development (number seven.” After this particular school did not achieve AYP, it was observed by this researcher that the district level interpretation of the 
Running head: EFFECTS OF THE EMPHASIS ON ACHIEVING

NCLB regulations did not allow for input from the school faculty and administration. The NCLB funds provided for professional consultants and commercially prepared materials. These materials came from provisions of the NCLB Act which included language that "mandated scientifically based research to support programs with proven effectiveness” (Labaree, 2004, p. 191). Labaree also pointed out that the United States Department of Education (USDE) established the What Works Clearinghouse in 2002 for the "purpose of promoting scientificallybased research standards for evaluation of educational research” (Labaree, 2004, p. 222). It appeared to this researcher that the USDE was allowing certain educational products to be imposed on teachers without regard for any input from the teachers who spend time each day with students.

Changes in the behavior, attitude, and morale of the faculty and the overall climate of the school became apparent to this researcher when the district placed an instructional consultant at the school and required the teachers to make changes in their regular teaching strategies without allowing them to have any input or control at the school level. The teachers at the school were very willing to talk to this researcher about what was taking place at the building. "Finally, someone cares enough to ask how I feel about all of this” was a common reaction from many of the educators at this school where this researcher worked. It was as if the interaction was therapeutic for them in some way.

These comments led this researcher to believe that the teachers initially were very demoralized and saddened by the fact that the students' scores had not been high enough to meet the level required by the state to make AYP under the mandates of NCLB. The comments of the teachers revealed that they felt personally responsible for the students' scores. They were quite willing, for the most part, to try to integrate the consultant's recommendations into their daily 
Running head: EFFECTS OF THE EMPHASIS ON ACHIEVING

teaching regimens. Many teachers commented that they were hurt by the way these methods had been imposed on them upon the release of the test scores. It was as if, what they had been doing was, in their words: "wrong, incorrect, and unsatisfactory.” According, to what was said by many of the teachers, "If they (the teachers) had been included in the initial planning and decision-making that preceded the selection of the consultant and the materials, perhaps a great deal of the negative effects on teacher morale could have been avoided.” Research shows that there are provisions in NCLB that allow and encourage teachers and local schools to design training that "best suits their needs" (Jorgenson, 2003, p. 7). Perhaps then, more ownership of the program would have been given to the school's faculty and results would have been more positive overall. The conclusions of a Rutgers’ study done by Hoy and Woolfolk (1993, pp. 355372) were that teachers' sense of efficacy; their belief in their ability to have a positive effect on student learning was related to student learning. The label as a School in Need of Improvement had a very negative connation. That label on this school led to a great deal of resentment by the faculty and contributed to making the overall climate of the school one of stress and low morale, according to comments of the teachers and the observations of this researcher while working at the school.

Although the teachers were initially hesitant to accept the consultant, they did incorporate many of her strategies and techniques into their daily teaching activities. Using the commercially prepared test preparation materials had also become accepted by the majority of teachers at the school. However, the teachers expressed that concentrating solely on the test had taken a great deal of the "fun and creativity out of the academic activities of school." Elliot Eisner (1998, p. 193) wrote that "what children learn from their teacher as a person that does not emerge on the standardized achievement tests ... may be among the most important things that 
Running head: EFFECTS OF THE EMPHASIS ON ACHIEVING

they (children) learn in school.” The teachers did express to this researcher that they saw the need for making preparation for the state test their main instructional focus. Wallin (2006, p. 85) emphasized that, "Worksheets reduce complex phenomena to their most manageable, evaluable and isolated units. Learning is reduced to a discovery epistemology wherein students only uncover what has been superficially predetermined.” In contrast to this, Tony Wagner (2008, p. 263) wrote, "In today's world, academic content must be the means by which we teach core competencies - rather than through merely memorizing (and often forgetting) academic content for its own sake.”

These teachers suggested to this researcher that they would, "like to speak to superintendents in other districts about how to handle the situation of not achieving AYP with teachers at other schools." These comments led this researcher to believe that this particular group of teachers had almost come "full circle" (Hahn, 1997, p. 113) with what happened to them after their students' state test scores were found to be inadequate to meet AYP. These teachers wanted to be able to ensure that these feelings of low morale and stress were not imposed on faculties at other schools that did not achieve AYP. "Feelings of personal teacher inadequacy are immediately at the forefront as soon as the phrase - your school did not meet AYP - is uttered" remarked one teacher at this particular school. These teachers' suggestions caused this examiner to believe that these educators now had an understanding of their experiences and of what happened to them. This understanding seemed to lend itself to using phenomenological hermeneutics as a methodology in the further study of this topic by this researcher. According to David Hoy in The Philosophy of Hans-Georg Gadamer (Hahn, 1997, p. 113), "there is a circle in hermeneutics, since what is being interpreted is interpretation itself." It appeared to this researcher that these teachers now had a "self-understanding" of what 
Running head: EFFECTS OF THE EMPHASIS ON ACHIEVING

happened to them as a result of not achieving AYP and now were ready to apply this to the benefit of others in a similar situation. Hoy stated that his interpretation of Gadamer is that, "understanding cannot be broken into pieces and is always conditioned by its context” (Hahn, 1997, p. 113). These teachers recognized the problem in its context; they dealt with it; they responded to it; and they were now ready to use what they had learned to help other educators.

\section{Purpose of the Study}

The background information collected for the introduction and from the experiences of this researcher comprised the many reasons for continuing to do a research study in this area. The stress that was placed on this particular faculty of hard working, focused, goal-driven, and student-centered teachers was quite evident and appeared to this researcher to be something that could have been alleviated at least to some extent. The data and information collected have triggered this examiner to continue to do research and to interview teachers at other elementary schools in other districts where AYP had not been achieved.

As a result of the collection of this background information and the experiences of this researcher two purposes were proposed for further study at schools that had not achieved AYP on the state mandated annual tests according to the guidelines of NCLB.

The purposes of the study were as follows:

1. To determine the effects of a consultant working with teachers and administrators at schools that did not achieve AYP.

2. To determine the effects of the emphasis on achieving AYP on teachers and administrators at schools that did not meet the required proficiency level on the NCLB mandated annual state tests. 
Running head: EFFECTS OF THE EMPHASIS ON ACHIEVING

\section{Research Questions}

The following research questions were used only to guide the investigations of this examiner:

1. What are the effects of a consultant's work at schools that did not achieve AYP on the following:

(A): teachers' instructional techniques, daily work loads, and teaching strategies used with students

and

(B): administrators’ daily work loads, and leadership styles?

2. What effects does the emphasis on achieving AYP at schools that do not meet the required proficiency level on the NCLB mandated annual state tests have on the following:

(A): teachers

and

(B): administrators?

\section{Justification}

These research questions emerged from an analysis of the mandated requirements imposed on schools that did not achieve AYP according to the mandates of NCLB and the experiences of this researcher while working at a school that did not achieve AYP. These research questions served only as a guide for this researcher during the interviews that were conducted with teachers at schools in other districts that had not achieved AYP on the annual state test according to the mandates of No Child Left Behind. In using qualitative research methods in individual interview situations, the answers, solutions, and an understanding of the 
Running head: EFFECTS OF THE EMPHASIS ON ACHIEVING

problems set forth in this research study were attained. This researcher also sought to understand the consequences that the pressure to achieve AYP had on teachers' relationships with their students, teachers’ classroom practices, teachers’ feelings of professionalism, and teachers’ overall well-being. This researcher also felt that further justification for the study could be substantiated from looking at the effects of the emphasis on the achievement of AYP as measured by quantitative tests could be attained by using qualitative methods that took into account the teachers who taught the students who took the mandated annual state tests. It appeared to this researcher that there was evidence of a lack of the voices of the teachers in the literature surrounding the mandates of No Child Left Behind and the quest for the achievement of Adequate Yearly Progress. This researcher attempted to interview teachers and listen to their voices. After the interviews were completed, this researcher endeavored to put the voices of those educators into this study.

\section{Limitations}

This research study was limited by the number of teachers, working at schools that have not achieved AYP, who agreed to be interviewed. The applications of the study might be limited in that the implications of the findings may only be useful at schools that have not achieved AYP. The findings of the effects on teachers' stress as related to the emphasis on achievement of AYP could possibly be used in a general way in all educational settings. The findings perhaps would not be useful at schools that only serve children with disabilities or at private schools. The teachers and administrators interviewed were only those working at elementary schools. These facts might limit the usefulness and applications of the findings of this study.

Elliot Eisner (1998, p. 188) wrote that, “Our views of schooling and what we believe constitutes responsible and effective teaching are the results of our socialization, both personal 
Running head: EFFECTS OF THE EMPHASIS ON ACHIEVING

and professional." The goal of this researcher in the development of this study was to expand and extend the understanding of others who might read this study and who might have had similar situations, experiences, and encounters. This researched attempted to be open, unbiased, and impartial during the interview dialogues with the educators with the hope that each individual would respond freely and openly about what each one had encountered.

\section{Definitions}

1. All Category - The category used by NCLB regulations that is the total population of all students who took the annual state mandated test.

2. A Nation at Risk - A report concerning the status of public education in the United States published in 1983 by a federal commission created by President Ronald Reagan.

3. Adequate Yearly Progress or AYP - The status achieved by schools on the annual state mandated test when the required scores are achieved in all student categories (race, disabilities, and socio-economic status) according to the NCLB requirements.

4. Content Standards and Objectives or CSOs - The state curriculum standards that are in direct alignment with the state mandated annual tests. Teachers must follow these CSOs in preparing students for the test.

5. Education for All Handicapped Children Act - The Act passed by U.S. Congress in 1975 that orders all public schools to provide an education to all disabled children.

6. Elementary Secondary Education Act or ESEA - The Act passed by U.S. Congress in 1965 that provided aid to schools with large numbers of children living in poverty.

7. Highly Qualified or $\mathrm{HQ}$ - The status that all teachers working in public schools must have to teach according to NCLB. These regulations include various subject area certifications and college degrees. 
Running head: EFFECTS OF THE EMPHASIS ON ACHIEVING

8. National Defense Education Act - The Act passed by the U.S. Congress in 1958 in response to Russia's launch of Sputnik. It called on schools to enhance their math and science curricula.

9. No Child Left Behind or NCLB - The Act passed by U.S. Congress on January 8, 2002, which was the largest reform of ESEA since it began in 1965. The goal of this Act was to ensure accountability, flexibility, and equitable support for the education of all of America’s children.

10. Proficiency - The NCLB Act states that all public schools receiving Title I funds must make adequate yearly progress toward reaching proficiency. It also states that by the year 2014, all students must be proficient. The word proficiency means to have a level of competence in a particular skill or academic area. NCLB allows that these proficiency levels be established by each individual state.

11. School of Choice - The label that a receiving school is given when the students from a sending school that, according to the guidelines of NCLB, did not achieve AYP are given the opportunity to transfer to a receiving school that did achieve AYP.

12. Subgroup - A term used to refer to one of the categories of students taking the state mandated annual test. The subgroup categories are race, disabilities, limited English Proficiency (LEP), and socio-economic status (SES).

13. Title I - A section of the Elementary Secondary Education Act (ESEA) enacted April 11, 1965. This section is an extensive statute which funds primary and secondary education, while forbidding the establishment of a national curriculum. As mandated in the Act, funds are authorized for professional development, instructional materials, and resources to support educational programs, and promotion of parental involvement. 
Running head: EFFECTS OF THE EMPHASIS ON ACHIEVING

14. Title III - A section of the ESEA Act involving program development which helps eligible academic institutions to become self-sufficient and expand their capacity to serve low-income students by providing funds to strengthen their academic quality, institutional management, and fiscal stability.

15. West Virginia State Board of Education Policy 2510 - This is the West Virginia State Board Policy that is entitled Assuring the Quality of Education - Regulations for Education Programs. This legislative policy establishes the regulations for all educational programs for all students in West Virginia schools in grades pre-K to grade twelve. These programs are designed to prepare all students for the twenty-first century by assuring a quality education.

These definitions and the information reported in this introductory chapter are provided in an attempt to give the readers a better understanding of development of the public school system of this country. This researcher hoped that the history provided in Chapter One would give the readers at least a small background of facts prior to their reading of the literature review in the next chapter. This researcher has tried to furnish the readers with a basic understanding of the circumstances and situations that led to the development of the NCLB legislation. The information in Chapter Two has been provided to show some of the research that is available and that supported further study in the areas surrounding the effects of the emphasis on achieving adequate yearly progress on teachers and administrators working at schools under the constraints of the No Child Left Behind guidelines. 
Running head: EFFECTS OF THE EMPHASIS ON ACHIEVING

\section{CHAPTER 2}

\section{Review of the Literature}

The goal of this literature review was to find resources that addressed the two research questions that were the focus of this study. The information obtained in this literature review was organized around the individually listed research questions. This method was used in an effort to find information and data that were already available to guide this researcher and others in attempts to address the requirements of No Child Left Behind and its mandates on teachers.

\section{Effects of a Consultant's Work at Schools that Did Not Achieve AYP}

The American School Board Journal published an article that supported the idea that “when teachers feel good about their work, then student achievement rises” (Black, 2001, p. 2). This source supported the concept that school leaders should give teachers a say in their daily activities. Teacher morale was boosted when teachers knew that what they did was supported by and important to their administrators. This article sustained the same feelings that the teachers at the school of this researcher expressed when they stated that they wished that the superintendent had announced things in a different way and that he had included them in the process of selecting the staff development and the design of the changes in techniques, practices, and teaching strategies. "Time constraints" also were mentioned in Black's article. It was stated that the factor of time can contribute to "emotional exhaustion and low job satisfaction." This represented another issue mentioned by one of the educators at the school where this researcher worked, “There's not enough time to get everything done and this leads to feelings of pressure.”

Gerla, Gilliam, \& Wright (2006, p. 280) found in their study that if a collaboration existed between the administration, teachers, and the workshop presenters, then the staff development experience would be positive for all involved. Their study discussed a situation 
Running head: EFFECTS OF THE EMPHASIS ON ACHIEVING

where a principal and his faculty designed a model staff development format with the authors, who were university professors. The principal's goal was to design an effective program in which the teachers were involved, attentive, and a part of the process. The principal wanted the university faculty along with his staff to design a program that would enhance literacy. According to the authors, the teachers and the university staff all together designed the program and all of it components. One unique component of the program was the continuous monitoring and support provided to the staff of the elementary school by the university partner consultants. The findings of this study maintained that this arrangement was very “advantageous” for all involved. This source supported the idea that staff development, if implemented as a cooperative partnership, could have significant positive results. Maehr, Midgley, \& Urdan (1993, p. 16) stated in their report for the National Center for School Leadership that, "When teachers are engaged in the change process, such involvement and purpose affected the overall level of motivation and it apparently also affected the quality of motivation.” This connection gave the teachers a voice and personal investment in their work and in the goals of the school's programs. Lumsden (1998, p. 5) further stated in an article entitled, Teacher Morale that, "If teachers are empowered by being involved in the decision-making process, then their morale is sustained.”

Maehr, Midgley, \& Urdan (1993, p. 16) wrote that the teachers working with them expressed, “If we are going to create a task-focused environment for students, we’ve got to work in one.” They further concluded in their work that, "Empowering teachers not only enhances staff morale, it is critically instrumental to altering the psychological environment of the school as a whole.” Joffres \& Haughey (2001, p. 4) found that, “When teachers felt that they could not influence student achievement; then they felt very unsuccessful.” The teachers that this researcher worked with indicated that it was their fault and that they felt the blame was placed on 
Running head: EFFECTS OF THE EMPHASIS ON ACHIEVING

them for the low scores. Joffres \&Haughey (p. 5) also commented in their article on the idea that, “Teachers experience pain, exhaustion, and discouragement when they cannot meet the standards that they set for themselves.”

Author Debbie Miller in her book, Teaching with Intention (2008) guided teachers through the scripted lessons that consultants and new textbook developers encouraged them to use as a means of achieving AYP status. Miller reminded teachers through her writing that in theory there is no difference between theory and practice; but in practice, there is. She wrote, “Real life isn’t scripted, neither is real teaching” (Miller, 2008, p. 17). Teachers must search for ways to align their personal philosophies of teaching with the current research and strategies aimed at getting every student to the required proficiency level. Miller, (2008, p. 101) noted many teachers find themselves asking, “Am I about covering and getting through, or am I about... giving them [students] the time and tools to understand big ideas deeply and well?” Miller insisted that in this era of high-stakes testing it is very difficult for teachers to stop hurrying on through the curriculum. That is why she advocated that teachers must find purpose in the daily testing mandates by always being clear about their individual teaching philosophies and beliefs. Teachers must find a way of "defining beliefs” according to Miller (p. 17) and in this way they will change their teaching on a daily basis.

In a similar perspective, Deborah Meier (2000, pp. 13 -14) commented that, "Due to the fact that schools have become too large and too standardized, few youngsters and few teachers have an opportunity to know each other by more than name (if that).” She also added that children can see that their teachers are taking cues from their supervisors, "What kid wants to be seen emulating people who are simply implementing the commands of the real experts” (Meier, 2000, p. 15)? Workshops were conducted by consultants at the school where this researcher 
Running head: EFFECTS OF THE EMPHASIS ON ACHIEVING

worked when the students were in the classrooms with their teachers. This article by Meier reminded this researcher of those experiences. Meir concluded that, "In these settings it is hard to teach young people to concern themselves with others or the community. Until the students are taught this connection no list of particular bits of knowledge will be of use” (Meir, 2000, p. 14).

The present U.S. Secretary of Education, Arne Duncan said that, "There is an unbelievable, untapped potential that all of our kids have, if we as adults really believe in them, invest in them, have the highest expectations and stay with them for the long haul!” Duncan spoke on National Public Radio, Feb. 4, 2009 and went on to say that, “At every level, there’s a very significant reform agenda.” Duncan explained that, “President Obama’s plans call for expanding early childhood education; improving the quality of education from kindergarten to twelfth grade; investing in teachers; ensuring that all students graduate from high school with college-ready, career-ready standards; and breaking down barriers to higher education.” Duncan insisted that he is going to push hard at all levels to improve the education policies of this country. In order to do this Duncan added that he was "Going to analyze what worked; see where things don't make sense; be pragmatic; and we're going to fix those things.” He admitted that, "The principles of NCLB made a lot of sense, there were implementation challenges in certain areas” (Duncan, 2009, p. 1). It appears to this researcher that Deborah Meier felt and might have suggested to Duncan that, "In the absence of strong human relationships rigorous intellectual training in even the most fundamental academic subjects cannot flourish” (Meier, 2000, p. 19). Further advice from Meier might have been that, "For learning to be efficient, the engagement of learners on their own behalf developed in relationships between schools, 
Running head: EFFECTS OF THE EMPHASIS ON ACHIEVING

communities, teachers and students is required; not imposed by standards and centralized systems” (Meier, 2000, p. 18-19).

In further response to implementation challenges, Mike Zellmer and colleagues did an electronic survey for the Wisconsin Association for Supervision and Curriculum Development. The survey was sent to administrators in each of Wisconsin’s school districts, (Zellmer, 2006, p. 44). "Seventy-three percent of the responses were negative, and of these, the largest number, thirty-four percent, were directly related to the disruption of education services due to NCLB mandates” (Zellmer, 2006, p. 45). One survey respondent's answer to an open-ended question indicated, “Testing shifts the focus, for at least a month, from learning to testing; from actual time spent testing to loss of guidance and reading specialist support to loss of administrative support” (pg. 45). Another respondent wrote, “The intrusion on classroom time and continuity of instruction cannot be underscored enough. Our teachers and students suffered significant disruption to the important jobs of teaching and learning” (Zellmer, 2006, p. 45). Eighteen percent of the negative comments were related to narrowing of the curriculum. Some of those comments were as follows:

- The downside is the loss of higher-level instruction related to the limited exposure to higher-level thinking skills.

- The test is a demotivator for quality of instruction, especially for differentiation of instruction.

- Math and reading are important, but are not the only things that we want our students to get out of school.

- I am afraid that what gets tested may become what gets taught. 
Running head: EFFECTS OF THE EMPHASIS ON ACHIEVING

- What about the arts and other skills that cannot be tested?

(Zellmer, 2006, p. 45)

Fitzgerald and Shah of the Minnesota 2020 Group surveyed eighty-seven elementary teachers in the Chaska School District of Minnesota in October, 2007. The responses included the following:

- Sixty-five percent said the NCLB process of identifying schools that have not met AYP will not lead to school improvement.

- Sixty-five percent indicated that NCLB increases teacher focus on students just under the passing score at the expense of other students.

- Only thirteen percent said sanctions improved teaching.

- Almost ninety percent said they were under unfair pressure to improve student test scores.

- More than ninety percent said they are more likely to stay at a school designated, in need of improvement, if factors such as class size, having experienced teachers on staff, and more money for materials were important.

- About eighty-eight percent believed that NCLB had caused teachers to ignore other important aspects of the curriculum.

(Fitzgerald and Shah, 2008, p. 3)

In September, 2004, Gail Sunderman, Chris Tracey, Jimmy Kim, and Gary Orfield of Harvard University released a survey, Listening to Teachers: Classroom Realities and No Child Left Behind, in which teachers stated their feelings that NCLB sanctions negatively affected their work. Teachers selected for this study represented eleven school districts in six states: Arizona, 
California, Illinois, New York, Virginia, and Georgia. Findings of the survey showed the following:

- Teachers rejected the idea that the NCLB testing requirements would focus teachers' instruction or improve the curriculum.

- The sanctions changed a teacher's focus from subject matter and individual time with students to narrowing the curriculum to tested subjects.

- Teachers were committed to student improvement regardless of the impositions of NCLB.

(Sunderman, 2004, p. 34)

Teachers also indicated that they are rushing to cover as much material as possible and must place more emphasis on good test-taking skills. Further findings by Sunderman and colleagues revealed that, “Teachers wanted less focus on standardized tests, less time lost to testing, and test results based on how much progress students made during a particular time period” (Sunderman, 2004, p. 45). Teachers also expressed that their needs were not being met. Some of the areas mentioned were as follows:

- Support in the form of good materials, good administrators, and funds for serious parent outreach programs.

- Less stress as a result of more respect and positive treatment of teachers to lower tension and produce a more positive climate.

- Teacher dissatisfaction with unfair punishment and reward systems.

- Collaboration which provided more time to work at school with colleagues. (Sunderman, 2004, p. 44) 
Running head: EFFECTS OF THE EMPHASIS ON ACHIEVING

Other studies had similar conclusive results like those in September 2006, when the National Council of Teachers of English (NCTE) released a study that allowed teachers to respond to the "efficacy of statewide testing as a means of measuring school performance." The responses included the following:

- Taking class time away from meaningful instruction; NCLB is strangling authentic learning and very damaging.

- Too much time testing and too few interesting projects.

- Lost over a month of teaching time.

- It has lowered the bar and made teaching robot-like.

(NCTE, 2006, p. 3)

Ron Wideman of Nipissing University of Calgary found in his 2002 (p. 2) study that, “There were only limited effects in changing teachers’ classroom practices when top-down change initiatives in teaching practices were mandated by school board officials.” Wideman found that:

Teachers were central to educational change. The voices of professional teachers who investigate their own practice for the purpose of improving student learning must be listened to and respected if school improvement is to become reality and the knowledge about education further developed. (Wideman, 2002, p. 11)

James McKenzie wrote in an article for the September 2006 issue of No Child Left (p. 1) that, "We need a law with a focus on capacity building and encouragement rather than testing, fear, and punishment.” McKenzie refers to this time of NCLB as a time of stagnation. He emphasized that, "Rather than extension, amplification and enhancement, this decade has been 
Running head: EFFECTS OF THE EMPHASIS ON ACHIEVING

characterized by retrenchment and retreat -- the best thinking and the best thinkers have been ignored” (McKenzie, 2006, p. 7).

Effects of the Emphasis on AYP Achievement on Teachers and Administrators at Schools that Fail to Meet the Constraints of NCLB

There are other impact factors directly correlated to NCLB. The study by Million (2005, p. 16), stated, "While NCLB is not a cause for daily unhappiness, it is still capable of taking its toll on staff morale.” She further mentioned that, "Even though teachers at certain schools may work hard through difficult situations and their students may make gains; it may not be enough for NCLB requirements.” Million (2005, p.16) also stated that resourceful leaders will create numerous ways of keeping morale high. She suggested that these leaders will "Focus on the positive and be scrupulously honest.” She pointed out that good leaders will believe in and respect their teachers. This respect, according to Million (2005, p. 17), is shown by leaders through "various perks” such as notes, T-shirts, and various other forms of recognition. Million (2005) surveyed leaders from schools across the nation in order to collect these ideas.

Diane Ravitch, a research professor at New York University, wrote in Education Week, (June, 2009, p. 31) that, "Schools that do not make progress toward the goal of one hundred percent proficiency for every group are subject to increasingly stringent sanctions.” Some of the sanctions for failing schools mentioned in her article were as follows: “Giving students the choice of leaving one school to enroll in a better public school; free tutoring after school; converting the public school to private management; dismissal of the entire staff; and/or takeover of the school by the state.” She pointed out that, from her research, these sanctions have not been proven to work in most instances. This inflexibility and public humiliation for not meeting federal goals has ignited much frustration among educators. She added, "Most states have 
Running head: EFFECTS OF THE EMPHASIS ON ACHIEVING

adopted very low definitions of proficiency, endorsed low standards and inflated their scores to meet NCLB’s nonsensical requirements” (Ravitch, 2009, p. 31).

Burkhardt, Fraser, and Ridgway wrote in an article entitled, The Dynamics of Curriculum Change that:

If teachers hold beliefs compatible with innovation, acceptance will be more likely to occur. If teachers hold opposing beliefs or perceive barriers in enacting the curriculum; then low take-up, dilution and corruption of the reform will likely follow. Teachers can be either -- conveyances of or obstacles to change.

(1990, pp. 9-10)

The study implied that the failure of many educational innovations has drawn researchers to look toward gaining an understanding of teachers' beliefs as a significant mediator in curriculum implementation. The authors cited the failure of programs that used prepared products and rigid sets of procedures to follow without taking into account teachers’ knowledge, beliefs and behaviors. This manner of implementation reminded this researcher of a quote from a teacher in an Education Week Blog on June 11, 2009 which read, “Don’t talk to me about not plowing the field; talk to the mule, he’s pulling the plow.”

Diane Ravitch reported in Education Week (2009, p. 31) that there is no evidence for the effectiveness of NCLB and its sanctions. She wrote, “The law’s remedies for failing students -school choice and tutoring - have also been a bust.” Her findings suggested that fewer than five percent of eligible students leave their schools and fewer than twenty percent of eligible students sign up for tutoring. Ravitch (2009, p. 32) added, "Few schools have converted to charter status or private or state management. Most preferred 'restructuring', in which the school gets a thorough shaking-up, in some cases, the entire staff is dismissed.” Her findings revealed that 
Running head: EFFECTS OF THE EMPHASIS ON ACHIEVING

even after all staff had been replaced, most “failing schools continue to struggle and give some district officials the political leverage to make radical changes under the cover of NCLB.”

A study done by the National Council of Teachers of English (NCTE) in April 2006 (p. 1), showed that, “Among teachers charged with implementing the NCLB Act, seventy-six percent believed that the Act had at least a somewhat negative influence on teaching and learning in English and reading classrooms.” This NCTE study showed that, “The more people know about NCLB, the more inclined they are to have an unfavorable opinion about its effects on public schools, teachers, and students” (NCTE, 2006, p. 1). The NCTE survey asked the participants to rate how well NCLB had done in reaching the four reform goals of the U.S. Department of Education. The results were as follows:

1. Encouraging stronger accountability for results - Fifty-eight percent generally ineffective.

2. Providing more freedom for schools and communities - Ninety-three percent generally ineffective.

3. Encouraging proven educational methods -- Eighty-one percent generally ineffective.

4. Providing more choices for parents - Eighty-one percent generally ineffective.

(NCTE, 2006, p.1)

In this study, eighty-six percent of the respondents reported that, "More time is now spent on test preparation, while only five percent agreed that students are positively motivated by test results” (NCTE, 2006, p. 2). Sixty-two percent of the responding educators reported that “Changes associated with NCLB were having a negative influence on their satisfaction with 
work; motivation, and commitment to the profession.” Responses to open-ended questions included the following statements:

- We work under a sense of impending doom - always aware of the mythical 'they' who are going to come in and take over our classrooms.

- My ability to teach all aspects of writing has been taken away.

- My freedom to be innovative and creative in the classroom has been severely limited.

- I have less time to actually help the students because of all the time spent trying to determine what to do to please the government.

- Anyone who thinks we can achieve one hundred percent 'meets or exceeds' has no clue about students' abilities or teaching. (NCTE, 2006, p. 3)

Apparently some educators were principals as the comments also included: "I have to spend more time trying to motivate staff; they are professionals, are demoralized by the government suggesting they are incompetent” (NCTE, 2006, p. 3). The remarks of these principals coincided with the thoughts of Iannone and Obenauf (1999, p. 743) when they stated, “This means teachers and students must design their own in-depth integrated curriculum. They understand their context better than anyone else.” It appeared to this researcher that the goals of NCLB were not specifically designed to allow this kind of focus. Sandra Nichols (2006, p. 1) writing for Education Matters for the California Public Schools quoted a departing New York superintendent as saying, “Today’s school reform is really regression.” Nichols believed that this administrator like others had grown intolerant of, “The naysayers and chuckleheads who 
Running head: EFFECTS OF THE EMPHASIS ON ACHIEVING

look at numbers and throw mud; teaching in low performing schools should be a rewarding experience, yet these schools are labeled failures” (Nichols, 2006, p.1).

Many of the teachers at the school where this researcher worked had voiced their concerns about being required to teach their students how to take the state tests in math and reading. It was becoming apparent to them that science, social studies and skills for the twentyfirst century were not at the forefront at the present time.

Jamie McKenzie wrote in the September 2006, issue of No Child Left that some traits of NCLB included the following:

- Shame -- using public humiliation as a prime motivator for change.

- $\quad$ Fear -- using the possibility of job loss and school closure to develop change.

- Threat -- warning that failing schools would lose their students to charter and/or private schools.

- Favoritism/ Cronyism -- using educational programs endorsed by the U.S. Department of Education despite a section of the law that prohibited it and training teachers in a single highly scripted program endorsed by the government for pseudo-scientific reasons.

- Damage to morale -- the whole issue of teacher morale has been put on a backburner as if it had nothing to do with student performance.

- Blindness to social causes - ignoring the research which shows that poor school performance is strongly influenced by factors outside the school like poverty and difficult living conditions. (McKenzie, 2006, pp. 2 - 6) 
Running head: EFFECTS OF THE EMPHASIS ON ACHIEVING

Dr. Stephen Paine, West Virginia (WV)State Superintendent of Schools said as recently as January 28, 2010 in an email response to this researcher that, “West Virginia’s curriculum is well-rounded as clearly stated in West Virginia Board Policy 2510. However, because of targeted testing like that of NCLB, sometimes additional concentration is dedicated to math, English, language arts and reading.” Judy Hale (2010), president of the WV American Federation of Teachers (AFT) sent an email reply to this researcher in reference to Dr. Paine's comments and added, “That [referring to Dr. Paine’s remarks] combined with the looming spectacle of working in a school labeled as failing, deals a blow to teacher morale.” U.S. Representative, Shelley Moore Capito, Republican - WV (2010), agreed in her recent email reaction to this researcher concerning the above mentioned comments that, "We're putting a lot on our teachers and our administrators, by saying - you [the teachers] must make our children successful.” Rep. Capito supported the original NCLB legislation and stated in her email to this researcher that her comments are geared toward recognizing areas that can be improved. She encouraged a degree of flexibility for teachers that can make NCLB more effective and reflective of student success.

In Boston in July 2006, AFT National President Edward McElroy spoke to more than 4,000 AFT members stating the concerns that teachers have voiced about NCLB included: "Too much testing at the expense of instructional time; no credit for improvements-only for arbitrary goals; low teacher morale; high stress; narrowing of the curriculum; boredom from constant test preparation” (McElroy, 2006, p. 1). Stephanie Jones of the University of Georgia presented at the 2008 International Reading Association (IRA) meeting in Atlanta, Georgia and emphasized the following points in her speech: 
Running head: EFFECTS OF THE EMPHASIS ON ACHIEVING

- Some say that this is an oppressive time to be a teacher; because curricula are narrowing.

- The teaching of reading and writing has been progressively restricted to discrete, isolated skills.

- Teachers and students are under more pressure than ever to achieve high test scores.

- Teachers are going through the motions of scripted curricula and test prep booklets.

- While working with the 'bubble' students, teachers shake their heads and sigh at the leaving behind of children who have test scores too low to be a realistic goal for this coming year.

(Jones, 2008, pp. 1-5)

Jones further pointed out that, "Those in leadership positions do not have to be warriors for the system even though they must hold tests under lock and key and make teachers and children follow a lock-step regiment of test-taking.” She shared options for leaders and suggested that they print out the Code of Ethics for Education Professionals, highlight passages, and ask administrators and politicians if they are asking that the Code be broken. She stated, "We cannot afford to wait for someone else to fight this fight. You can be a warrior for the children, families, and teachers who are living more stressful and anxiety-ridden lives because of the NCLB mandate of high-stakes testing” (Jones, 2008, pp. 3-4).

Furthermore, Dr. Robert Burke, an associate professor in the Department of Teacher Education at Miami University of Ohio and a member of the National Advisory Board of the University of Maryland - School of Medicine, Department of Psychiatry, stated in an email response to this researcher on February 5, 2010 the following: 


\section{Running head: EFFECTS OF THE EMPHASIS ON ACHIEVING}

NCLB has defined teaching to mean only the transmission of information in mechanical and scripted ways. It has redefined learning to mean only the results of student performance on standardized tests. NCLB's features - its inflexible mandates, sanctions and arbitrariness - lead to teachers’ frustrations about being less able to meet individual students' needs. The essence of education is the relationships between one teacher and each individual student. That's why people go into teaching; they want to make a difference in children's lives. It's frustrating when there seem to be so many obstacles.

(Burke, 2010)

Dr. Burke wrote in an article for the Journal of School Health (2006, p. 447) that, "The combination of the exclusive focus (of NCLB) on academic enhancement and the absence of accountability indicators for social and emotional growth and development among students is likely to hinder efforts aimed at academic achievement.” Dr. Burke’s article (2006, p. 449) pointed out that, “Through NCLB’s connection to the Individuals with Disabilities Education Act (IDEA), there are resources that could be used to support overall school mental health.” Dr. Burke's article reinforced that these services could address both the academic and non-academic needs of students as well as the pressures on teachers and administrators as a result of the intensive focus on meeting the standards of NCLB.

In addition, Moody and Barrett conducted a study entitled Stress Levels of School Administrators and Teachers (2009). The participants in the study included thirty-four educators (nine administrators and twenty-five teachers) with an average of seventeen years of educational experience. The results showed that, “Administrators cause stress; administrators know their teachers are stressed; teaching is stressful; educators are aware of their stress and stress affects 
Running head: EFFECTS OF THE EMPHASIS ON ACHIEVING

students” (Moody, 2009, pp. 3-8). Some of the educators' responses in this study included the following:

- Teachers responded: We are frustrated with the school bureaucracy and often feel it is an -- us versus them -- environment.

- Administrators noted: We should do what we can to prevent stressful situations as well as provide support to our staff to relieve stress at the workplace.

- Teachers indicated: We become so accustomed to our levels of stress that we don’t even realize the price we are paying physically.

- Teachers realized: In looking back on some of the worst tense filled days, there's a pattern with the students; they are responding to the demeanor and attitude of their teacher.

(Moody, 2009, p. 8)

Findings of this study coincided with many of the responses of the teachers at this researcher's school. After the review of the literature and the experiences of this researcher while working at a school that had failed to achieve AYP, it was apparent that job related stress both affects and is recognized by educators - teachers and administrators. These research articles lent support to the hypotheses behind this researcher's questions.

1. Teachers' instructional techniques and teaching strategies are affected by consultants placed at schools that do not achieve AYP on the yearly mandated state tests according to the regulations of NCLB. The literature further supported the ideas that teachers can be affected in a positive manner through the use of a leadership style that allowed teachers to participate in decision making at the school. 
Running head: EFFECTS OF THE EMPHASIS ON ACHIEVING

2. Administrators and teachers can be adversely affected by the constraints of NCLB. A positive approach in the leadership style of administrators can help keep teacher morale high. Emphasis on the achievement of AYP by a consultant sent from outside the school can have negative effects on teacher morale. Teachers need to feel ownership of the new strategies to be implemented. The choosing of the instructional strategies to be used at the school should be a task done by the teachers and administrators of the school.

The goal of this researcher in pursuing further study and investigation was to find information and research in regard to NCLB and the effects of the implementation of its various programs and strategies on educators - teachers and administrators. This researcher had maintained the belief that the best and most pleasant educational environment must be established for all individuals involved in enabling students in their pursuits of learning. In the next chapter, this researcher has attempted to discuss the procedures used in interviewing fifty educators in the school environments in which they worked while trying to achieve adequate yearly progress while maintaining positive learning conditions for the students who were under their guidance and care. 
Running head: EFFECTS OF THE EMPHASIS ON ACHIEVING

\section{CHAPTER 3}

\section{Methods}

Described in this section are the: participants, schools, materials, procedures, and research design used in this study to determine the following:

1. The effects of a consultant working with teachers and administrators at schools that did not achieve AYP.

2. The effects of the emphasis on achieving AYP on teachers and administrators at schools that did not meet the required proficiency level on the NCLB mandated annual state tests.

\section{Participants}

The participants in this study were teachers and administrators at six schools in six different districts of the state. All six schools had not achieved AYP under the regulations of NCLB and all six schools had at least one consultant. Each school had one head principal and all (four females and two males) six of them agreed to be interviewed. Four of the six schools had one assistant principal (two males and two females) and one of the schools had two assistants (two males), only one assistant principal (female) agreed to be interviewed. Seven (five females and two males) administrators agreed to participate in the study. Of the two hundred sixty-two teachers who worked at these six schools, forty-three (female) teachers volunteered to participate in the interviews. One hundred twelve teachers indicated that they did not want to participate and gave no reason for that choice. Another eighty-eight wrote that they chose not to participate due to fear that confidentiality might somehow be violated and their supervisors might retaliate if any negative comments were made during the interviews. Nineteen response sheets were not returned. 
Running head: EFFECTS OF THE EMPHASIS ON ACHIEVING

\section{Information about the Administrators}

Seven administrators participated in the study. The six principals (four females and two males) and one assistant principal (female) that volunteered for this study had spent from eight to twenty-four years teaching prior to becoming an administrator. The average number of years spent teaching prior to administration was sixteen. The seven administrators had spent from one to sixteen years in administration at their present school with an average time at the present school of seven years. The total time spent as an administrator ranged from three to thirty years and the average time spent as an administrator was eleven years. Four of the administrators held a Master's degree plus forty-five hours and three of them held a Master’s degree plus sixty hours. The assistant principal that participated in the study had nineteen total years in teaching prior to becoming an administrator. This assistant principal had worked at the present school for fourteen years as an administrator. This individual held a Master's degree plus forty-five hours. (Appendix IV).

\section{Information about the Schools}

Three of the six schools had grade levels ranging from pre-kindergarten to grade five and three of the schools had grade levels from grade five to grade eight. The total number of students in all six schools was three thousand one hundred fifty-six. The student enrollment ranged from two hundred sixty students to seven hundred twenty-five and the average enrollment was five hundred twenty-six students. The total number of administrators was twelve (six males and six females). One school did not have an assistant, four schools had one assistant and one school had two assistants. The total number of teachers working at these six schools was two hundred sixty-two. The number of teachers at each school ranged from thirty to fifty-six and the average number of teachers at each school was forty-three. The range of years of not achieving 
Running head: EFFECTS OF THE EMPHASIS ON ACHIEVING

AYP was one to five and the average number of years not achieving AYP was three. One school failed to make AYP in the All Student Category in Reading and also in Low SES - Reading and Math. The five other schools failed to make AYP in both Special Needs and Low SES in both Reading and Math. (Appendix V)

\section{Information about School One (PK - Grade 5)}

This school had a total of forty teachers. Nine teachers volunteered to be interviewed from this school. Their years of teaching at this school ranged from three to seven years. The average number of years spent at this school was six. The range of total years taught was from three to thirty-seven. The average number of years in teaching was twenty-four. Four of these teachers held a Master's degree plus forty-five hours, one held a Master's degree plus thirty hours and four held a Bachelor's degree plus fifteen hours. This school had one principal (female) and one assistant principal (female). Only the principal agreed to be interviewed. This individual had nine years of teaching experience prior to becoming an administrator. This individual had five years experience as a principal and all five years had been spent at this school. This principal held a Master's degree plus forty-five. There were four hundred sixty students at this school. It had not made AYP for two years in the All Student Category in Reading and also in the Low SES category in Math. (Appendix VI)

\section{Information about School Two (PK - Grade 5)}

This school had a total of fifty teachers. Ten teachers at this school agreed to participate in the interviews. Their years of teaching at this particular school ranged from two to thirty-two. The average number of years taught at this school was fifteen. The range of total years taught was from six to forty-two. While the average number of years spent teaching was twenty-five. Four of these teachers held a Master's degree plus forty-five, one held a Master's degree plus 
Running head: EFFECTS OF THE EMPHASIS ON ACHIEVING

thirty, three held Master's degrees, and two held a Bachelor's degree plus fifteen. This school had one principal (male) and one assistant (female). Both of these individuals agreed to participate in the interviews. The principal of this school held a Master's degree plus sixty and had eight years of teaching experience prior to becoming an administrator. This individual had thirty years of administrative experience and was currently in the first year at this school. The assistant principal held a Master's plus forty-five and had nineteen years of teaching experience prior to becoming an administrator. This individual had fourteen years of administrative experience and all of them were earned at this particular school. There were five hundred eighty students at this school that had not made AYP for one year in Reading and Math in both the Low SES and Special Needs student population categories. (Appendix VII)

\section{Information about School Three (PK - Grade 5)}

Thirty-one teachers worked at this school. Only two teachers volunteered to participate in the research interviews. Their years of teaching at this school ranged from three to twentyseven. The average number of years spent teaching at this school was fifteen. Their total years of teaching ranged from fifteen to twenty-seven. The average number of years teaching for these two individuals was twenty-one years. One held a Master's degree plus thirty and the other held a Bachelor's degree plus twenty. This school had only one principal (female). This individual had twenty-one years of teaching experience prior to becoming an administrator. This principal had three years experience as a principal and all three had been spent at this particular school. The principal held a Master's degree plus forty-five. The student enrollment at this school was four hundred seventeen. This school had not achieved AYP for two years in both Reading and Math in the student population cells of Low SES and Special Needs. (Appendix VIII) 
Running head: EFFECTS OF THE EMPHASIS ON ACHIEVING

\section{Information about School Four (Grade 5 - Grade 8)}

Fifty-six teachers worked at this school. Ten teachers agreed to be interviewed as a part of this study. Their years of teaching at this school ranged from one to thirty-six. The average number of years spent teaching at this school for this group of teachers was thirteen. The range of total years taught was two to thirty-six. The average number of years spent teaching was twenty-one. One teacher held a Master's degree plus sixty, three held a Master's plus forty-five, one held a Master’s plus thirty-six, one held a Master’s plus thirty, two held a Bachelor's plus fifteen and two teachers held a Bachelor's degree. This school had a principal (female) and two assistants (two males), only the principal agreed to be interviewed. This principal, who held a Master’s degree plus sixty, had sixteen years of teaching experience prior to becoming an administrator. This individual had spent another sixteen years as a principal all at this particular school. The student enrollment at this school was seven hundred twenty-five. The school had not achieved AYP for four years in Reading and Math in the Low SES and Special Needs categories. (Appendix IX)

\section{Information about School Five (Grade 5 - Grade 8)}

This school had a total of fifty-five teachers. Only two teachers agreed to participate in the interviews. One of these teachers had taught for ten years and the other for twelve years at this school. Their average number of years at this school was eleven. Their range of teaching all total was from eighteen to twenty-three years. Their average years taught was twenty years. One teacher held a Master's plus thirty and the other held a Master’s degree. This school had one principal (male) and one assistant principal (male). Only the principal agreed to be interviewed. This principal had spent seventeen years teaching prior to becoming an administrator. This individual had five years of experience as a principal and all five were at 
Running head: EFFECTS OF THE EMPHASIS ON ACHIEVING

this school. This principal held a Master's degree plus forty-five. Student enrollment at this school was seven hundred fourteen. The school had not achieved AYP for five years in Reading and Math in both the Special Needs and Low SES student population cells. (Appendix X)

\section{Information about School Six (Grade 5 - Grade 8)}

This school had a total of thirty teachers. Ten teachers agreed to participate in the study. Their years of teaching at this school ranged from one to thirty. The average number of years spent at this school was twelve. Their range of years in teaching was from two to thirty-three. Their average number of years teaching was eighteen. One of these teachers held a Master’s degree plus sixty and this teacher also held a National Board Certification. One teacher held a Master's degree plus three; three held a Master’s degree; two held a Bachelor's degree plus fifteen and three of the teachers held a Bachelor's degree. This school had one principal and one assistant principal. Only the principal volunteered to be interviewed. The principal of this school had a total of twenty-four years teaching prior to becoming an administrator. This individual had seven years of administrative experience and six of those years had been spent at this particular school. This principal held a Master’s degree plus forty-five. Two hundred sixty students were enrolled at this school which had not achieved AYP for four years in both Reading and Math in both the Low SES and Special Needs student population cells. (Appendix XI)

\section{Materials}

The participants in the study were asked to openly discuss their experiences concerning any issues that dealt with the emphasis on achieving AYP, consultants, and any other aspects of the mandates of NCLB. This researcher read the introductory script (Appendix XII) at the start of each interview session. The interview questions (Appendix XIII) were used only as a guide by this researcher during the interviews. The questions were not given to the participants and the 
Running head: EFFECTS OF THE EMPHASIS ON ACHIEVING

questions were not asked unless there was a pause in the conversation. If the teacher paused and this researcher noticed that some of the questions had not been covered then and only then was a question interjected. At all other times the interviewee was allowed to just talk about topics which they felt related to the introductory statement. Every effort was made by this researcher to allow the participants to take their time and to freely express any thoughts, experiences, and concerns that seemed relevant to the topics. This researcher tried to keep the atmosphere as natural, open and relaxed as possible. These interviews were not structured. This researcher attempted to make the interviews more like an opportunity for the educators to reflect and express their thoughts about issues of concern to them. This examiner tried to listen and respond in ways that did not direct or shape the conversation of the participants. In most cases the educators talked quite freely and at length about the many and varied aspects of their efforts of trying to attain AYP, meeting all of the demands of NCLB, and working with consultants. A digital recorder was used to tape the interviews and this researcher also took notes. The transcript of one of the interviews appears in Appendix XIV. All transcripts were typed and then analyzed by this researcher. This researcher used NVIVO8 (2007), qualitative research software, to help manage, shape, and make sense of the fifty interviews done in this study. Although the software does not decide the themes or code the interviews; it does provide a sophisticated workspace that allowed this researcher to manipulate and move the interviewees’ responses in an organized manner.

\section{Procedure}

In early August of 2009, this researcher sent out letters (Appendix I) explaining the purpose of the study and asking permission to interview the administrators and teachers in the school district. These letters were sent to ten school superintendents in districts within 
Running head: EFFECTS OF THE EMPHASIS ON ACHIEVING

approximately a seventy mile radius of this researcher's home. This distance was chosen only because it represented a reasonable amount of one way driving time for this researcher. According to Creswell and Clark (2008, pp. 200 - 201), this is called convenience sampling. This is a type of non-probability sampling which involves a sample being drawn from a part of the population which is close at hand, convenient and willing to participate. These schools were also specifically selected for the information that they could provide to the topics being investigated - not achieving AYP and having a consultant. Creswell and Clark (2008, p. 201) also used the terms captive samples and volunteer samples in application to convenience sampling. After the superintendents of each district gave permission to proceed with the study, it definitely appeared to this researcher that the sample was captive, it remained to be seen if any of the educators would volunteer. This researcher believed that the measures taken helped to assure that the sampling was representative of the larger population of educators at schools that did not achieve AYP. This researcher realized that the degree of "representativeness" (Creswell, 2008, p. 200), which could not be determined, limited the generalizations that would be made from the results about the total population. The question for this researcher was what sample would have been representative enough. Although, this researcher considered this a convenience sampling, it was a targeted and narrowly defined sample of the population. This researcher only wanted to talk with teachers and principals at schools that had not achieved AYP on the NCLB state mandated annual tests and had also experienced a consultant doing workshops and integrating strategies at the school. These districts were chosen because they had at least one school that had not achieved AYP in at least the prior school year and the school/s had worked with a consultant. The generalizations from the results of this study were limited to only schools that could be defined in these terms. Teachers and administrators working at schools that have always 
Running head: EFFECTS OF THE EMPHASIS ON ACHIEVING

achieved AYP would probably not benefit from this study and generalizations from this study to those schools would not be advantageous. Although, a superintendent or principal, who encountered a school recently designated as not achieving AYP, might possibly look at these findings before designing implementation strategies.

Before the end of August 2009, six of the superintendents had responded affirmatively to allow their school administrators and teachers to participate in the interviews. No responses were received from the other four superintendents. In each of the six districts there was one elementary school that had not attained AYP and all six of these schools were presently working with a consultant. After permission to conduct the interviews was received, this researcher applied to the West Virginia University Institutional Review Board for the Protection of Human Subjects for approval of the project. Approval (Appendix II) was granted before the end of October 2009. At that time, this researcher began travelling to each of the six schools. During the first visit to each respective school, time was spent meeting the principal, showing the letter from the district superintendent allowing the school to participate in the study, setting the principal's interview date and time, and placing an introductory letter (Appendix III) in the mailbox of each teacher at each school. On the return visit to each school, the principal was interviewed; the teacher responses, which had been returned to an envelope on the school secretary's desk, were collected; and the dates and times of each teacher interview were arranged. No attempt was made to contact those teachers who responded negatively or those who had not responded at all.

Each volunteer participant was individually interviewed for approximately fifty to ninety minutes. The interviews were conducted by this researcher at the participant's school. Most interviews were conducted either before or after school, although some teachers did request their 
Running head: EFFECTS OF THE EMPHASIS ON ACHIEVING

interviews during their planning periods. These few requests were verified by the principal. The interviews were electronically recorded and this researcher also took notes. The transcription of the interviews was done by this researcher. The interviews were completed at the end of the second week in December 2009.

\section{Research Design}

The methodological design of this study was qualitative, specifically phenomenological investigation and inquiry. Phenomenology, the study of structures of experiences - phenomena as they appeared and they meanings they had for the educators in this study was used as the basis of this researchers investigations. In the study this researcher sought to determine how the participants understood their professional experiences. This method was chosen because the topic being investigated in this study lent itself well to this process. This researcher was deeply interested in the topic and had a personal curiosity and investment in similar experiences related to the topic. As a researcher, there was a need, really a desire, to gain a better understanding of the topic in question. This researcher believed that this procedure would be effective in both obtaining and managing the data collected in this study. This researcher studied, considered, and thought about the conversations collected in this research to see how they as Pinar (2004, p. 495) characterized, "presented themselves in the lived experience" of the educators who participated in this study. As the individual interviews were recorded and later transcribed, this researcher believed that eventually everything would come together, all of the parts, into a whole that had meaning and would result in enough information to properly evaluate the hypothesis of this study. This researcher worked diligently to establish a trusting relationship with each 
Running head: EFFECTS OF THE EMPHASIS ON ACHIEVING

individual interview participant. In this way, it was calculated so that the interview encounter allowed for a more straight forward access to the experiences of each individual. In gaining the trust of the individual participants, then this researcher did not need to ask questions during the interviews. In most instances, the conversations flowed from the participants and hopefully, due to this, a richer understanding of the situations encountered by each individual was captured. This researcher made a “disciplined, rigorous effort to understand these experiences profoundly and authentically” (Pinar, 2004, p. 405), in doing so, this researcher was sensitive to the fact that "working phenomenologically is vigorous; it requires a profound sense of what is competent and practical in educational conduct, and a sense of political consequences” (Pinar, 2004, p. 406). With great respect for these requirements and with respect for the participants in this study, this researcher attempted to serve as a mediator of the participants’ experiences to other interested individuals who might read this study.

In order to convey the findings of this study and to approach the tasks set forth in the two research questions in a methodological manner, the principles of hermeneutics were applied. Hermeneutics, the study and practice of interpretation, originated from the mythological Greek deity - Hermes, whose role was that of a messenger of the ancient gods. Hermes served as a mediator between gods and humans. Hermeneutics, one of the earliest philosophical methods dealing with the understanding of the relationships between language, experiences, perspectives, and logic lent itself well to the focus of this study. Because the research questions guiding this study implied burdensome suggestions, it was planned by this researcher that the inquiry method of hermeneutic investigation would allow findings to be gained from a 
Running head: EFFECTS OF THE EMPHASIS ON ACHIEVING

“commitment to generativity and rejuvenation and to the question of how we can go on together in the midst of constraints and difficulties that constantly threaten to foreclose on the future” (Smith, 1991, p. 189). According to Pinar, (2004, p. 423) "hermeneutics has functioned to enlarge the phenomenological endeavor to include the social negotiation of meaning as well as individual attunement to truth.” Similarly Smith believed that, "In the phenomenological discourse on hermeneutics, phenomenology becomes explicitly political; pedagogy is concerned with mobilizing the social conscience of students into acts of naming and eradicating the evils of the times” (Smith, 1991, p. 196). This researcher hoped that the findings from this study would provide some information to enable those concerned with the problems associated with NCLB to begin a positive approach to improving the situation.

With a careful sensitivity to Smith’s statement, this researcher endeavored to write the results of the emergent themes in a language that gave clear meaning to the lived experiences of the participants. In so doing, this researcher intended that the sense and feel of what the educators who participated in this study experienced could be understood by those who read the study and would allow those readers to go into different directions and to use alternative methods when they experienced similar situations. This researcher realized that hermeneutics is a theory of conveying oral communications through written text into an understanding that is humane, objective, and useful to those who read it. This researcher recognized generalization or external validation as major challenges of qualitative research. This qualitative researcher selected this study in an effort to understand a particular situation in depth as reflected in the study's research questions, not to investigate what is true in general or in similar 
Running head: EFFECTS OF THE EMPHASIS ON ACHIEVING

situations. Hopefully, this would be realized by others who might read this study, and these findings would be used as support in making decisions in similar situations in areas of concern to them. This researcher simply looked at what could be learned from an in-depth analysis constructed from interviewing participants from similar incidents. Perhaps, the knowledge gained from this venture would allow readers of this study to determine how the findings of this researcher could be used in their particular situations and contexts. In this way, any external validity and generalization of the study would be recognized.

With that goal in mind, the analysis of the transcripts was undertaken with a careful intention to represent in an objective way all of the experiences of the participants while at the same time leaving out any duplicity and overlapping similarity so that the data were conveyed in an organized, concise, and relevant manner to the readers. At the same time, this researcher attempted to provide a reporting of the data that would truly represent what the participants intended. This researcher attempted to “organize the perceptions in the context of immediate purposes and relationships which must correspond to the context as well as to the phenomenon” (Patton, 2002, p.597). Although this researcher brought a background of understanding and related experiences to this research study, those only served to enable this researcher to interpret the expressions of the participants during the study. In naturalistic investigation, according to Lincoln and Guba (1985, p. 201), the goal is to include "as much information as possible and to detail the many specifics to give the context a unique meaning." This researcher studied the data [the interviews] and through "an inductive content analysis the unitizing or coding and categorizing of the information 


\section{Running head: EFFECTS OF THE EMPHASIS ON ACHIEVING}

emerged” (Lincoln, 1985, p. 203).

Hopefully, this researcher's background knowledge and experiences allowed the inquiry, interviews, and interpretation to be a truly adequate representation of the subject matter as in the idea stated by Flinders (1993, p.184), "the meanings, intentions, motivations, and reasons that stand behind the expressions and actions of human beings.” Flinders (1993, p. 190) further stated that, "from the perspective of validation hermeneutics -- the task facing the qualitative inquirer is to 'get it right'.”

Realizing that this researcher's use of language and knowledge of the subject matter could be both conducive and limiting to the understandings drawn from the qualitative inquiry process, it was essential for this researcher to point out the importance of striving to depict the various sources of meaning that evolved from this study. In qualitative inquiry "the challenge of hermeneutics is expressed as the kind of relationship that exists between one subjective being and another subjective being as the former attempts to interpret the latter.” (Flinders, 1993, p. 186) To clarify this question of meaning, the qualitative inquirer must remember that there are three possible sources of meaning. Flinders explained that as follows:

One source of meaning resides with the author of the expressions; a second source is within a set of objective historical conditions; and the third source is that meaning does not have an independent existence, is brought into being as a result of dialogue between and among people. (Flinders, 1993, p. 185)

Flinders (1993, p. 187) added that the inquirer is part of all of these sources. In recognition of this, it was with the greatest care that this researcher ventured to be a part 
Running head: EFFECTS OF THE EMPHASIS ON ACHIEVING

of the "hermeneutic circle" by giving "interpretation of the expressions of others" (Flinders, 1993, p. 187)

In attempting to represent the intended meanings of the participants' interview responses, this researcher also respected as Flinders (1993, p. 191) identified, “The basic moral imperative of speech, which is to respect the interviewee's intentions.” "The qualitative process is a very practical, ethical, and moral task; and at their core human beings are ethical and moral beings; and understanding at its core is ethical and moral” (Flinders, 1993, p. 197). These concepts of ethics and morality were kept at the forefront during all components of this study. This researcher fully understood the responsibility and importance of conducting a study in an ethical manner. This concern was of the utmost importance to this researcher, and this researcher gave further validation to the study by remaining objective and unbiased as the interviews were critically analyzed for emerging and overlapping themes.

In an effort to provide additional verification and internal validation of this study, the triangulation method of multiple analysts was used. After this researcher analyzed the transcripts of the interviews and identified the emergent themes, the transcripts were reviewed by two other readers. This method of triangulation is termed peer review. These readers read the transcripts [the raw data] and determined and assessed that the same recurring ideas and relationships could be verified. Further findings of the peer reviewers are discussed in Chapter Four of this document. According to Phillips, "When researchers try honestly to refute their own dearly held beliefs, then bias, other shortcomings and judgments reached should be objective in the relevant sense” (Phillips, 1990, p. 33). Appendix XV shows the background of the two 
Running head: EFFECTS OF THE EMPHASIS ON ACHIEVING

readers/peer reviewers. According to Lincoln and Guba, (1985, p. 379) these reviewers or auditors should "possess such characteristics as methodological sophistication, minimal knowledge about the subject of the study, integrity, and experience with analyzing." This researcher talked to the peer readers about being open and objective to the responses of the participants. The peer reviewers were asked to read "Chapter Eleven” of the book Theory and Concepts in Qualitative Research, (Flinders, 1993, pp. 183 - 199) as an overview of hermeneutics and qualitative inquiry. This researcher discussed "Chapter Eleven” with the readers. They were also asked to scan the book, Translated Woman, (Behar, 1993). This researcher felt that these activities would assist the readers in gaining a basic understanding of the concepts of hermeneutics, phenomenological research, and qualitative inquiry methods.

The emergent themes of the interpretation of the interview data obtained by this researcher were checked for consistency and credibility by the two readers to determine whether the findings of this investigator were reasonable based on the raw data gained from the interview transcripts. This method of using other analysts not only allowed for validation of the study, but also for reliability. Even though, this researcher fully realized that duplication of a qualitative study would not generate the same results, the more important issue was whether the results found by this researcher were consistent with the data that was collected. The method of triangulating analysts who independently read and analyzed the data also provided a check on any biases of this researcher. The readers were able to do the following as delineated by Patton (2002, p. 560): “(1) verify that the respondents’ perspectives were clearly conveyed; (2) point out problems and areas of concern; and (3) give any other ideas or interpretations.” 
Running head: EFFECTS OF THE EMPHASIS ON ACHIEVING

This researcher hoped that by using this method of triangulation involving other analysts to review the themes and data that the credibility of the study was verified. This researcher does not want the study to be perceived as Patton (2002, p. 563) cautioned as an "artifact of a single method, a single source, or a single investigator's blinders.”

The results of the fifty educator interviews have been divided into the teachers' themes in Chapter Four and the principals' themes in Chapter Five. By dividing the results into two distinct chapters, this researcher believed that perhaps the reader would be able to gain a better understanding of the experiences of the teachers as a separate array of experiences from their administrators. Although, some of the results are similar for the two groups of educators - teachers and principals, it is important for the reader to realize that the comments of the teachers represented encounters and conditions that were separate situations from those of the administrators. 
Running head: EFFECTS OF THE EMPHASIS ON ACHIEVING

\section{ICHAPTER $\square$}

\section{Discussion of Results}

The results of this study were reported around the two research questions which were used to guide the interviews. These questions were not asked during the interviews, but were only used by this researcher if the conversation was not flowing or if certain questions appeared to not be answered during the interviews. When that occurred, this researcher made every attempt to ask a question in a natural way that fit into the interviewee's conversation at that moment. Much to this researcher's surprise and satisfaction, in most of the interviews, the educators talked very freely, openly and at length.

The research questions for this study were as follows:

1. What are the effects of a consultant's work at schools that did not achieve AY P on each of the following:

(A): teachers' instructional techniques, daily work loads, and teaching strategies used with students

(B): administrators’ daily work loads and leadership styles?

2. What effects does the emphasis on achieving AYP at schools that do not meet the required proficiency level on the NCLB mandated annual state tests have on the following:

(A): teachers

(B): administrators?

As this researcher began studying and analyzing the transcripts for various common themes, patterns began to emerge. As different sections of the transcribed interviews 
Running head: EFFECTS OF THE EMPHASIS ON ACHIEVING

were highlighted and moved together under the research questions, it became easy to see the dominant ideas that were developing. It was also noticed by this researcher that the interviewees all seemed to dwell on certain topics more than others. It became apparent which areas were of greatest concern to them and which areas were not as significant. It also appeared that a few extraneous topics were also touched on by the educators. These individuals who had volunteered to participate really wanted to talk and seemed to be glad that someone was listening. It surprised this researcher that these educators wanted to talk at length with someone who had no authority to do anything positive for their situations, except to listen to them. The talking seemed to be almost therapeutic for the participants.

This topic was of personal significant interest since this researcher had experienced the effects of consultants and the emphasis of AYP while working at a school that had not achieved AYP. However, it was still amazing to this researcher to realize that other individual educators across the districts had lived through comparable experiences and had also felt and were expressing the effects in a similar manner. This researcher, while listening to the fifty interviewees for more than ten weeks, continually tried, as Moustakis (1994, p. 34) cautioned, “to set aside personal experiences, as much as possible, in an effort to take a fresh perspective toward the phenomenon under investigation.” The personal experiences that had affected this researcher were briefly described in Chapter One of this document. Throughout the discussion of the results, this researcher has attempted to "bracket out personal experiences” (Creswell, 2007, p. 59) and simply collect the data representing the experiences of other educators as related to the phenomena. 
Running head: EFFECTS OF THE EMPHASIS ON ACHIEVING

Portions of the actual collected data, the transcribed interviews, are listed after the discussion of each theme. Although, it was difficult to completely refrain from interjecting personal experiences and ideas, this researcher has tried diligently to do that, especially in the development of the themes. In regard to that issue, the NVIVO8 qualitative software allowed this researcher to set-up nodes or hierarchies centered on the research questions determined at the beginning of this study. As the "significant statements” (Creswell, 2007, p. 60) were "highlighted, according to "horizonalization” (Moustakis, 1994, p. 95) for content, this researcher was not aware of which types of statements were being used more than others by the interviewees. After all of the interviews were highlighted for significant statements, this researcher “developed clusters of meaning” (Creswell, 2007, p. 61) from the statements into the themes. When this was completed for all fifty interviews, the themes, as described, had been determined.

In the list of themes on the following pages, there are numbers in parentheses that represent the total significant statements that the fifty interviewees made under each theme. There were forty-three (female) teacher interviewees that contributed comments under the thirteen themes in sections A and B that follow. There were seven (five males and two female) administrator interviewees that contributed comments to the seven themes in sections $\mathrm{C}$ and $\mathrm{D}$ that follow. This researcher analyzed the data and reduced the information into the twenty themes. In that matter, this researcher "developed a textural description for the experiences of the interviewees” (Moustakis, 1994, p. 60). This researcher wrote these textural descriptions or themes from the significant statements that represented what the interviewees had experienced. 
Running head: EFFECTS OF THE EMPHASIS ON ACHIEVING

Some of the significant statements, also included what Moustakis (1994, p. 99) referred to as "imaginative variations or structural descriptions." These described the "context and the setting that influenced how the participants experienced the phenomenon” (Moustakis, 1994, p. 99). This researcher felt that the significant statements representing the structural descriptions were quite often blended in the significant statements that also represented the textural themes of the participants' experiences.

The following list represents the themes that emerged from the teacher interviews:

A. Effects of a consultant on teachers

1. Changes in daily teaching activities and work loads. (232)

2. Changes in class management and teaching styles. (190)

3. Changes in yourself. (147)

4. Most difficult aspects to integrate. (137)

5. Empathy received from District Office and/or State Department. (125)

6. Time to spend with individual students. (61)

7. Parent involvement/students' home life. (26)

B. Effects of AYP emphasis on teachers

1. Staff morale, feelings, attitudes, and motivation. (413)

2. Suggestion for other Districts. (247)

3. Empathy from District Office and/or State Department. (144)

4. Training time on new programs. (89)

5. Staff changes, transfers, and retirements. (65)

6. Time to spend planning with teachers in the school. (57) 
Running head: EFFECTS OF THE EMPHASIS ON ACHIEVING

The themes that emerged from the principal interviews were as follows:

C. Effects of a consultant on building principals

1. Changes in principals' daily work load and routine. (69)

2. Most difficult aspects for principals. (58)

3. Noted changes in teachers. (42)

D. Effects of AYP emphasis on building principals

1. Suggestions for other districts. (163)

2. Noted changes in staff morale, feelings, attitudes, and motivation. (103)

3. Empathy from District Office and State Department. (85)

4. Staff changes, transfers, and retirements. (33)

The results have been discussed under each of the themes as listed. A sampling of actual interviewee remarks has been arranged after each theme. This researcher reminds the reader that the remarks provided in the results section after each theme are the actual comments taken from the interview transcripts. Each reader should remember that these are real educators who are currently working in the public schools.

\section{Results of the Teachers' Interviews}

The remainder of this chapter has been devoted to the themes and the comments in regard to teachers' interviews and the emphasis on achieving adequate yearly progress. The reader is reminded that these comments represent the experiences of real teachers who are currently working under the constraints of NCLB and its guidelines.

\section{Teacher Theme One: Effects of a Consultant on Teachers as Related to Changes in Daily Teaching Activities and Work Loads}

As the data were read concerning the teachers' daily activities and work load the 


\section{Running head: EFFECTS OF THE EMPHASIS ON ACHIEVING}

major ideas that evolved were, “overwhelming feelings of too many programs and the frustration of being in the game where the mole comes up through a hole and is being punched back down.” The teachers also experienced the sensation of having no foundation and being "stirred up" in their own classrooms. To further add to their anxieties, teachers mentioned, “not being able to finish one thing before another one came at them.” They stressed the need for more help with the new programs and a need for time to fully learn and understand the programs before trying to teach with them. However, sadly many teachers mentioned the need for help from the special needs teachers who can't come as often to their classrooms because there are more special needs students and fewer special needs teachers. As the special needs students are placed into full inclusion and as the tier intervention methods are used to make the small groups for instruction those special needs students are included, but they are separated in the tiers, in some instances. These were sad and frustrating experiences for these classroom teachers.

The teachers noted that they have so many jobs besides teaching, "We are nurses, counselors, parents, and special educators.” The paperwork is so demanding that, "I can't focus on teaching my students.” The constant stream of consultants and others coming into the classroom is unnerving. A teacher said, "The human element has been removed.” We are just doing "blips of this and that”. “All of this information was presented to us in an unorganized manner” according to one teacher. Another teacher implied, “Our voices are not being heard.” There was "no brainstorming or input” from the teachers. These teachers wanted to be a part of the "makeover" of their schools; instead it had been turned into a "takeover." 
Running head: EFFECTS OF THE EMPHASIS ON ACHIEVING

The need to have "time” was very apparent in the words of these teachers. They expressed the need for time to "learn new programs, schedule for the students, do lesson plans, do individualization for students and to learn and to use the new technology.” The question was asked, “Are we really improving student learning?” These teachers were, "trying to set priorities and make sense of all of this" was a theme expressed in their statements. In the mean time, many of them felt that they “can't find their way through all that they were being faced with.”

The teachers saw that the only, “consistent thing is change and this constant change seems to be just a new spin on the same old thing.” These teachers realized that instruction must be “data driven”, what happened to "student-centered” was the question that they posed.

\section{Results - From Teachers at all Six Schools in regard to Effects of a Consultant on}

\section{Teachers as Related to Changes in Daily Teaching Activities and Work Load}

Feelings of being overwhelmed, frustrated, and rushed due to the scheduling times were expressed by many of the teachers. Some of their feelings are reflected in the following comments:

Ann: I became overwhelmed the more that I was exposed to various programs. I still feel, you know -- the game where the mole comes up and they punch him back down - I am that mole. I learn something and I try it and they punch me back down in the mole hole and want me to do something different. Even though, I have not figured the first thing out yet.

Mary: We have all these little time slots in our daily schedule now. We are plugging and unplugging our students like we are the technology and we want them to do all of these higher level things, but there is no foundation and no time to practice the needed techniques. We are 
Running head: EFFECTS OF THE EMPHASIS ON ACHIEVING

stirring the students up.

Cary: We, as teachers, are in a state of constant frustration because we feel like we aren't allowed to finish one thing before we start something else with the students. How can children go deep into the subject matter and become proficient in the foundation items in this new scheduling model - that is what I worry about the most.

Rose: Our jobs are changing daily. We are counselor, teacher, special educator, nurse, and parent. It's frustrating - there's so much put on a teacher. Every time that I turn around it's more paperwork. Everything has to be documented. It's sad when you can't come to school and focus on teaching the students and helping them to learn. I am constantly worrying - did I mark this off, am I on schedule, did I fill out this form and turn in that one. I do so many things that take away from meeting the needs of the students. I know that the students pick up on this. They know. Every time I turn around there is someone walking in the room for something else or to observe. It really is crazy for me and the students.

Tonya: I feel the scariest part is that the human element -- the human interaction has been removed from our profession. We are doing all of these little blips of things throughout the day and we are still not getting the things that are most important for student learning done.

Joan: I try to sneak some creative things in. I feel like a thief in the night. And, if someone comes in to observe and I am not exactly on my schedule time, then I have to explain later. I have to defend myself. Ten or fifteen years ago we had principals who could let us be creative and teach in the moment, not now. They can't and we are not supposed to do that. We must follow the scripts and stay on the schedule. Where is the time for imagination, creativity, individualization for students and for teachers? Are we really improving teaching and learning for students and teachers?

Teachers indicated, in regard to Theme One that they were trying to set priorities, 
Running head: EFFECTS OF THE EMPHASIS ON ACHIEVING

study test results, and use those results to meet the needs of individual students. Included in some of their comments were the following statements:

Meg: It's been a pretty good year for me so far. After twenty-nine years, I admitted to myself that I am going to try to meet the expectations that my principal has and that the consultants and others have, but I can't honestly do everything they are asking. I just have set priorities that I feel are most important for the students and I follow the CSOs. But, my peers are stressing over lesson plans. I am not. I do what is best for the students in my room. I have studied their files and I am trying to get to know their individual needs. I have studied their test results from last year's test.

Sally: Assessment! That's one thing that we do a lot of anymore in our daily routine. We assess the students. We do this assessment and that assessment. And, we never have time to teach to the individual student needs according to the assessments. So, what's the point?

In regard to the special needs students it was disheartening to hear these results: Liz: I have several special needs students in my classroom. I believe that right now I have eight. They all have different requirements that I must meet according to their IEPs. So, I try to provide all of the modifications for them. The special needs teacher is also responsible; she can't come to my classroom every day. So, basically it is me. I can't always meet all of these each day in each subject. It really upsets me and I know it is not good for the students.

Mae: I now have fourteen instructional groups a day. How can I do lesson plans? It takes me forever. I do not have enough time. It is unreasonable. I have all of my IEPs (Individual Education Plans) done accurately and they still want more. I can follow the IEPs and a substitute could too, but they still want very detailed plans. I had been doing all the plans on the computer and I had a good system. Well, now the computer has been down for weeks. I just can't do them by hand anymore. So, I am telling the principal in the morning. He needs to get my computer 
Running head: EFFECTS OF THE EMPHASIS ON ACHIEVING

repaired if he wants those plans.

Lane: Those students are the ones left in certain tiers and the others have tested out, so the special needs students are left at the lower levels. I do not see how this is inclusion -- just because they are in the regular classroom - they are still in a separate small group.

Several teachers expressed that many of the things they were required to do for accountability were unnecessary. Their comments included these remarks:

Debra: There are so many things that we have to do now in addition to what we always did before. I don't see where anything got taken away. They keep saying it has. I don't know what it was. I have to do the benchmarks, Acuity, Tech Steps, and tier interventions in reading and soon in the math. Lesson plans are so much more involved. Everything has to be so specific. A notebook has to be kept for all of the data that we collect. And, that is unnecessary as we can look everything up on the computer. What's the point? Just more work.

Jill: I have so many different things that I am now responsible for each day. Then, someone walks into the room and interrupts and says they need the benchmarks right now. Or, we get a reminder about the Tech Steps and the kids have not been online enough. Do they think that we keep them off of it on purpose? We just don't have the time to fit everything in each day. Then you have to keep track of all these passwords and then they don't work. Then someone says there was a mixup in the computer room sign-up and that changes everything. It's like all of these things come in pieces.

Kate: I feel guilty this year since I only have nineteen students and most of the other teachers have between twenty-three and twenty-five. When I started the year, I thought to myself, I can do this no matter what. I actually took a sigh of relief, all these new things came in and I am trying to find my way through learning about how to teach the tiers, the interventions and the new technology program. I do feel guilty as my peers have way more students than I do. And, then there are so many 
Running head: EFFECTS OF THE EMPHASIS ON ACHIEVING

forms to fill out and keep track of, it is unbelievable.

Maria: The work load now is probably at least twice as much as last

year. And, we are given the same amount of time to do it. The scheduling

is a nightmare. There is not enough time in the day to do all that needs

done. So, there are things that just don't get done.

It was indicated that changes would be implemented more readily if the teachers had been given input and more time to learn. These views were represented in these comments:

Jan: If they really want these new methods to work, then they need to give us time to learn them and implement them one at a time as we go.

Change takes time. It might be good if they had gotten these methods to us in a more organized manner and if they had allowed us, as classroom teachers, to brainstorm with the administrators about the best way to change the schedule and the format of the day.

Diane: If you know that your voice is heard you are so much more connected to making changes and doing things differently. If you are just told to do this and that, then you are less apt to feel a part of the total makeover.

Barb: I feel that we are called to workshops and told what to put in our schedule, how to do it and when to do it and there is no such thing as teacher input. It's like they think that we don't have a thought in our heads.

These remarks represented the worry that many teachers mentioned about being able to continue to put in the extra time:

Jane: I'm here almost every night until almost 10:30 p.m. Then I am here by 6:00 a.m. and start over again. I come in on the weekends. Some of that wouldn't be so bad if I wasn't trying to get used to the new curriculum and technology. I'm trying to learn everything new and teach at the same time. I have been here at this building for twenty-eight years. I feel like I can't keep up and I have so much to learn.

Kay: We have to follow the CSOs. Well, I really do not have trouble 


\section{Running head: EFFECTS OF THE EMPHASIS ON ACHIEVING}

with that, but our textbooks do not match. So, I am digging on the internet and other books to get information to match each one of them that is not in the text. This takes a great deal of time.

Sharon: We have very little time in a day's schedule to allow the students to refocus and get organized. I feel sometimes that the attention deficit students who are pulled out for various tiers and programs do not have time to focus. So, aren't we just adding to their problem? These students who have trouble attending and focusing might have four or five different teachers in one day. That has to be very difficult for them. Really, I feel it is difficult for most elementary students.

Sue: I have instituted the skill and drill into my daily schedule in both reading and math. It is pure drudgery. I hate it and the students hate it. I can't convince the people making the decisions that it is not working. They only want to hear about our transition times from one subject or group level to another. Transition is all that matters and what we do before or after transition is not what they want to hear.

Teachers wanted to be able to schedule more small group instruction, the need for more time and teachers would be beneficial as indicated by these comments:

Cindy: All of the programs call for small group instruction, but our class sizes are growing and there is really no room to do it appropriately. There are no extra teachers in the building to help with this task either. Edith: We are told to institute all the different tier levels in reading, actually there is not enough time in the schedule to do all the needed tiers. Really, we need more teachers to do the tiers in the time that we have scheduled in our school day.

Teachers realized that lesson plans must be written, the need for the correct materials would benefit making the writing of the plans become a classroom reality:

Martha: One evening I was working in my classroom and the phone rang. It was the principal. He told me that he was looking at my lesson plans for science and that I did not have fifty percent hands - on activities. I told him that we were studying the cell and the school had no materials 
Running head: EFFECTS OF THE EMPHASIS ON ACHIEVING

for that. I explained that we would be looking at videos and using the internet. He informed me those were not hands - on. He told me to buy some seeds and have the students to plant seeds. How would that be hands-on for cells? I told him I needed some microscopes and slides. He told me again to plant some seeds.

Alice: I truly wonder how much time these consultants have spent in their own classrooms trying to implement what they are telling us to do. They still keep trying to tell us to keep all of the subjects separate, but with the addition of all the intervention tiers for reading and math, it just can't be done unless you integrate science with math and reading and social studies with reading and various other combinations. What is wrong with that as long as I cover the CSOs and do the interventions. They are very concerned about the state mandated minutes in the day and for each subject. Everything will not fit into the length of the day.

Carla: We are constantly being bombarded with new things. Every consultant that comes in has something else for us to add. We have new technologies, new data collection systems, and new software. We need new computers. It's always a new spin on the same old thing. We have new assessment methods with the Acuity program. It relates directly to the state test. It will show us the weak areas of the student and then we will do more interventions to try to help them get better scores. It is all so data driven, not student-centered.

The use of technology had apparently been accepted by these teachers, their comments expressed the needs for -- time to learn the programs and the computers:

Rose: We had a good computerized program for reading based on research concerning the brain. It seemed to be really working, especially with the really struggling readers. We had been using it a couple of years. The students were improving and they enjoyed the program. We had the scores from within the program that showed their improvement. Well, they took it off the computers. We had just got it integrated and the schedule was working well. 
Running head: EFFECTS OF THE EMPHASIS ON ACHIEVING

Ida: Our lesson plans have really changed. They have to be so detailed to show what we are doing. We have to show the technology that is involved. We spend a great deal of time doing that and then the computer doesn't work and the whole lesson is changed. We must stress the CSOs and what and when we teach and re-teach. I believe we are more focused in some areas, but leave out things that need to be done even if they are not tested.

Carol: I know that I am overwhelmed. There are people always coming into my classroom and making suggestions. I try to change the way that I do things. I switch things up and integrate technology. I try to get the students to try the new thing, but it is very difficult to have so much change going on and I feel like there is no consistency. Well, there is we are consistently changing things.

\section{Teacher Theme Two: Effects of a Consultant on Teachers as Related to}

\section{Changes In Class Management and Teaching Styles}

The question of who provided the research for these new research-based methods was posed by many of these educators, "I do what I am told” said one teacher. These teachers reported that no one asks them what they think. They also wondered, “Had these presenters actually worked with students?” The teachers seemed frustrated when they talked about changing techniques, methods, and styles from one year to the next as the district put in programs and then took them out. They remarked that, "It is all about what is mandated, not about the needs of the students.”

Another concern was managing the classroom technology. It was noted many times that, “The technology components require much time, training, and daily preparation.” The teachers did not feel that the district was concerned about this 
Running head: EFFECTS OF THE EMPHASIS ON ACHIEVING

aspect. Many teachers further commented about teaching things in "isolation” and not "association.” They did not feel that type of instruction represented "life skills.”

The confusion and conflict between the presentations of many of the consultants was also expressed as a concern by these educators. The teachers wondered if the district supervisors communicated with each other about the consultants' topics. A teacher remarked that, “the right hand doesn't know what the left hand is doing.” In response to these "mixed-up methods" many teachers were adapting their own styles and doing what was best for the students” and they interjected, "I have to look over my shoulder to see who is looking in my doorway.”

It was very hard to focus during uninterrupted reading when, "Students are pulled in and out and consultants come in and out.” The teachers said they tried to do the best that they could. It was admitted by many of the teachers that, “The schedule runs us and we can't take an extra minute for anything." The "test is our focus" and those are the "skills we work on daily." "I have to be checking to see if everything was done on time and checked off.” The teachers mentioned that some of their principals gave them a list to check off their daily activities. "Everything has to fit the mold, but I sneak in some fun” admitted one educator.

\section{Results -- from Teachers at all Six Schools in regard to Effects of a Consultant on Teachers as Related to Changes in Class Management and Teaching Styles}

These teachers recognized that there were many positive benefits for everyone involved in full inclusion. However, they expressed that when they found a useful program it was often removed. Their remarks showed their concern:

Ruth: I am required to do benchmarks on one program four or five times a year. I use interventions and tier grouping. I analyze the data from the 
Running head: EFFECTS OF THE EMPHASIS ON ACHIEVING

annual state test and I also study the IEPs of the students in my inclusion regular classroom. I do not have time to really study all of this information and formulate a plan that would be most effective for each student. If I could have time to do all of these things then I could better adjust my instruction to meet the needs of the individual students. I just don't have the time to do it the way that it should be done.

Kris: Just as soon as I get used to a program they take it out. We had a brain research-based computerized reading program. It was really working well with the students. Well, then we lost it due to funding or something. It was proving that it was working and they took it away. Also, one good thing - even though it can be very difficult to schedule - is including the special needs students into the regular classroom. I don't mean that I am sure it helps all of the special needs students, but in some cases it does. It has really helped the regular kids to know how to interact with children who have issues. Some of these regular kids can be inconsiderate, so at least now we can show them how to help those that are less fortunate. Some really good things as far as student friendships have developed because of that implementation.

Lou: The test scores for this building are slowly improving; they still are not good enough. We have the special needs students fully included in most cases, but as a regular teacher there is not enough time to do all of the modifications across all the subject areas for these students. The special education teachers can’t do it all either. We need extra help to manage all of this in a manner that will truly help.

Ina: Last year I had the special needs teacher in my classroom more often. Now, this year she can only stay for one half of the reading block because she needs to be somewhere else. I have twenty-six students in there and nine of them are special needs. It is supposed to be uninterrupted reading instruction. I try to plan it so that I can give them as much help as possible and to pair them with the more advanced students when the special teacher leaves. 
Running head: EFFECTS OF THE EMPHASIS ON ACHIEVING

Page: At the bottom of my grade book pages I have notes about everything that I need to remember and integrate during the day. I have information for individual 504s, IEP stuff, the intervention and tier groups and where they go, the benchmark levels - who is weak on what, and who needs to have things read to them. It is all so much to keep up with and still teach and work with the students minute by minute.

Teachers expressed their frustration over all of the changes in methods that had been presented to them at workshops and by various consultants. Their concerns were expressed by the following comments:

Becky: We had organized our class management and teaching styles around the methods for a certain model of reading instruction. Many workshop hours had been spent in preparing us for that model over the last few years. They sent us to conference in Atlanta, Toronto, and Chicago. Now, all of that time, money, energy, and expertise is out the door because we failed to make AYP. They are changing everything to some new research-based model. Who is doing this research? That's what I want to know. How do we know that these changes will work? I think a lot of time and money have been wasted, but I will do what I am told. No one is asking what I think or what any teacher in the classroom thinks. It all comes from the state and district level administrators. I want to know when those people actually worked with students.

Patti: We changed our teaching styles last school year to accommodate for open-ended test questions. We worked all year on those in preparation for the end of year mandated testing. And, then we found out a few days before the state test that the students would respond on bubble sheets for the test and not write in the test booklets. Do the people at the state not know that is a skill that must be practiced? Do they realize how many adults, forget students, have a difficult time looking at a test booklet and then bubbling in the answer on another sheet of paper? I wonder how that affected the test results. And, just what were they thinking when they came up with that? Why didn't they ask a practicing classroom teacher 
Running head: EFFECTS OF THE EMPHASIS ON ACHIEVING

about that idea?

Sandi: Teaching skills in isolation has been a problem for me as well as my students. I can't convince anyone above me that it does not make any sense. We do not read things in isolation, everything is by association, but we are being made to learn this and to implement it. We rarely get to read a story all the way through in one sitting. I feel this is bad for comprehension and student attention.

Pam: There seems to be some confusion between our various language arts workshop presenters as to whether or not creative writing is a part of the ninety minute reading block. One presenter teaches it one way and the other does it a different way. Hopefully, they will get this cleared up. I really do not know what to do. So, I put it in when I feel it is appropriate. I guess they will tell me sooner or later.

Ann: They are always telling us we need to evaluate in order to drive instruction and we have to assess. I think that they need to be assessed. It seems to me that the right hand doesn't know what the left hand is doing. Who puts these workshops together, who picks the consultants, who decides what will be taught to the teachers? They do not even know that they have given us conflicting information until we tell them. They tell us to work smarter, not harder. It sounds real good, but it is impossible. Mary: I wasn't sure about the new response to intervention program. It seemed that it concentrates too much on how fast the children can read. They are scored either slow and right or fast and wrong or vice versa. What about comprehension? Doesn't the state test focus on comprehension? I know that we need to build up basic skills; it seems we never get around to higher level things with most of the students. And, the students who could use acceleration are really left out.

Cary: I am actually teaching a couple of intervention groups during reading. I love it and I love the kids. It is a lot of work. I am starting, developing, and teaching this new stuff all at the same time. The state tests were used to determine the groups, the tiers and now we are trying to 
Running head: EFFECTS OF THE EMPHASIS ON ACHIEVING

work on the skill groups that will raise the test scores. That is our focus.

Rose: I work harder just to keep my head above water let alone accomplish all that they ask. I want to accomplish it all. I just can't. When the presenter comes to train us - she tells us to do it a certain way. Then, she returns in three weeks and tells us to flip it another way. It's like learning to roller skate for the first time and when you finally get it, they say skate in the other direction.

Tonya: They want everything to fit in a little mold. I try to do that. I understand what they want. Everything is so regimented. They are children. We do this to them at the lower grades and by the time they get to high school they can't stand school. They have never seen that learning can be fun. I still try to do that. The consultants don't ever tell us that; at least, not in any of the workshops I've attended. They just talk about keeping on schedule and moving the groups to the next station or the next room.

The limited technology training and the lack of appropriate equipment caused anxiety and unnecessary problems for these teachers. These comments expressed their concerns:

Joan: We were thrown into the new state program for technology this year at all grade levels. Well, some of the students have never been exposed to anything. The training for the teachers was very limited. This program seems pretty good, but it should have been phased in slowly from kindergarten on up. Then the students and the teachers would have been prepared, instead the students and the teachers are in over their heads and we have to complete the mandated projects. Everyone is trying very hard. We have to save the student projects at the end of every class period and the school has only purchased four jump drives for each classroom. Do you know how much time I spend opening up projects at the start of class and then saving them at the end of class? Did the state really think this through or is this just a problem in our building. 
Running head: EFFECTS OF THE EMPHASIS ON ACHIEVING

Meg: The training on the Acuity program, the program that is geared directly to the state CSOs in various subject areas. It is a really beneficial program. We need to use it in place of our textbooks really. Or, just use the texts as a supplement to it. That program follows the CSOs and uses the verbiage of the state test. Sometimes the students miss the questions because of the words used and the way the questions are laid out, not because they do not know the material. So, each teacher needs to revamp their teaching style to incorporate the use of this program in to the subject matter each day. Of course, this means we need more computers right in our classrooms. Just once or twice a week in the lab is not enough. If you want us to teach to the test, this program will do it. So, get us the classroom laptop computers. I am ready.

The feeling of having too much to do and constantly checking things off a list was conveyed as a task that consumed much time for some of these teachers:

Sally: I am constantly checking. Are my individual student notebooks up-to-date, are the benchmarks done on time, are the percentages done and are the computers ready to go? I am just checking things off with no real time to spend on any one thing. I have to Google this and get a website for twenty-first century skills. I think we need to stop and rethink all of this. Where are the basics? When can I show the students how important reading is so they can develop a love for it?

Liz: While I am teaching I have to put in grades online and up load them. I have to keep track of the curriculum mapping. I have to make notes on the benchmarking and the CSOs covered. I have to do Acuity matching to the CSOs. Our principal has given us this checklist for depth of knowledge; I have to make sure I check that off for each item taught each day. And I need to make sure that my lesson plans are revised each day to reflect what I did and did not get covered. It's not too bad.

All of the movement of students from room to room cut into the instructional time and this was a serious problem according to these teachers. The following remarks are filled with their concerns: 
Running head: EFFECTS OF THE EMPHASIS ON ACHIEVING

Mae: Because our school is on an improvement plan, we got a reading consultant. She is here every day all day and she tells us what to do. She sets the times that we will meet with the students. She requires us to have certain lesson plans. We have these ninety minutes of so called uninterrupted reading, but every thirty minutes the students move to a different room. I don't mean they go to a different group in my room. No, they go to a different room. We lose so much time.

Lane: I know what content the students need to have mastered before they leave for middle school. So, it's like I do two different things. I mean, you know, I do what the consultant and the principal say in the manner that they expect. Then when they are not looking I do what I know interests the kids; is fun for them, and yet gets them to enjoy learning. I do what I know is best. This causes stress as I need to be looking over my shoulder to see who is coming in my room to observe. Debra: At this school we have a different consultant for technology, reading, and curriculum and don't forget we have the principal. If I did everything that all of them asked I would have to move a cot in my room and have my students come two hours early and stay two hours later each day. I would never be able to leave on weekends either. It was stressful, but now I prioritize. I do one thing each day to make each of those four happy and that is all that I can do. The rest of the time I focus on the needs of the students.

Jill: Just recently for two days both of the principals and the reading coach were out of the building for a meeting. It was wonderful for everyone. We did not let the schedule run us. If we looked down the hall way and someone said they needed ten more minutes to cover a topic before we moved the kids, well we did it. It was a great feeling. The students were not rushed. The teachers did not worry about a supervisor coming in and seeing that you were off the schedule a little. It was great for two days. And, you know what we still covered a lot of CSOs.

Kate: We have had so many different administrators here, that emotions 
Running head: EFFECTS OF THE EMPHASIS ON ACHIEVING

really run high. I have resigned myself to doing what I feel is right for the students. I can't keep learning how to please all of these people that come and go. So, I don't do things like most of the other teachers. I accept what they say and move on. I do what I can. I am really ok with integrating most of the new programs and ideas. I still have Fun-Fridays. I still do themes. On the days that I do the theme, I integrate it through all the subjects all day. I also have a theme for the whole year - this year it is - Amazing Animals. The students look for those things. Sometimes they even find things at home and bring in books or information. It makes things a little more interesting and it shows the kids that they can learn here and outside of school.

\section{Teacher Theme Three: Effects of a Consultant on Teachers as Related to}

\section{Changes in Themselves}

In describing changes in themselves one teacher summed it up, "I feel like one of those gerbils in the little round cage running faster and faster and getting nowhere, just tired and frustrated.” Many teachers voiced that they felt badly about the test scores and wondered if their administrators actually tried to make them feel worse by not revealing, in some cases, how close the school had come to achieving AYP in some academic areas and in some of the cells. It was a consistent statement for teachers to say they felt "overwhelmed and frustrated.” They remarked that, “The different presenters' topics provided them with so much information that they felt like they were in a whirlwind from which they couldn’t escape.”

In addition to all of the classroom responsibilities, several teachers mentioned feeling responsible and guilty about the home lives of many of their students. These teachers expressed that they, “...try to do all that they can to make school the best part of the child's day.” These teachers realized that they can't make up the 
Running head: EFFECTS OF THE EMPHASIS ON ACHIEVING

difference in what is missing from their students' lives. They also commented about the necessity to satisfy the basic needs of these children before addressing learning each day.

Many educators spoke about the many hours that they spend in the school building each day, night, and on the weekends. One educator added, "I had to change to survive.” Another said, “I don’t want my daughter to teach. I don’t want her to feel this way every day.” Another stated, “I want to retire, but I can’t afford to do it. I never thought I would feel this way." “All the joy has been taken out of the job” was commented by another teacher. "I come into the room and put on a happy face for the kids and do it my way” expressed another educator. These teachers have tried to make a “plan for survival.” “I used to like my job, now I’m not excited about it” stated one. Sadly a teacher commented, "I feel negligent and sad, because I am leaving some students in the dust as I race to keep on schedule.” “Other students are bored, but I have no time for enrichment” was a comment shared by one teacher. Feeling overloaded, many students and teachers are left behind due to the many challenges facing them each day. Many educators mentioned the need to be allowed to move more slowly in an effort to successfully implement the changes.

\section{Results - from Teachers at all Six Schools in Regard to Effects of a Consultant on Teachers as Related to Changes in Yourself}

Teachers talked about feeling guilty for not being able to meet the needs of their individual students. Anxiety was expressed in the following comments:

Maria: I see so many of the students struggling, I have to move on. This makes me feel negligent and sad. It's like I am just leaving some students in the dust. That doesn't give me a good feeling. I also feel guilty about 


\section{Running head: EFFECTS OF THE EMPHASIS ON ACHIEVING}

the ones who need to move on and have enrichment. They are getting frustrated and some of them are bored and then have disciplinary problems. I feel as if is my fault.

Jan: They cut a special needs teacher last year. It is much harder on me, now. You would not think that would be much extra work, losing just one teacher. It really is. I have one group that I teach by myself. Then, I have five grade level classrooms that I go into and co-teach. The teachers all want me to do something different. The classes are at different times and I feel like I am just sticking my head in for a little while, doing what I can, and running to the next room.

Diane: We are required to do so many things every day, but the assessments are what really stress me the most. It's like we do this constantly, and that really bothers me because I do not feel that I get a chance to know my students or their weaknesses or strengths before it is time to assess again. When do we have time to adjust the instruction? It is all very stressful for me.

These teachers could not understand why the presenters didn't take the time to know more about their school and students before presenting a workshop. This blending of information appeared to be important to these educators:

Barb: It is overwhelming to attend all of these different workshops, which are put on by different individuals from the State Department of Education. It seems that each presenter is trying to prove that they are worth the money they are being paid. They stand there in front of us and present their information as if it is the only thing that we have to implement. Each voice thinks it is the most dynamic force and has the most powerful program that is needed for every teacher's classroom. They do not even know what we are doing in our classrooms. They do not know our students. They do not even realize we have all of these other things that are having equal thunder coming down on us. I feel as if I am in a great whirlwind and can’t escape.

Jane: One year it was just announced to us that we did not make AYP, and then two months later the principal finally told us that we had made it 
in reading and only failed to make it in math by a very small margin. Why did he want to allow us to be so humiliated, when actually we had a reason to be proud? It seemed that he wanted us to feel badly. Did he believe that would make us work harder?

Kay: We have an administrator that is never wrong. So, you can't argue or say anything. I just want to scream after dealing with him.

When I walk into my classroom and the kids are there I just say to myself, put on a happy face and don't be a grouch.

Sharon: I do what I can. I even told the curriculum specialist that she needed to choose. I asked her if she wanted detailed lesson plans that were never really used or a teacher that was rested, refreshed, and ready for the students. She did not really answer me. So, I just keep doing it my way. I see changes in my peers. I hear them talking. They are staying late, coming in on weekends, and taking things home. They are neglecting their own kids and their spouses. I decided that I was not doing that anymore. So, I came up with my own plan for survival. I am better now. Sue: When I get up each morning I think about the day ahead. This is going to be a challenge and I don't want to be at school any more, but I'm not sure that I am ready to give it up yet. I know that I am making a difference for the students. I also feel the stress of facing each day and what it does to me.

Cindy: That is one frustration that I have. They just get us trained on one program and it fits into the schedule and then that program is gone. Then they train us on something else. Don't they realize they are wasting time and money? Who checks on that? They are always checking on us. Who checks on them? I have seen so much waste. It is really wrong. I guess I am resentful.

A feeling of responsibility for their students' home lives and their own home life was a serious concern for these teachers. These comments reflected their attempts to compensate: 
Edith: We are made to feel responsible for the home life that some of our students are exposed to before they come to school. We are very concerned about this and we try to make up the difference, but we are not responsible for the home life of our students. Most teachers know that school is the best part of many of their students’ lives. So, we try to make our classrooms very enjoyable learning places. We want our students to know that we are here for them. It's not just about academics. It also includes satisfying basic human needs before we can ever attempt to teach them reading and math. Have the people at the state level forgotten this?

Martha: I still do my own thing. I take those teachable moments when they come along. I hope for the best. Even though, all of these programs are making it harder and harder for me to continue to be hopeful.

Alice: I had to make changes in my life at the start of this school year. Last year, I was practically living at this building. My house was a mess. I never had any time to do anything to my house. I just had enough time to sleep there. My alarm was always set for three a.m. I use to be a happy person. I had to change this year and monitor how much time I spend at school. I like my job, but I had to pull myself away from certain things after a certain time each afternoon. All of the teachers here at this school talk about the need we have for more time to plan what we need to do the next day after we finish with a group of students.

Carla: I feel so badly because my mother was a teacher and that was all that I ever wanted to do. Now, after nineteen years in the profession, I tell my own daughter not to even think about becoming a teacher. The job has changed so much over these last six to eight years. It is not worth it any more. I do not want my daughter to end up feeling like I do now. I used to really enjoy my job, not now. All the joy has been taken out of this job. Rose: I used to like my job. I mean I still care and all that, but I can't say that I really am excited about it anymore. No, I have changed. It is just hard to like it now. Not having the time, not having the resource staff, and having so many different problems in my room at once. It is so 
challenging.

Ida: I have a four year old and most afternoons I have to call my grandmother to go and pick her up from the sitter's because I need to stay late again. Luckily, I can do that. Many teachers do not have that luxury, so, they drag everything home and then they are stressed because they neglect their children and their spouses.

Thoroughly realizing and accepting all of the responsibilities of elementary classroom teachers, these educators figured out some personal methods for their own survival as reflected in these remarks:

Carol: I had always been a teacher of gifted students and until last year never had my own classroom. I never dreamed all the responsibility of an elementary classroom teacher until I became one. I really do not think many of our supervisors at the district, state, and federal levels realize what responsibilities face classroom teachers.

Wendy: I have adjusted a little better to all of it. It is better now than I ever thought it would be, but it took a lot of changing in me. I just had to accept what I could and couldn't do and to let the rest go. That is very difficult for me. I, not only, feel like students are being left behind, but the teachers are too.

Paula: It's so frustrating. The local Board of Education and the state Board say that they want to help the teachers and give us what we need to be successful with NCLB. Well, they just keep giving us more work. I feel so overloaded. Some teachers say, well this will go away soon. They say what goes around comes around and that soon we will see the good things that we used to do circling back just with a new name. Well, I'm not sure all of those things were good. I just know that we can't survive in this overload. We need to move a little more slowly. Change takes time. Robin: I feel like one of those little gerbils in the little round running wheel. I just keep running and running, faster and faster. I am getting nowhere and I am very tired and frustrated. Where am I going to end up, if I don’t stop? 
Carol: I got into teaching late in my life. I wanted to do something to be of service. Well, now even after just these few years in the profession, I want to retire. I can't retire. I never thought I would feel this way. It started in the last two years. I just don't want to be here. After putting in all that money and time to go to college, now I am not enjoying it.

\section{Teacher Theme Four: Effects of a Consultant On Teachers as Related to the}

\section{Most Difficult Aspects to Integrate}

There are many difficult aspects that evolved as common themes associated with the consultants. Several teachers mentioned the frustration associated with the presentation of "conflicting ideas from different consultants" and the confusion that was often caused as a result. Many of the educators were faced with the challenges of changing the intervention strategies from year to year to accommodate the research-based programs being used. Also, expressed by the teachers was that the consultants, on occasion, had admitted to them that they had just learned the program and hoped that the teachers would be understanding of that. The same teachers mentioned that they received "no consideration” when they stated their need "to get to the lab and practice with the programs before using them with their students.” Special educators were anxious because they were recently required to go from room to room to work with their students. With staffing cuts, these teachers stated that they “can’t be everywhere to help the students and the classroom teachers.”

The students are also being moved from room to room to go with the methods of intervention according to the consultants instructions. These students have no time to focus. Many teachers questioned if all of this was really research-based. 
Running head: EFFECTS OF THE EMPHASIS ON ACHIEVING

The manner of scheduling students and consultants in and out was terrible according to the comments of many teachers. It is as if, "I never know who is coming or going" responded one teacher. The mention of "too many programs in and then done away with” also presented a problem according to numerous teacher comments. "It is difficult to keep up with what we are supposed to use and what is gone” added one teacher.

Many teachers commented that, "We need time to spend on really reading, so that students can learn to love reading.” Another frustration was with the computers. “They don't seem to work when we plan to use them” was a common complaint. "Time is wasted every time this happens and it is not our fault” noted another teacher. Frustration was voiced in this statement by one educator, "The students are struggling in the inclusion programs; their benchmark scores are lower.” Another teacher shared, “No matter what we do, it isn’t correct or else it needs changed; why can’t they get their act together?”

\section{Results - from Teachers at all Six School in Regard to Effects of a Consultant On Teachers as Related to the Most Difficult Aspects to Integrate}

The needs of the special education students were a main concern for these teachers as represented by these comments:

Ruth: We need the special educators in our classrooms more often. I agree that these special needs students should be in the regular classroom, but they still need the extra support. These teachers know how to modify and adjust the curriculum for the special students to meet their IEPs. I can't do that even if I had the time. The children are suffering and it is not fair to them. 
Kris: I have a student whose IEP requires that everything on tests be read to her. So, I have someone do this, when I don't have time. Then the frustration comes on the state testing days and throughout the year on the benchmarking when no one can read to her. This sad, disgusted look just takes over her face. It is hard to deal with.

Lou: I have so many special needs students included in all of my classes throughout the day. I try really hard to give them the extra time and attention that they need. I think sometimes it is to the point where the regular students get neglected and sometimes I think they notice and get a little resentful. It is hard to balance where any extra time is spent.

Ina: It is very difficult to accept that we are testing the special needs students on their grade level and not their ability level. This law needs changed. I guess I have been around too long. We were doing better the other way. I do not mind the special kids in my regular classroom. It is upsetting to me that they are not getting the help they need. I get some of the accelerated students to work with them one-on-one. I can't do it all. The special teachers come in and out as much as they can.

Page: This all started with No Child Left Behind. Being a special educator, I find this NCLB has pretty much ended up leaving many children behind. It is too uniform of a mandate. I believe that individuals who did not know what public schools were really like thought it was the fair and equitable thing to do as they spelled it out in the law. Special education is still dealing with the ramifications of this law. They tell us to do so many things and yet they cut the money. That's why I believe they really do not know what goes on in our schools on a daily basis. I am now nothing more than a glorified resource teacher. I go to six different teachers a day for forty-five minutes each. No child gets serviced very well or for very long.

Becky: Well, the funding got cut somehow and now we lost one of our special education teachers. Does that make any sense? They are not going to fill the position. We are told that we have to intensify with those 


\section{Running head: EFFECTS OF THE EMPHASIS ON ACHIEVING}

students and the other special educators in the building will take up the slack. Now, that cell is the one that brings down the scores and they cut a teacher. Go figure!

Patti: In becoming a teacher, my primary goal was to work with kids. I became quite good at working with the moderately impaired and dyslexic students in my regular classroom. I learned to use several different strategies that could help them over the years, now I am required to keep them on grade level materials as I try to help them overcome their deficiencies. These children are in need of more help than I can give now because of all that is expected of me. I am now so constrained with time and trying to keep on schedule that I can't do a good job of it anymore. It is very frustrating to get everything in and correct what needs to be corrected with the students.

Sandi: This whole group instruction is very difficult to handle. I know that they think that all of the students, no matter what their reading or math level should be in the large group for certain things, but the kids are struggling. I know the argument is that the kids will assimilate things just by hearing the discussions in the class, but they are struggling. I can tell by their faces.

These teachers expressed that they wanted to do what was expected of them, quite honestly, they appeared frustrated, tired, and concerned as reflected in these comments:

Pam: Well, we had an experience the first month of school. We had received all of these directives from the principal of how we were going to change things. Then we had a consultant from the state department come in one day after school and she explained the reading program the tiers and interventions. Then another day a consultant came from the Regional Education Service Agency (RESA) and she told us the exact opposite of how to implement the tiers. Then she grouped us at grade level tables and told each group different things as she went from one to another. When we left that day, we were all really confused. 
Ann: Just recently the school psychologist told us that the interventions are going to be changed because the county has to implement some research- based program. We are to continue what we are doing for now, but in about six weeks we are going to be trained on the new program and then things will change. It really doesn't matter to me. I have so much confusion now, it doesn’t matter.

Mary: I have tried to implement all of the changes from the trainings they have given to me. I really do want to do what they ask and do a good job for the students. All of us have been really working hard here at this school, but it never seems to be enough or to be right. If this is the way it is going to be with change after change, well I'm just tired of it and I guess I just shouldn’t be here. Why can’t they get their act together?

Difficulty in keeping up with all the changing programs caused anxiety, frustration, and more reasons to find fault with the system. Their issues were:

Cary: They bring things in and they take things out. This year we had to take out the learning centers and put in the intervention groups. They took out one long standing reading program and put in Acuity. It is difficult to keep up with all of this stuff. They need to put in one thing and let it work for awhile. How do we ever know what is working? Don't they know that it takes time to get results - long term?

Rose: As we go through the Acuity testing and the benchmarking we expose the students in the upper grades, especially fourth and fifth, to longer passages that must be read to do well on the test. These kids tell us right up front, when we ask them what happened with their score, that they did not read that long passage. They also admit that they aren't going to do it on the state test and they didn't read them last year. This is very difficult. They do not give us time to teach them to really learn to love reading. So, the whole approach does not mesh together.

Tonya: The scheduling is really terrible and hard to accommodate. We do not know when students are coming for various interventions. It is 
Running head: EFFECTS OF THE EMPHASIS ON ACHIEVING

hard to know which consultant or special education or Title I teacher will be here to work in the classroom with you. Then some days we have something planned and one of those co-teachers will be called to the District Office for a meeting. Oh yeah, that gets to me. I can't veer off the schedule, but the District Office overrides everything. Are they prioritizing the education that we are giving to the children?

Joan: It is very difficult to implement all of the different tier interventions and various programs in the length of the school day that we have. The students are really the ones that suffer. It is like they are an object for us to direct with a TV remote control and we try to zap and hurry them from room to room so they won't be late and they will have enough time to accomplish something, really these students can't focus like this. How is this research-based? The kids are snap here, snap there. Some days the poor things look very confused. I can't keep up with their schedules either. We change them so much due to the assessment and benchmark results.

Meg: I am a special educator and some of my students are on the alternate assessment because they have very low academic skills. I believe that when their scores are averaged in they actually help the overall scores of the school and of the special needs cell. Overall, the scores are pulled down by the students with learning disabilities and mild impairments who take the regular annual test. There are so many of those students and now with inclusion, I can't give them the individual attention and time that they need. I just don't see them enough to overcome their deficient areas. It is very frustrating as a teacher. I have been trained in both intervention strategies and grade level CSO modification, but I don't have enough time to be where I need to be often enough. Many of the regular classroom teachers have never received training in modification strategies and differentiation. So, the things that need to be done with those students are not getting done. It is no one’s fault. It is the system. 
Running head: EFFECTS OF THE EMPHASIS ON ACHIEVING

Sally: One consultant came to explain about Tech Steps. She said she was just learning it herself. She told us to just do the best that we could and to get the kids on it as much as possible. You know they monitor how much time the kids spend on that program. Then another consultant came for Acuity training and Odyssey retraining. We did get some pretty good information from her, but I have not had time to get back in the lab and practice. I hope I can remember what it was that she taught when I get back to it.

Liz: I went through the progress monitoring scores of some of the children that are pulled out several times during the day for various groupings. The students who were not pulled increased the most and the students who were only pulled once did the next best. I have a real issue with this. I really believe that we are moving these children too much throughout the day - throughout the building. It is not good for them and they just can't stay focused.

Lack of enough working computers and training time would have allowed these teachers and their students to benefit from the technology as confirmed by these comments:

Mae: We have so many computer programs now that I can't keep track of every student's passwords, log-in procedures, expectations and which CSOs they meet. And, we get more all the time.

Lane: They keep expecting us to use the computer more and more, and all of these new programs require it. So, I plan to do a certain thing in the lab. I make sure that I have everything together and I go to the lab with the students and the internet is down, or several computers are not working. They need to make our technology in this building match the materials that they are training us on. We waste a great deal of time and it really is not our fault. Of course, when this happens I go back to the room and either catch us up on something or maybe do something fun and creative. 
Debra: It is very difficult to get in enough computer time for each student. Yes, we have the lab, but we don't get in there often enough. I have four computers in my room and twenty-seven students. Well, it is hard to teach a lesson and still keep track of who is rotating through the computers. Then they miss things that I am teaching. Or, the computers don't work correctly. We need more computers in the classrooms if they are going to have all of these programs.

\section{Teacher Theme Five: Effects of a Consultant on Teachers as Related to}

\section{Empathy from the District Office and/or the State Department of Education}

A strong desire to be listened to and appreciated was apparent throughout the teacher interviews. The question mentioned, "When will they listen to us about what is happening in the classrooms with all of this implementation?" "When do we get to make suggestions?” One teacher stated, “It is really important to embrace the people involved in the change and give them their voice.” Teachers suggested that brainstorming sessions be arranged. It was also commented, “They wait till the test results come back in the fall and make more changes.” It was suggested that test results might be different if, “They talked to the teachers throughout the school year about how things were going and made little adjustments along the way.”

It seemed trivial to some teachers that supervisors were concerned, "about things like being exactly on schedule.” They tell us they are not giving us more, “It is in place of, but nothing is ever removed” added one teacher. "As teachers we can’t do it all and students can only absorb so much” was a comment that revealed the lack of empathy. “The Five Year Strategic Plan is supposed to be a valid document, but we have no input” remarked many teachers. “Our supervisors don’t seem to care enough to find out what really goes on in our classrooms” responded 
Running head: EFFECTS OF THE EMPHASIS ON ACHIEVING

one teacher. The teachers said, "If our supervisors cared they would come to us prior to the writing of the Five Year Plan.” Other concerns mentioned included that many teachers felt the district officials did not consider, "how the parents and the home life" affected these students. It was also felt that, "Too much instructional time was lost due to participation in pilot state testing and in the NAEP (National Assessment of Educational Progress) testing.”

These teachers needed to hear "something positive or at least be acknowledged for what they were facing” each day in their classrooms. As one teacher commented, "It would be nice to be appreciated." Another remarked, "We chose to be teachers and we take our jobs seriously. I see the looks in the students' eyes, especially the special needs students, and I'm not getting to do the things that I became a teacher to do.”

\section{Results - from Teachers at all Six Schools in Regard to Effects of a Consultant on Teachers as Related to Empathy from the District Office and/or the State Department of Education}

The importance of having their ideas, concerns, and input listened to would be greatly appreciated by these educators. These comments expressed their serious concerns:

Jill: I don't feel that most people realize that we, teachers, are in this profession because we want to be in it. We chose this profession. We do take our jobs very seriously, most of us. We try to do the very best that we can all the time, every day. We don't want to just teach; we want to go above and beyond and most of us do just that. It would be nice to be appreciated and to be shown a little gratitude from the officials at the top. Kate: I do not mind listening to all of the consultants from the District and the State, but when will they listen to us. We are the ones trying to 
Running head: EFFECTS OF THE EMPHASIS ON ACHIEVING

do these things in the classrooms on a daily basis. We should be able to give a review of what's happening as a result of the implementation, back to them. No, they just want to see the test results in May. Don't they think we should be able to make little suggestions along the way? Maria: Our Title I Director never has anytime to listen. Of course, he is also the Director of Special Education. I know he is busy, but so are we and we really needed to ask some questions and get his thoughts on things. He never has any time for us. He just says do whatever your principal says.

Jan: I went in at the very beginning of the year and told the principal that I knew that things needed to change and that most of the teachers were quite willing to do whatever was needed. I said that if there is going to be a change, it is really important to embrace all of the people involved and encourage them and let them have a voice in the change. I said that I would be willing to set up some brainstorming sessions and get things organized so that the teachers could have some input. I thought that the principal could use this as a launching board for the decision making. I am still waiting for the launch. Instead our principal just tells certain people on staff to get the word to the rest of us about what needs to be done.

Diane: There are lobbying groups for all other professions. Well, I think that teachers need one. And, I don't mean AFT or NEA. They have been taken over by big business. Ordinary teachers need to go to D.C. and talk to our representatives and let them know what is really happening in the schools. Those people can't really know. When were they in a school last? I know they haven't been here and I have been here for thirty years. We need to go to them.

Feelings that their supervisors do not understand or care was a real problem expressed by these educators. They wanted the district officials to show true concern: 
Barb: The very logic behind NCLB is flawed. Because every child is different and has different academic abilities and ways of learning. You can't expect every child to have the ability to reach the same potential as every other child. Yes, I will concede, you need to work with each child to reach their own individual potential, we need time to do that and more teachers to help, and I honestly believe they reach a point where they have a plateau and there's only so much that I can do about that. I may be wrong, but I can't see everyone getting to the same level.

Jane: I don't know if the district officials don't care or maybe they truly don't understand. If they don't understand, why don't they care enough to find out what is going on. For instance, with all of the measuring assessment. I mean that is great. We take the special needs kids into a regular classroom and we modify and adjust the curriculum. It is not just on a weekly basis, this has to be done nightly. Things happen that you did not plan for on the week's plan. So, each night you readjust. This is hard and it is continuous and on top of that some of the regular teachers don't want me or my kids in their rooms. Do the district officials realize all of this?

Kay: One day the Title I supervisor came into my classroom and went straight to my desk and my plans. She said, right in front of the students, you should not be doing this now. You need to be doing reading, math is finished. I was only five minutes over and we were reviewing for a test on the next day. The students had some really good questions and it just was not a good time to draw that instruction to a close. They needed some help and were genuinely interested in getting their problems solved. We stopped what we were doing and switched gears. That was stress for me and for the students.

Sharon: Stop telling us that what you are giving us to do is not more. They say it is in place of something. Well, each superintendent better check with their district supervisors and ask what is being removed. Not one thing has been removed. Maybe the superintendents don’t really 
Running head: EFFECTS OF THE EMPHASIS ON ACHIEVING

understand what is happening in the schools in their own district. As an adult I can only do so much. How do they expect the students to absorb all of these new things and changes in the daily schedule?

It was expressed by one group of teachers that their principal did have concern for what was happening at the school. However, most of the other teachers felt that even just a little acknowledgement from their supervisors would be helpful:

Sue: Our principal has stuck by us through all of this. She has been at this school for a long time and could have gone to other places. We appreciate her always sticking up for us. The district office gives her a bad time for it. We all know it. And, even when we disagree with her it is still alright. She is great.

Cindy: I don't think the district officials really understand about the parents and how the home life of the students affects everything that goes on here at school. If they really cared and understood about this, I think they would address it.

Edith: I can't believe that the superintendent doesn't understand what it is like to work in a school with more than seventy percent of the students on free and /or reduced lunch. How can we be held to the same level as other schools? I know that he can’t change the law, but if he at least showed that he understood.

Martha: It would be nice if someone either in the office or at the district level would acknowledge that we are trying our very best instead of just blaming us. We never hear anything very positive. Do they realize what we are up against? Do they understand the children that we serve and where these children come from? Do they have a grip on what they are giving to us in all of these new programs? If they would just acknowledge that they realize what we are facing, I think that would help me.

These teachers' input and suggestions were left out of the Five Year Plans at their schools. Their feelings were as follows:

Alice: I guess it's like the “Emperor's New Clothes”. We got this half million dollar grant and nobody is going to say -- we took all this money 
Running head: EFFECTS OF THE EMPHASIS ON ACHIEVING

and nothing happened. We're supposed to say we took all this money and had great and glorious things happen in this building to these students. No one listened when the teachers of this building tried to tell them at the District and State level over these last few years that things weren't going well. No, every year they wait till the test results come back and make more changes, but no one listens to us. The truth is we took all this money and went backwards. The scores got worse. I mean we were better off before we had all the money and all this stuff. The scores were better. They may not have been where they should have been in some areas, but they are not better now.

Carla: I know that it is not right. Someone writes that Five Year Plan. Then, the principal brings it around for some of us to sign and read, but we don't have any real input. I know that is not how it is supposed to be. They treat us like we could not write a plan; like we aren't smart enough, but they need our signatures. What if we refused? I mean, I don't really want more work. They don’t even say we did you favor and didn’t create another committee. In doing it this way most of us don't view the plan as a worthy, valid document. We are supposed to know about it and improve it throughout the year as things change, but we don't and believe me things change here daily.

Flo: Well, I don't think the supervisors understand all of the different modes of learning and all the things that we are trying to fit together in one day. Even though everything is being driven by the test. That doesn't make it right. Many things are being left out. Important things like social skills and citizenship are removed from the curriculum. Students are being cheated out of time to learn many important things for their adult life. I just don't think the supervisors understand that like we do.

Ida: Even with our principal speaking against it, the district still made us participate in the NAEP (National Assessment of Educational Progress) testing and in the pilot state testing last year for the revised annual state mandated test. We got no respect from the superintendent. We put a 
committee together and they spoke with the superintendent, but it did no good. I would suggest to other superintendents not to do this to your failing schools. That was almost two weeks of instructional time that was lost.

\section{Teacher Theme Six: Effects of a Consultant on Teachers as Related to Time to Spend with Individual Students}

In this theme cluster, it appeared that the teachers' common focus was on both ends of the spectrum as far as time to spend on individualization with their students. They were concerned about both the special needs students and the advanced students. They expressed they did not have enough extra time to spend with either group of students. The students who don't quite qualify for special needs can’t really survive on their own. Teachers voiced, “The individualization of special education has been removed.” A special educator expressed that she sends her students out for inclusion and then she must run around the building trying to assist in all the various classrooms. She remarked, “When we get back to our room, we can’t catch up.”

The loss of a "chance to establish one-on-one rapport with a certain teacher or classmate” has been taken away due to all the "pulling in and out from room to room for different skills.” The importance of this aspect has been removed for students, as well as, teachers. The teachers found that they must "pick and choose when and with which students to spend extra time.”

One special educator admitted that she, “...tries to perform a stressful juggling act to have children on alternate assessment so that she has time for individualization takes them off of it prior to their leaving for middle school.” She expressed her stress and heartache about this, "I do not want to mark a child for life by causing them to be able 
Running head: EFFECTS OF THE EMPHASIS ON ACHIEVING

to only get a modified diploma.”

Another teacher believed, “The different interventions and tiers in reading are a start to individualization for all students” "the classes are too large to do it correctly.” As an afterthought she stated, “We don’t have all of the kinks worked out of this reading schedule and now they are training us to do math.” Also mentioned by another teacher, “The children, who are capable, above average, aren’t getting what they need and, there are those children who are "falling through the cracks.” She shared that she, “tries to work with them as a top priority." The idea of assigning "peer tutors helps in some cases.” It was noted, "I thought the idea was to leave no child behind.”

“We used to be able to reward those students who worked hard, still didn’t quite make the passing score with a few extra points for effort” remembered one teacher. The teacher further stated, "However, now the benchmarking requires that everything match.” It appeared from her remarks there are no extra points for extra effort. Another kind of anxiety as a result of the lack of individualization was expressed when a teacher stated, “It’s almost Thanksgiving break and I don’t have a handle on knowing each child. I mean, I know them in class, but not in the grocery store.” This, not knowing, the students was a result of such large classes and the children moving in and out so often. The tier groupings also changed often and the teacher stated she had different students. She followed with the statement that, "I used to take advantage of the grocery store and have a parent conference; not now" she expressed.

\section{Results - from Teachers at all Six Schools in Regard to Effects of a Consultant on Teachers as Related to Time to Spend with Individual Students}

Teachers were concerned about not getting to really know their students. They 
Running head: EFFECTS OF THE EMPHASIS ON ACHIEVING

remarked that:

Carol: I see the looks in their eyes and I can't go to them individually as much as I know that I should because I am so bound by the schedule. I'm not getting to do the things I need to do for each student. I'm not getting to do the things that I became a teacher to do.

Wendy: The children who need it the most have no chance of establishing one-on-one rapport with a certain teacher or even a certain classmate, because they are being pulled in and out from room to room for different groups and skills. Some students are not even sure who their homeroom teacher is. One-on-one teacher student relationship was a big reason for becoming a teacher. What has happened to that?

Paula: I like having the special needs students in my classroom, but I do not like that I can't give them as much individual time as they need. The special education teacher can't give them the time that they need either. They can't master the CSOs if we do not provide the extra help.

Robin: I don't know what it is about me, kids come into my room before school and they just want to talk. They always want to know if it is ok if they tell me something. I have to tell them that they can tell me anything, but if I decide it is harmful to them, then I have to report it. I have reported a lot of things to the counselor who reports it to the proper authorities. I don't know why they don't go to her in the first place, but anyway, I guess the word has gotten around all these years that I have big ears.

Carol: I want to continue to treat and reward the students individually like I used to in the past, there is just not time to do it now. Also, I used to give a few points on their classroom tests for effort, especially for those students who are really trying at their highest potential, and just can't do much better. They need to see that reflected a little in their daily grades, but not now with the benchmarking, everything has to match up. You know our supervisors at the district look in on our benchmarks and see how the students are progressing throughout the year. 
Running head: EFFECTS OF THE EMPHASIS ON ACHIEVING

Ruth: I can’t get a handle on knowing every child individually yet. It is almost Thanksgiving. I mean I know them when I see them in class. I have eighty-four fifth graders for math throughout the day. When I see one of them in the grocery store with their family and the parent, grandparent or whoever asks how the child is doing, well I can't recall their grades off the top of my head anymore. I used to, now with so much stuff; I just can't do it. So, I have to tell them to come in and see me. And, of course they never do. I use to take advantage of grocery stores and have parent conferences, not now.

The needs of the advanced and high-achieving students were also felt by these educators. These teachers worried that these students would become bored without enrichment activities:

Kris: I am very worried about the advanced students. I can’t get enough enrichment materials to them and I don't want them to get bored. I don't understand why there is no emphasis on them. I don't mean just the gifted. Not every upper level child qualifies for gifted, but there are those who can do more. I don't want them to get frustrated, bored, and turn into discipline problems and eventually drop out of school.

Lou: We do have some students who need acceleration, but who has time to do that. We need to respond to the needs of those children. I do not know where we would make the time. This is frustrating. I try as much as possible to bring things in for them. Most of my extra time goes to the special needs students in my classrooms. They really need individual help and the special teachers have to run around the building helping all of their kids now that they are included everywhere.

Ina: One of my biggest frustrations is that the children who are capable, above average and high achieving are not getting what they need either. We never have time to do any accelerated things for them. And, no one at the District Office even mentions those kids. Wouldn't enrichment for them help the scores overall? That is what administrators seem most interested in any way. 
Running head: EFFECTS OF THE EMPHASIS ON ACHIEVING

Page: Many of my students are falling through the cracks. I try my best to study their permanent record cards and see what has been done for them in the past years. I refer every child that I feel needs it. I try to catch all of them. Someone has too before it is too late. I try to meet with the parents. It is so hard to get them to come into the school. I try to work with these students who don't qualify for special needs as much as I can. It has always been one of my top priorities. Sometimes I discover a child that needs more, needs enrichment. I try to provide that also. Those students are being left behind. It is awful. After all, won't they be the ones to run the country and get jobs one day?

Special needs teachers had been cut from the faculty at some of the schools and the teachers expressed that the children were being left behind:

Becky: The individualization of special education has been removed. My students are integrated into the regular classroom at their grade level and not their reading level. Then, when these students come back to me for a short time, how can I catch them up? I have to divide my time going to all of the different classrooms where my special needs students are included. Patti: My schedule required that I teach an inclusion math class and ten of the students out of the twenty-four were special needs. I had some really needy students in that class, it was rough. The special needs teacher could not spend her time with us every day as she was needed in other classrooms in the building. I did not get to spend much individual time with those students and they needed one-on-one time, believe me.

Sandi: I teach children with mental impairments who need extended standards and children with dyslexia who need help in reading, but are normal in most other ways. I have to pick and choose for them. I do not have enough time to spend individually with all of them. So, what I do is I study each child's case thoroughly and some I put on alternate assessment so they can get what they need and help the school. The others, who can work with me for a little time and survive in the inclusive classroom, then I plan their schedule that way. I have to always watch the 
Running head: EFFECTS OF THE EMPHASIS ON ACHIEVING

students very closely, especially those on alternate assessment. Because most of them need to be switched back to the regular annual test before leaving for middle school. The students who remain on alternate assessment through middle school can only graduate with a modified diploma. I do not want to mark a child for life. Having them on alternate assessment allows me to have the time to work with them individually and to build their reading skills to a level that will allow them to at least pass the annual test in middle school at the novice level and be on course for a regular diploma. This juggling act causes me a lot of stress and heartache; it is worth it for the kids.

Pam: Special needs teachers are not being given the time now to spend with those students individually. Those teachers are trying to get around to all of the classrooms where their students are and they are just spread too thin. I try to provide as much individual help as possible. I also assign peer tutors and that helps in some cases. There is a great need for more special educators if we are going to continue inclusion to this level. I thought the goal was to leave no child behind. Well, they are!

These teachers remarked that the different interventions, tiers, and assessments were a start toward individualization for all students, but without more teachers and smaller class sizes, it was expressed that much was being lost:

Ann: We rarely get to read for an extended period of time and I feel that this is bad for comprehension skills. And, even if we do read for an extended period, several students are pulled out for different things and then I rarely have the time to get them caught up. This whole model needs more work.

Mary: I believe that all of the different interventions and tiers in reading are the start to individualization. Our classes are too large to do it correctly. Most of us have twenty-four students and even when we move students for the interventions we all still have several groups. The theory behind this new program is good, I believe. It is not broad enough and we have too many students and not enough teachers to do it effectively. We 
Running head: EFFECTS OF THE EMPHASIS ON ACHIEVING

have to cover too much in too little time. We can't really look at the students in small groups and don’t even think about individually. And, next year we start the interventions and tiers in math. We haven't worked the kinks out of the reading schedule yet and they are training us to do math for next year. When do we step back and make changes to the reading, before we go on to another subject.

Cary: We use to have more after school programs. I don't really know what happened to them. They were well attended. We spent a great deal of time doing one-on-one there. It was just a couple hours in the afternoon and we worked on things which we knew the students needed help in each day. The teachers who did not work the after school program left notes for us to be sure to work on certain things with certain students. It was a very good thing.

\section{Teacher Theme Seven: Effects of a Consultant on Teachers as Related to}

\section{Changes in Parent Involvement and Students' Home Life}

Parent involvement in the schools seemed to have some widespread differences. Apparently, at some of the schools the level of involvement had gotten a little better in some specific instances, but overall it was not what it needed to be according to these teachers. One teacher shared, "I have talked to teachers around the world through the internet in countries comparable to ours. It was agreed by her group of peers that low SES parents, especially, “just don’t seem to care.” It seemed to her that they are just too involved in their own lives.

The teachers have tried to bring parents in with meetings that offered food and prizes. “That seems to bring them in sometimes." Most of the teachers felt that the factors of low SES and home life are out of control, but teachers are still held accountable for how the students' scores are affected by them. Some teachers stated, 
"When these children go home after school and start talking about all of the different classrooms they are in and out of and all of the different teachers they have, then phone calls are provoked.” The parents are angered and want to know, “What’s going on?”

“Even when a child is ill, many times the family can’t be reached” remarked many teachers, and, "the child gets better care at school in the little room next to the office." It was pointed out several times that, "these students are exposed to a lot.” A teacher noted, "The stories that some children tell me have to be reported to the DHHR (Department of Health and Human Resources).” It seems that the teachers are disgusted that they have "to deal with all of this and yet AYP must be their top priority." Several teachers wondered if the federal, state, and local school officials were aware of the hierarchy of needs.”

What seemed to really sadden these teachers was as they said, “These children would rather be here at school than at home.” One of the saddest stories shared was about the teacher who looked out her classroom window and saw one of her students being walked into the school by a police officer. When the child got to her room, she took him aside and asked him to explain. He told her that he had missed the bus and started walking to school on what was a very cold December morning. The officer saw him and the student told the teacher that he told the officer what had happened, "I told him I didn’t want to go home and I was walking to school.” The officer gave him a ride.

\section{Results - from Teachers at All Six Schools in Regard to Effects of a}

\section{Consultant on Teachers as Related to Changes in Parent Involvement and}

\section{Students’ Home Life}

Some teachers mentioned that many of their students lived with older parents, 
Running head: EFFECTS OF THE EMPHASIS ON ACHIEVING

relatives, and grandparents. Their remarks indicated true concerns:

Rose: An older couple came into the office to pick up one of my students the other day to go to a funeral. I had never met any of his family, so I took him down to the office. They were his grandparents. The poor people were so distressed looking. They couldn’t possibly relate to this child. My goodness, they were two generations removed from him. How can they understand what he goes through on a daily basis? I was glad I met them. Don't get me wrong - they seemed nice, it was just so sad. I know that a great number of these kids are not being raised by their parents, and, in most cases that is probably for the best. The kids deserve more.

Tonya: We have so many students who don't even live with their parents. They live with grandparents, aunts, cousins and who knows. It is very sad. The students tell me, all of the time, that they feel that no one really cares about them. They hate to go home at the end of the day. They don't really like breaks and summer vacation.

Joan: I have many students right now who are living with their grandparents who are much older and very sick. I have quite a few students who live just with one parent. I have one boy whose dad died when he was four and he lives with his mom who is in her late fifties and the other brothers are in their thirties. He is exposed to a lot. The stories that he tells me are unbelievable and many times I have reported things to the Department of Health and Human Resources. We have all of this to deal with, the students have all of this to deal with and yet we have to make AYP our top priority. Whatever happened to hierarchy of needs?

Did the State Department ever mention that?

These educators fully realized that when a parent somehow happened to be available that moment must be fully utilized. Their quick thinking was represented in these statements:

Meg: The only thing that brings our parents in is free food and prizes. We do that once a year at the Title I Fair. Parent Involvement is not really 
Running head: EFFECTS OF THE EMPHASIS ON ACHIEVING

something that we can help. Socio-economic factors are out of our control. We send home notes, make phone calls, and even do some home visits. We can't get the parents in here when the kids become sick. We don't have the extra time to spend with these children one-on-one and the parents won't come in to be trained to help their own kids. It is very sad.

Sally: The children can't keep track of all the teachers that they now have due to all of the pull-out programs and tier groupings. When these students start going home and telling their parents that they have a different teacher for this and another teacher for that, the parents get very confused. I've had parents call in and ask what's going on. They say I thought that you were my child's teacher. Some parents have been very angry. Especially when I explain or try to explain that the teachers will change when the child goes to another tier level.

Liz: It's very hard for a parent to know exactly what is going on with their child. When they start all these different reading programs, parents have no clue. Probably the reason I had so many parents come in for the parent conference last time was because they were actually trying to figure out what was going on. They really are interested and concerned, at least some of them.

Mae: This year the level of parental concern has actually been a little better than last. It just depends. In the past, most of the time the parents can't be reached even when the child is ill or has a serious discipline problem. It is very difficult to find them and to get them to come into the school.

Lane: We have some parents who do not want their children in a classroom with certain students from certain families. These parents have so much political clout with the District Office that the students actually get moved. The sad thing is that rumors get out and the other students are hurt by this. Who do these people think they are? Why do some people have so much influence and are allowed to have what they want while hurting other students? 
Running head: EFFECTS OF THE EMPHASIS ON ACHIEVING

Debra: I could not believe it when a small group of mothers came in and asked me after school one day if I thought that they should get together and drive their children to school in another district because they had heard that the education that the children received at this school was not good enough to prepare their children for college. I was really upset. I showed these mothers the scores of their children and explained that they were doing well, actually quite well. After I explained the overall picture, they understood and felt better. You know, it was a real shame and I was quite humiliated. I have worked here a long time and we do a good job of educating the students.

Jill: After the second grade teacher and I took the training on the tier interventions for reading, we tried to work together with our groups. Even though I have kindergarten and she has second. She had some very low level readers and I had some who were advanced. So, once we figured out our intervention groups we switched off. We happened to have a parent stop by one day to drop something off for a student and she saw all the groups and asked if she could be a volunteer. Well, we got permission from the principal and we set up a training evening. The mother brought five other mothers with her. We trained them and it has been going so well. The kids love it and everyone is getting a lot of attention. The mothers are doing a great job.

These teachers still recognized and wanted to provide individual attention to meet students' needs. Their concerns were shown in these accounts:

Kate: I know that coming to this school is the best thing in the life of some of our students. If they come in and get sick, we generally do not call home. If we do, no one usually comes. The students get better care in the little room off of the office than they would at home. It is sad what some of these kids go through on a daily basis in their homes.

Maria: Somehow the administrators figured out a way to change the schedule so that we have what they call an extra planning two days a week. Those of us that have that spend time tutoring the special needs or 
any other student who is assigned to us for that period of time. I like to do this. I think it really helps, but the students still need more.

Jan: In special education you are taught to individualize and adapt for each student. Well, now as I go in and out of the regular classrooms, it is very difficult. First, there is not enough time. In some of the rooms there are nine special needs students, most of the rooms have five or six, so I have to balance my time and go from student to student or try to make little groups in the classroom. There needs to be more time for individual help, especially, if our goal is to get them to grade level mastery.

Diane: I believe that the ideas behind NCLB are very good, they are not realistic. We have to look at individual students and their needs. I don't think those people in D.C. look at those things. I wonder who advises them. It's like saying every child has to take courses to be ready for college. That is just not right. I go along with the idea that every child has to be ready for some kind of employment. There is a real difference as far as I am concerned.

Barb: I feel that I can see certain kids improving. If I just had more time to spend with them individually, I think it would make a difference. Also, if some of the discipline problems could be handled in a different room, then instructional time would not be taken from the others who are trying to attend to the instruction.

Jane: We send these kids to school so early. Four years old is really young. The parents like it though. The school has taken over raising the children for the family. I know that handicapped children need to receive stimulation earlier. Is it necessary for every child? Is it helping? I know the parents expect it. Don't even ask most of them to help out or come into the school.

Kay: We have a lot of students here at this school who I would say are deprived in their lifestyles. I mean they haven't been out of the district. No one takes them anywhere. They have only been exposed to what is here in this town and on TV. Now, we have no more school trips. Even 
Running head: EFFECTS OF THE EMPHASIS ON ACHIEVING

educational ones are frowned on unless we do our own fundraising. That is really not feasible because the parents won't help. We have no way of broadening their exposure at all except through the internet and it doesn't work a lot of the time. When it does, we have to do Acuity and Tech Steps.

Sharon: Our kids want to be at school. They do not want to be at home. Now, that is how bad their homes are. For example, the other morning I looked out the window. Class had already started and I saw a police car pull up. I saw the officer and one of my students get out of the car. I thought to myself, “What is going on?” This child was a good kid, but had a rough home life. He had no parental support. When he got to class, I took him aside and asked what had happened. He told me that he had missed the bus and he was walking to school, because he did not want to stay at home. Now, this was a very cold morning. He said the policeman stopped and asked why he wasn't in school and when he told him, the policeman gave him a ride to school.

Efforts were made by many of the teachers to get the parents to provide support for their children. These efforts are recognized in these comments:

Sue: The state and federal supervisors in education and human resources need to work together on parental issues. These parents need to be held responsible. Their so called welfare checks need to be tied to what they allow their children to do. We report many incidents to DHHR about things that we know have happened to some of our students. These children are exposed to so much at home and in the community. What can the school do? All of these things affect the kids and they suffer and they can't feel good about themselves. How can they do well in school?

Cindy: Also, in our area, it doesn't matter how much money is pumped in here. We have a very low SES. We can have all of this stuff in the classrooms, but we have illiterate parents. These children come from some very dysfunctional homes. The children have no parental support. They can pour all the money they want into these schools, but something 
Running head: EFFECTS OF THE EMPHASIS ON ACHIEVING

has to be done to help the parents. The kids look up to the parents.

Edith: I worked hard at the end of last school year to get many of my students registered for a day camp at one of the local colleges that is about a thirty minute drive from this school. It would have not only helped with their reading and math, but it would have also exposed these students to a college campus and what is there. The parents could not figure out how to get the kids there. Even among themselves, they could not car pool. Only two kids got to go. The district couldn't find any money for a bus. Really the parents should have been responsible for this. It wasn't a priority for them.

For some of these teachers, it was easy to see why getting an education was not one of their students' top priorities. The teachers remarks explained this:

Martha: Some of these students just don’t want to do anything. So, when I get the parent to finally come in to see me, the parents say that they really do not see why anyone needs to know this stuff, and then I understand the student's attitude. Now, this helps me to see where the child is coming from and why the child does what he does.

Alice: I really don't think that most of our parents care, or even if the general public cares for that matter. Most parents that I meet don't seem to be the least bit concerned about AYP. I don’t really think they understand it. They don't think about their child's future, college, and a job. I don't think they see that far ahead or care.

Carla: I talk with teachers all over the world, thanks to the internet. We share many things, and sadly it appears that the home life and the parents of our children are very similar to that of children in other countries. That is countries that are comparable to ours. Parents just don't seem to care anymore at least the parents of the low SES children. I guess they are so involved in their own lives that they just leave their children to us.

Flo: These parents don't even read the newspaper and we are asking them to read to their children. I know there are some who do, but they are few and far between, especially at this school. That makes it very hard. 
Running head: EFFECTS OF THE EMPHASIS ON ACHIEVING

Ida: I don't blame these students for not setting their education as their top priority is. When you meet the parents, then you see why the students don't care. We have to care here at this school, because quite often no one else cares very much about some of these students.

\section{Teacher Theme Eight: Effects of AYP Emphasis on Teachers as Related to Staff}

\section{Morale, Feelings, Attitudes, and Motivation}

Consistently, the teachers expressed that they felt that morale was low, in some cases; there was a general acceptance that low morale, stress, and frustration were to be expected and accepted. It appeared from some of the comments that teachers were learning to deal with the effects of not achieving AYP. Most teachers expressed that they, "feel badly about not making AYP" and knew they "had worked as hard as possible to do their best." They commented that this feeling of "pressure” was "not good” and added in some instances, “I just don’t know how long I can take it.”

The stress of the consultants telling them what to do also made it seem that what these teachers did "was never right and never enough.” Also, questioned were the, “research-based programs.” One teacher commented that she understood about working in a lab situation and collecting data. She seemed to doubt that some of the new programs had really been tested and commented that she thought, "Some of these programs were being tested by us as they keep changing programs from year to year when the scores don’t improve.” She added, “This causes, “a lot of anxiety.”

Teachers also expressed the need to be able to get together with their peers and plan or even just enjoy each other's company. One group of teachers created, by accident, their TLC (Tender Loving Care) group. It appeared that some of them were together in the copy room one night after school and just started talking. As these unplanned 
Running head: EFFECTS OF THE EMPHASIS ON ACHIEVING

meetings continued they turned into actual nights out at restaurants with their spouses.

"We just laugh and enjoy each other” the teacher noted.

It was sadly commented, “They are taking away our professionalism; they are taking the art out of teaching.” Another educator expressed feelings of "not being trusted and not doing things right or AYP would have been achieved.” The teachers expressed that they "feel responsible for this, but just don't know what more to do.” Regretfully it seemed that these teachers realized that some of their peers had retired too early and those still there said that, “The system should not define when I am ready.” They felt a teacher should, "go when she is ready." Many of these teachers felt that they were "made to feel they had nothing to offer." Even more seriously, teachers talked about having to go to therapists, being on medication, not being able to sleep, and not dealing with the stress in a healthy fashion. One shared, "I worked with a therapist and learned to prioritize.” This teacher stated it was "a matter of accepting the job and getting my anxiety under control.” Many expressed that some teachers "just take a day off” and noted high rates of teacher absenteeism.

It appeared that younger teachers were able to work through the stress on their own. They experienced the stress, but expressed that working like this, "is all that I have ever known.” These younger teachers didn’t remember teaching under other conditions, “as the older teachers do." They felt that was in their favor and were able to "just go with the flow.” One younger teacher admitted that it bothered her for her older peers and said she tried to remind them to "calm down and chill out." She also had taken the time to place motivational printouts in their mailboxes. She expressed, "We need to help each other.” The comments of some of the teachers showed that they had all been there 
Running head: EFFECTS OF THE EMPHASIS ON ACHIEVING

together for so long that they thought morale was pretty good, but it was because, "we all stick together and get along." They made it a "nice place to work in spite of AYP.”

Results - from Teachers at all Six Schools in Regard to Effects of AYP Emphasis on Teachers as Related to Staff Morale, Feelings, Attitudes, and Motivation

Levels of stress were expressed and apparently handled differently by many of these teachers. Frustration and anxiety were voiced in these concerns:

Carol: It really makes you feel badly; when you know you have worked hard and tried hard to do your best. This school is a result of the consolidation of four different schools. The first year that we opened, I guess it is about six or maybe eight years ago now, we really had it rough. We had monitors that came all of the time. There were certain expectations for the school, and certain things that we were supposed to do. We all had the same pain, all of the teachers that is. That brought us together for awhile, we seemed to be meshing, but the more we were pressured it became overwhelming. We would learn something and try it and they would come and monitor us and it was never good enough. Now, with not making AYP these last few years, we feel all of that pressure again. It is not good. I just don’t know how long I can take it this time.

Wendy: If you really want to know, I think the job of a teacher is very stressful, but I have not ever known it any differently. I have not been at this very long and it has always been hectic. I do not think what we are doing works; it is however what they have had us do since I first came into teaching. It is not anything like what we learned in college. I have never known anything else because this is how it has been in education since I started. I take it differently than the older teachers who can remember when it wasn't this way. So, I go around and say, “chill out, calm down.” I even found a little motivational paper that talked about not neglecting yourself, your spouse, your children, and your home life for your job. I 
Running head: EFFECTS OF THE EMPHASIS ON ACHIEVING

printed it out and gave it to each teacher. We need to help each other. Paula: About two years ago I had a classroom of students who had all kinds of problems. It nearly killed me. I had the consultants in and out. There was an interpreter for one deaf student. One student had behavior problems and had an aide most of the day. Another student was in a wheel chair. I became really anxious and my husband said I needed to see a doctor. I was diagnosed with general anxiety disorder. I had taught for twenty-five years and I never needed medication before that year. Now, I take my medication and see the therapist. Thank goodness for the little that teachers' insurance pays. I could not survive otherwise. When I hear my peers complaining, I tell them what helps me. It really does help.

Robin: I worry about everything. It is bad enough to be worried and anxious when I am here at school, but I can't sleep at night. I wake up at three in the morning and start planning my day. I do not want anything to go wrong. I try to plan it out in my head. I try to go back to sleep and I can't. So, I just get up at around four and get ready and come into work at five and feed myself coffee all day. It is awful to come in tired almost every day. I guess I should see a doctor.

Carol: Everybody lives with stress differently. So, in this building you run the gamut of how people handle it. Some of us are highly stressed all of the time. Others are not so stressed at various times. Stress is here in this building in one form or another. One thing that all of us would agree on is - there are never enough hours in the day to get everything done. Ruth: That inclusion really stresses me out. It just depends on who comes in to teach with me. Sometimes you have no control in your own classroom. It's like my ideas are not important. If the special teacher isn't here for a day because of a meeting, then I can go it alone. I can't make any modifications without running it by certain special educators. That is just the way it is. I think I stress out more about things completely out of my control for instance: fixing the computers, making a password work, getting something for my classroom like a pencil sharpener or something 
Running head: EFFECTS OF THE EMPHASIS ON ACHIEVING

like that. It's like pulling teeth. Working with the students doesn't stress me. No, I love that. It is just all of the demands and things I can't control. Kris: It must be pretty bad. I was working on school stuff at home the other evening and my husband said that he would like to throw the laptop away and have me sit in the living room and just watch the news with him without it. I guess it is not only stressing me, it is stressing him also. He usually says nothing about me working at home.

Lou: I am very frustrated. I don't know; it seems like I can't teach anymore. I've got so many things to account for each day. It is really difficult to enjoy myself while I teach. I used to do that; I know that I did. These days once I get home and sit down; I say to myself I forgot to teach today. It makes me crazy. I know I was in the classroom with the kids. I just went through all of the motions that I've been told to do now.

Ina: For one thing the media doesn't help, always comparing our students' scores here in the U.S. to other countries. Look at who we educate here. We have free public education for every student; no student is left out. Most other countries don’t do that for their kids. Only certain students go on to do higher level things. I don’t know. It is bad enough to be compared at the local levels, where each school is somewhat different, but then you read a magazine or turn on the TV and there it is again at another level.

Page: One evening each month some of us teachers do something for ourselves. We stay after school and give each other TLC (tender loving care). We just came up with it. A few of us were in the copy room one night and we started talking. Now, we actually set aside one evening after school to just ask each other how we are doing. It has caught on by word of mouth. I think we have about ten teachers now. Sometimes we meet at a restaurant and bring our spouses and just laugh and enjoy each other.

Becky: Being here daily with the students is actually the most enjoyable part for me. When I take it home each day and on the weekends, it gets to me. This morning I woke up at around 3:00 a.m. and I was thinking, 
Running head: EFFECTS OF THE EMPHASIS ON ACHIEVING

"Well, I need to get that other group of papers graded." So, I got up, since I couldn't sleep, and did that. It's constantly in the back of my mind. I guess it is there even when I am asleep. My husband is worried about me. In addition to trying to handle their frustrations, these teachers commented further on the needs of their special students:

Patti: It is so frustrating to know that I have students right in my classroom that can barely read at all and I can't give them the individual attention that they really need. It's just very frustrating. Their special needs teachers can't get to them as often as they should either. Everyone is upset and frustrated - the teachers and the students. We do the best that we can though.

Sandi: We know from the comments of the consultants that we, as teachers, are being judged based on the benchmark results of our students. It really is not fair. We all have students on different levels. They come to us each year on different levels. The students in this school are from a high poverty background and we have many special needs students. How is all of this fair? It causes a great deal of anxiety. What can we do about the children that we have in our classrooms? In many cases we are asking the students to perform on things that are outside of their capabilities. That in itself is stressful for me and for my students.

Pam: Our test scores did not make the cut off due to the special needs student scores. We can't help that we have a large special needs population here. We do our job, identify and refer those students and then the school is penalized. We have to identify the students that need the extra help.

Ann: I try to figure out new ways to teach things. I feel that the kids have gotten low scores because I have done something wrong in my teaching -in the strategies that I used for them. At least that is what is portrayed to us by the principal and consultant. I try to make adjustments, but it never seems like I am getting through to the kids who need it the most. 
Running head: EFFECTS OF THE EMPHASIS ON ACHIEVING

Mary: Just being a special educator in this building causes me stress. Since that is the cell that causes the school not to make AYP year after year. I do not know what more I can do as a teacher. I have attended every workshop and listened closely to every consultant. I feel responsible and do not know how to fix it.

Cary: I am a special educator. I liked it better when I was self-contained. All of this inclusion is mandated. In the regular classroom, quite often, I have no say, even though; many of the regular education teachers have no background in making modifications. Some of them are very open to suggestions. Others make it known that it is their classroom and you are really not in charge. There is only so much I can do for the kids. Most of them, I do not have individually anymore or not for too long each day. This keeps me up at night. Left on their own, those kids are struggling. It really isn't right.

Teachers admitted that some of the changes were beneficial, but the focus on end-of-year testing was a cause for concern:

Rose: Well, I am not one to be real stressed to be honest. I take things pretty much in stride. I think a lot of the changes aren't beneficial. I do think there are some good points to it, also. I think the state has kind of fine tuned their standards and the CSOs. I don't have a problem with that at all. I don't have a problem with curriculum mapping either. I think it is actually helpful. These are things that I need to do. I can't do all of these things and work with the kids at the same time. That is where the frustration comes in to it all on a daily basis. We need time built into our day for these things.

Tonya: It really aggravates me that a child living in our area is expected to do as well as a kid living in California or New York. Our kids don't go anywhere or get exposed too much except TV and whatever goes on in their homes. I guess they see things on the internet, but in this rural area not many families get much internet. If they go to national standards, I think our children will be doomed. Someone needs to equalize all schools 
Running head: EFFECTS OF THE EMPHASIS ON ACHIEVING

nationwide if they adopt national standards. This really bothers me.

Joan: I see a real fallacy in basing everything for these students on one test score. I have a gifted student in my classroom and she didn't make the IQ cut-off score by just a couple of points. I feel guilty for referring her. She could have really benefitted from that program. I try to give her enrichment activities. I know that she gets bored. What can I do?

Meg: They keep raising the bar and we couldn't get over it as it was. Does anyone really believe that we could reach even seventy-five percent proficient? I wish that were true. I wish I could do that for them. Then, on the state writing test our below average students scored at some of the top levels and we knew that something was not right. What are you going to say? Come to find out, the test was computer scored. When the computer picked up on certain key words, then the scores were higher. I find that very interesting.

Sally: It's all about teaching to the test. That is what we have to do now. Nothing else matters. I am more concerned about the test and CSOs than anything else. I don't vary from the test because we haven’t made AYP. We have meeting after meeting. We are told how to do Acuity, benchmarking, Tech Steps and everything else. It is very stressful. Only young people can survive in this job now.

Morale was at different levels at most of the schools. Overall, though it was low as can be heard in these statements:

Liz: In this school for some reason, even after not making AYP for so long, we still have pretty good morale. We all stick together and get along. Even if we don't get to see each other for weeks, we still know that we support each other. That is pretty good for thirty some staff members, but most of us have been here a good long while. Even though our administrator has only been the principal at this school for a short while, she taught here for years. It is a nice place to work, in spite of AYP. Mae: Well, I think we are under so much pressure to achieve AYP for the school. We are all very open to all of the suggestions and changes that are 
Running head: EFFECTS OF THE EMPHASIS ON ACHIEVING

brought to us. We try to implement and integrate the best that we can. It is very difficult and no one ever says, 'You are doing a good job.'

Lane: I have not been teaching that long. I just go with the flow and watch everything that is going on. I try all of the things that we are trained on and I watch and listen to the teachers who have been here a while. I don't feel the stress. I do put in a lot of time though. I do get overwhelmed that I don't have time to get my work done at the school, but I knew that would be a part of it -- that is teaching. So, I have to take things home every night. I want to do a good job and also show that I can do what I am told. I guess I am still in the stage where I have to impress the boss.

Debra: I am lucky in that my colleague across the hall and I work together, and we are not afraid to "step outside the box.” Even though these consultants keep trying to give us new boxes. We have to change those boxes. I accept all of their ideas and I try them, but as a professional it is my job to adapt to the needs of the kids in my room. It is not just an assembly line job as they are now trying to make it -- not in my classroom. I won't let that happen. I know a lot of the old things need to be thrown out and I do that quite often, but everything that they are giving us is not working for all of these students. Some of the teachers collaborate to the other extreme. They are really following this 'stick to the schedule routine.” Some days if you happen to be going down their hallway you can actually hear two of them giving the same spelling word at the same time. I can't work like that, but it works for them.

Jill: They are just taking away our professionalism. They are taking the art out of teaching. They really do not trust us. They act as if our degrees from college do not mean a thing. It is all about these consultant workshops. What I feel they are saying is you obviously didn't do it right, you didn't meet AYP. So, now we will show you what to do. We know what to do and the scores show that for the most part, but those scores don't seem to matter. They are being hurtful to our whole profession. 
Running head: EFFECTS OF THE EMPHASIS ON ACHIEVING

Kate: Teachers are retiring before they really want to do it, they just can't take it any longer. I know that you should go when you are ready, but ready needs to be something that you define, not the system. However, the system is going to suffer because the new teachers are not going to have any experienced teachers to assist them. Also, these teachers who are retiring still have too much too offer. They can’t risk staying, beating their heads against the wall, being not appreciated and made to feel as if they have nothing to offer.

Maria: I am so stressed. I do not know what to do. I went back to school after my children were raised and gone. Now, I don't know what to do. I love the kids. I know that. I can't retire. I'm just going to work here till I croak. I will drop dead in one of these classrooms one day. I hope it is after school and the students aren't here. I love the kids. Jan: I had a really bad year about two years ago and I was ready to quit. I worked it through with a therapist and I got back on my feet. I used to love my job. I wasn't ready to quit. I had to think about myself. The therapist helped me to prioritize and learn not to blame myself for everything that happened at school. I got my anxiety under control and was able to accept that it is just a job. I can only do my best each day and I don't let the job define me. I have felt badly in the last few weeks. Several teachers have broken down, cried, and have gone home in hives. We have a lot of absenteeism here and I know a great deal of it is stress related.

Diane: It is really upsetting not to be trusted. That is what bothers me the most. I went to school. I am a professional. My professors gave me good grades and ratings in student teaching. Now, I can’t be trusted. I have to have someone looking over my shoulder all of the time. What other profession has this?

Changes in administration, lack of concern from the District Office, and changes in instructional programs all have added more anxiety and stress to the daily activities of these teachers. Their feelings of distress were expressed clearly: 
Running head: EFFECTS OF THE EMPHASIS ON ACHIEVING

Barb: It is very stressful to have the consultants to tell you that you are not doing it right. I mean I can take constructive criticism. I actually appreciate it. They rush in and give us a quick training. Then, we try our best to learn how to implement the strategies on our own. When they return, it is never enough.

Jane: They say all these programs are research-based. Well, I used to be a speech pathologist before I was a classroom teacher. I know about research-based. We worked in the speech lab and collected data. They could make that data support whatever they wanted. Results that you get in a lab situation are totally different from what really happens when you apply certain techniques and strategies in a regular classroom. All of that supposed research is driving the selection of the materials being chosen for us to use in our classrooms. Those materials should have been tested by us in our classrooms. In fact, I think some of them are being tested by us. They keep changing things when we don't make AYP. One year we used this and then when the scores came back that strategy was not to be used anymore and we were trained on something else. It causes a lot of anxiety.

Kay: That's another thing -- morale is pretty low here, and in addition to that, people are very angry. I feel, as a Title I teacher that many regular teachers think that I am just making up the things that have to be done. Every time that something changes, I can see people gathering in groups and whispering. Then, the rumors start flying. That is why we need common planning time so that we can get together and talk things over. Then they will know that we get our directives from the district office and we don't just do things to make it harder on all of us.

Sharon: The scariest part is all the technology. It is just too much, too quickly. The technology component is so huge and so important in everything that we are implementing. Yet, they have not trained us very well. They have not allocated any time for us to learn it before we try to expose the students to these new programs. This should have been phased 
Running head: EFFECTS OF THE EMPHASIS ON ACHIEVING

in very slowly. They have certainly snowed us under with these things. Sue: With all of the administrative changes here at this school in the last few years, it has caused many of us to just tell the District Office people to do what they want and we will continue to do what we know needs to be done. We can’t count on anyone to be here very long. So, the faculty here counts on each other, not the District, and not even the principal. We have to just wait and see if that ever changes. It is a hard school, but we stay. Why can't the administrators hang with us? Another thing that hurts teachers is some of those consultants have not had much experiences working in their own classrooms. They act like child experts. They may know the theory; practically speaking they don't know students. They treat us like losers, since the scores are low. Some days you just get tired of that feeling. The reading coach comes in and she has never had her own elementary classroom and she tells us what and how to do things.

\section{Teacher Theme Nine: Effects of AYP Emphasis on Teachers as Related to}

\section{Suggestion for Other Districts}

It was very apparent that these teachers had truly lived through the experiences of not achieving AYP. They had come "full circle” and could honestly help others who might just be starting this journey. The common aspects they expressed were as follows: that time should be taken; there needed to be an organized plan; and it should be phased in very slowly. Teachers remarked emphatically that, “They should have asked for our input at the very beginning.” The teachers wanted to have a voice in the solution, “After all, we are at the heart of the problem.” It seemed that they had accepted some of the blame and wanted to "get the facts straight from the administrators about the scores.” 
Running head: EFFECTS OF THE EMPHASIS ON ACHIEVING

As far as consultants, it was noted several times that "Most had no idea about what goes on in real classrooms.” The teachers didn’t seem to mind the trainings on some of the programs, but it "was the lack of organization, the lack of classroom experience, and the swift urgency of the implementation” that overwhelmed them. The teachers agreed, "The trainings needed to be in the summer, so that, there was time to learn, to plan, and to prepare for the fall.”

Another common idea expressed was the emphasis placed on assessment and the lack of time to properly use the results. The teachers saw the importance of both summative and especially the formative assessment. Also mentioned several times was the need to study the data from the state test results. The teachers realized that the state provided a great deal of very useful information when the scores were returned in the fall. "But, we never have enough time to really digest it - time spent in that way would be well worth it” echoed many teachers. These teachers expressed a real need for “...time to use the results to make real instructional changes for individual students throughout the school year.” In order to do all these things, the teachers suggested looking into the idea of either a "longer day, year-round school, or some combination." This is a real issue and a priority for these teachers. The teachers felt if there were more time and more staff, then students could be grouped through the interventions, and the movement from room to room could be minimized. It appeared another of their concerns was more “...real instructional time.”

Also, the teachers wanted to be able to focus on the "whole child.” It wasn't just about the tests and the CSOs for these teachers. These educators wanted to deal with the child's "hierarchy of needs" and showed a real concern that this priority had been 
Running head: EFFECTS OF THE EMPHASIS ON ACHIEVING

removed by federal, state and local officials. They also felt that programs needed to be started, probably through the schools, but in conjunction with other agencies, “...to deal with low SES students, parent issues, home life, and all the concerns that affect children and their basic needs. They felt that the proper method used in educations should be approached as “...basic needs before basic skills.”

The need for smaller class sizes and more regular and special teachers was also expressed. The teachers felt that this would help in "attending to the whole child and meeting the needs that the home doesn't.” In addition, it would improve instruction and get back to individualization for those students who needed it.

Another concern emphasized was the need for more positive communication among administrators, supervisors, consultants, and the teachers. Upgrading of the technology was expressed by these educators as a factor that needed to be addressed. Teachers wanted help with the scheduling, but expressed that when schedules are set, “Don’t send out district officials to interrupt us all the time.” Also noted was that various components of the curriculum need to be looked at so that teachers could bring back creativity and fun to the "art of teaching and learning.”

\section{Results - from Teachers at all Six Schools in Regard to Effects of AYP Emphasis on Teachers as Related to Suggestions for Other Districts}

Several teachers mentioned the recommendation of more teachers and smaller class sizes. These educators felt that more students could be accommodated if teachers had smaller groups. Their comments included the following statements:

Cindy: We need more teachers and smaller class sizes to do all that is needed. If I could talk to a superintendent that is just starting out with his new funding money, I would make suggestions about those two items. I think that then a school system could really benefit and meet the needs of 
Running head: EFFECTS OF THE EMPHASIS ON ACHIEVING

the students. It makes a difference - class size. That is where the money needs to be.

Edith: I would suggest that no matter what, they use the money to get more teachers and make smaller class sizes. All of the workshops will not help unless you have enough teachers to help the students in a way that matters.

Martha: I know it won't ever be done, but we need smaller class sizes. I know we are lucky when they put that cap down to twenty-five and twenty-eight for elementary, even that is too much. We need to have no more than twenty in the grades five and lower. These children in special needs and low SES need more individual attention. They say that if the home can't do it, then the school must. Well, no one can parent that many kids and that is what we do. We have to attend to the whole child and all of their needs.

Alice: More attention needs to be paid to the whole child. We need to take notice of where these kids come from in the morning. I can't approach the CSOs until I answer the basic needs of these kids. No one ever addresses that. It needs to be addressed before we can make any real progress. It all starts at home. The school can only do so much.

These teachers wanted to study and use the information from the annual state mandated tests. They expressed the need to have more time to do this efficiently right before school started each year. Their suggestions were as follows:

Carla: Someone needs to address the 'bubble-in’ answer sheets. Many children have issues with transferring their answers from one page to another. It is not just the special needs students who find this difficult. It is a problem for students who have basic attention problems, memory issues, eye-hand coordination, working memory and processing problems. I could go on. This was a bad idea. I am sure that the addition of the bubble sheet was a problem across the state. Did anyone ask teachers, currently practicing classroom teachers, about that idea? I guess my real suggestion for the state and federal individuals is to please run your ideas 
Running head: EFFECTS OF THE EMPHASIS ON ACHIEVING

by currently practicing classroom teachers. Those of us who are working with students of today -- not students of five or ten or more years ago. Children have changed.

Flo: Now, we spend all of this time throughout the school year on the formative benchmark assessments of each individual student, but all of the emphasis is on the end of the year when we do the mandated summative assessment. We should place more emphasis on using the results of the formative assessments and make real instructional and strategic changes for individual students. We do not have the time for this. They need to let us have the time for this, it really is important. The use of the summative assessment results gets way too much emphasis and exposure. Those results are used to penalize the schools and the teachers, while the students are neglected. Someone really needs to make some changes here.

Ida: Superintendents must make sure that the teachers in their districts have a sufficient amount of time to look over the entire annual test results at the beginning of the school year. Classroom teachers need to look at the scores of their new incoming students and the scores of those students who were promoted to another grade. There is a great deal of useful information in what the state gives us, but we never have much time to really digest it. Please set the time aside. It would be well worth it.

Carol: We need more time to look at the scores in the fall before school starts. Those scores really need our attention. I need to study the students who moved up a grade and the students coming into my classroom. All of that is very important. It takes more than a couple of hours to do it correctly and to prepare for the year. Also, I really believe with all of the technology, that more of the information could come to us already disaggregated in the format that we need. If they can't do it, then train the computer lab teacher so she can run it for us and we can study it. Or, just give us the instructions and we can get it online ourselves. We need the time to do this. Especially with all the emphasis on benchmarking around the CSOs this would be great. 


\section{Running head: EFFECTS OF THE EMPHASIS ON ACHIEVING}

Wendy: I think while the officials are making up all of this new testing. I would like for them to make up a test that each child had to pass in order to leave sixth grade. If they can't read at that level, then why let them go on. They need to stay at the sixth grade in some special school until it happens. I don't see why we can't do that. After all the federal government says there will be one hundred percent proficiency in 2014. Who knows what that means?

Teachers wanted to be trained properly on the new materials and programs. They did not feel that training in their classrooms was conducive to a good learning situation for them. They remarked that:

Paula: Superintendents should allow the teachers to start slowly, very slowly. Be sure that there is a sufficient amount of training time. Be sure they are trained well before they are asked to implement. Above all, be sure that the supervisors from the district office really understand the programs and could actually demonstrate if needed. Don’t implement too many things at one time. Look at the schedule and be sure that it is mathematically possible to fit everything in realistically. Time is a really big factor. It would also be helpful to only have twenty students in a classroom, especially when you have so many special needs and low SES students. If you can't provide that, then maybe a few classroom aides.

Robin: The supervisors at the district office should not allow workshops and trainings to take place during the regular school day. One day we had twenty-two substitutes in this building. It was awful. Our principal had to go to bat for us. She told the superintendent and now that doesn't happen anymore. Why would someone, who is supposed to have the best interest of students as their focus, ever do such a thing in the first place? Maybe our principal needs to be the superintendent. She remembers what it is like to teach and how important it is that the regular teacher be in the classroom most of the time.

Carol: Someone at some level has to be told to just phase things in slowly. Talk to the teachers and let them know all of the things that need 


\section{Running head: EFFECTS OF THE EMPHASIS ON ACHIEVING}

to be done. In this way, they can see the total picture and come up with a plan. We know that change is wanted quickly so that AYP can be attained, but it must be phased in slowly. We could develop a timeline. I don't understand why they don't ask for our input at the very beginning. Ruth: We are getting a lot of our training on the job. The consultant comes in the room and teaches us as we go along. The students are there and it is hard to ask questions. District and state officials should not allow this kind of training. I don't want to be out of my classroom and leave the students to a substitute either. These trainings need to be organized in the summer and that is when we need to be trained.

One suggestion made by several teachers included providing workshops, trainings, and classes for parents. Their suggestions included the following:

Kris: The superintendents in other districts need to institute programs for the parents. This is a major component that is not being addressed. The parents could help us to change things around for the kids. First, they must somehow be taught to understand and be made to get involved. Perhaps, there could be a joint effort between the local Board of Education and other agencies that serve these parents.

Lou: The federal government is holding each school responsible for the low SES subgroup. They are not doing anything about the parent and family factor that is contributing to that variable. I believe that should be their responsibility. If they would help the families, and I don't mean to give them more welfare money so they don't have to work. I mean really help them. They need to set up programs, trainings, and various classes that the parents must attend in order to get their money and then eventually work. This would help the problem overall. This will take time. We, as teachers, can’t turn this around ourselves.

These educators made other suggestions about: principals, longer school days, and various other issues. These remarks included the following:

Ina: The district officials need to know that they should listen to the classroom teachers who are at the heart of the problem. These consultants 
Running head: EFFECTS OF THE EMPHASIS ON ACHIEVING

who come around and try to tell us what we should be doing have no idea. We need to be able to rate our consultants. It appears that they are using the tests and the benchmarking to evaluate us.

Page: Two years ago we made AYP in reading, but not in math. When the person that was the principal then announced it to us, he didn't say that. He told us that we just didn't make AYP. I thought that I had heard from my friend at the state level that we had made it in reading. So, after a few days, I went to him and asked him why he hadn't told us that. He really did not respond to me. About eight weeks later he finally announced that we had made it in reading, but not math. You know, these administrators need to know their facts. That meant a lot to us. The district level officials need to be sure that their principals are wellprepared to make these announcements and that they understand the test scores.

Becky: I know that we didn’t make AYP in certain areas; we did not fail overall, though. It would help if someone at the district level would give us a compliment. There must be something that we have done right. Always try to give something positive.

Patti: It's time for year round school and a little longer school day. I know that most of my colleagues do not agree with me, but I really believe this. Other professionals work till four or five. The length of each school day needs to be adjusted so that the students spend a little more time. Then the schedule would not be so unbearable. With all of the transitions and movement from room to room, we are actually losing instructional time. No one has ever really checked on that in the way that it should be. How do they think that the students get from room to room? We need time for that. We can't just continue to rush the kids from room to room; that doesn't help them. People say that longer days are not the answer. Well, why do they always push for after school programs? Aren't the kids tired then? Does no one care? Is it really just about extra pay? I am not recommending extra pay. I just think the student day needs to be a little 
Running head: EFFECTS OF THE EMPHASIS ON ACHIEVING

longer. We also need time at the end of the day to meet with our peers. We can't build more planning time into the day. More staff would be needed for that; we could meet from 3:30 to 4:30. I really think it should be done. We want to be professionals, so we should have a more professional schedule. That is only my opinion.

Sandi: I wish that they would communicate with us in a more positive manner. The communication is very poor. So, I would tell another district superintendent to be aware of what is being said - how, when, where, and to whom. Some time the messenger is not doing things correctly. Communication is a big issue. Most of us Indians would like to hear it from the Chief!

Pam: I have already told my principal that I am willing to come in for Saturday school. I would do it for no charge. I want to hold it for those students who have not been doing well on the benchmarks, which indicates that they won't do well on the state test. I hope that he told the superintendent. I am serious. I think more districts should do this.

Ann: I wish that every child had a laptop. We are expected to take them to the lab and so many of our new programs are computerized. I just think every child should have everything on a laptop.

Mary: I want the officials at the top to know that just because they suddenly need something, we should not be expected to change all of our plans or put in extra time. They need these benchmark reports and they give us certain dates. We work hard to plan for them even when computers go down. Then there is a memo that they are needed three days earlier. Suddenly, we are allowed to change schedules and neglect instruction to get these done ahead of time. Don't do this to teachers. Don't expect us to always rework our schedules to satisfy your needs. Send out people from the district office to do the benchmarks in a hurry. Change their schedules.

Cary: The officials at the district and state level need to know that the students don't really like school anymore for the most part. The 
Running head: EFFECTS OF THE EMPHASIS ON ACHIEVING

supervisors at the state level are very worried about the drop-out rate. Well, all of these regulations and regimentation are contributing to that, in my opinion. The students never get to be creative or have fun. One day before Thanksgiving break, not many kids were present, so we reviewed a few things and then I asked them what they wanted to do. They wanted me to read to them. Can you imagine fifth graders saying this? So, I did. Then we did some hands-on activities in science that we hadn't gotten around to before. We did some creative writing and I turned on some nice music. It was a really good day. The people in charge need to know about this. The students learned and enjoyed themselves at the same time.

\section{Teacher Theme Ten: Effects of AYP Emphasis on Teachers as Related to}

\section{Empathy from the District Office and/or the State Department of Education}

As the teachers spoke about empathy, it became very clear that there was a lack of it, at least, according to this group of teachers. They responded that, "Some of these consultants don’t know what it is like to be a classroom teacher today.” "The consultants are too young to have had much experience and the district office administrators are so old they have forgotten.” Many things have happened to these teachers that have caused them to feel that no one cares. They reported, “A bad experience during the first month of school where one consultant changed the reading strategies." Then, the teachers explained that after a few weeks of implementation another consultant arrived and explained a different set of methods. The teachers shared their confusion and the lack of concern from their supervisors.

Along these same lines, teachers expressed, “It is like our experiences don’t matter and aren’t important.” Teachers asked, “Why doesn’t someone sit down and ask for our input? We have the full picture of our school.” The point was made that these teachers 
Running head: EFFECTS OF THE EMPHASIS ON ACHIEVING

felt that the top supervisors have lost sight of children. The teachers asked, "Why don’t supervisors come and do walk-throughs on test days so that they can see the tears of frustration of students trying to read a test written two grade levels above their skills?”

No appreciation has been shown to them as far as most of these teachers were concerned. No one has spoken in their support and yet the superintendent wants the teachers at one school to "serve at a dinner for the business partners, parents and district office.” This was not something these teachers showed an interest in pursuing.

As for their principals and the concern that they have shown for the teachers, it appeared that there were two extremes. Some teachers felt their principals did not understand and were just concerned about getting AYP achieved. Yet, those principals, who had recently been teachers, had earned the consideration of their teachers. Those teachers felt that, “The principal really tried hard to support us and spoke up about our problems.” The teachers felt lucky to have that principal and knew that she probably got "heat" from the superintendent for speaking out on behalf of the teachers.

Another area where teachers felt a lack of concern was from the federal representatives, state legislators, and even the governor's office. The teachers stated that they had written letters and asked for changes to NCLB at both the federal and state levels. It was apparent that they really expected empathy from the state governor as one teacher commented, "How about our governor, he is close to the situation and his wife was an educator?”

Results -- from Teachers at all Six Schools in Regard to Effects of AYP Emphasis on Teachers as Related to Empathy from the District Office and/or the State

\section{Department of Education}


Running head: EFFECTS OF THE EMPHASIS ON ACHIEVING

Most of these teachers commented that their principals and other supervisors appeared to not care about them. These teachers expressed their feelings with these remarks:

Rose: I don't think that my principal understands the state testing, so, I have to wonder if the other district officials do either. In the fall, one of the district supervisors was checking the scores from teacher to teacher. He came to me and said that he had noticed that the students that I had year before last scored better in most areas than the students that tested last year from my room. He wanted to know why my scores had gone down. I explained to him that it was a different group of students and they can't be compared. I told him to look at the present scores for the year before last students and to look at last year's scores for this year's students. I also told him that the state test had been changed and it was not really something that could be compared and that even the cut scores were not comparable. He didn't know what to say and just walked off shaking his head. Of course, he is not going to do that. It would be too much work. I can't be sure he even understood what I said. I know they are using those scores to rate teachers. They have no feelings for us. Tonya: I don't know about the district office and the superintendent or even the people from the State Department, but our principal supports us and helps us as much as possible. I guess it is because she was a teacher for years, down in these trenches with us. She knows what it is like and she has not forgotten. She probably gets into it with the Superintendent because she always backs us up. She tells them to phase things in slowly. She tells them we need training after school, on Saturday, or in the summer. She is not in favor of having too many substitutes in the building.

Joan: I think that we need support from the federal level. Our senators from this state and representatives have apparently no idea what is really going on with this NCLB. How about our governor? He is close to the situation. He knows. My goodness, his wife was a teacher. When will 
Running head: EFFECTS OF THE EMPHASIS ON ACHIEVING

someone speak up? We have written letters to our representatives at the federal and state levels.

Meg: Principals do not understand. Students are different now and the classrooms are different now. All of the methods of teaching and the strategies that we use have changed over the years. How can a principal who has been out of the classroom for more than ten years relate to our problems and what we are trying to do? Administrators have forgotten what the classroom is really like. It is a totally different environment in the classroom today. Children are diagnosed with all kinds of problems and they are on all kinds of medications. There are many discipline problems and it appears the only solution is suspension. How does that help?

Sally: Many of our district level officials have forgotten what it is like out here in this school. I grew up in this district and I have known many of them for a long time. They don't really care about us. They put on the show for the media and such. They just want us to do whatever it takes to make AYP. They don't even stop by and see what it is like. I feel really sorry for our principal; she tries so hard to represent us. I know that she probably gets the heat for us. She knows and she speaks up. She was a teacher for a long while in this district. So, she really knows and takes our situation to heart. We are lucky to have her, but I don't know how much she can take. I worry about that.

Liz: Our new principal is trying to be very open and positive with us. She seems to know what we have been through and that we have not had many pats on the back. I don't know if someone talked with her or if she is just naturally that way. Anyway, she is making a good impression and bringing us a little glimmer of hope. We really need that.

Teachers said that they felt no support from the community or the media. They did not understand why things weren't handled differently. It was expressed as follows:

Mae: It appears to me that some of our district supervisors and some of these consultants don't know what it is like to be a classroom teacher 
Running head: EFFECTS OF THE EMPHASIS ON ACHIEVING

today. I feel that the supervisors have forgotten. Most of them have been out of the classroom for too long. Most of our consultants are so young that I doubt that they have even taught for three years. They show very little concern for what we are experiencing.

Lane: They come in to our school, these consultants, and they give us all of this information, but they never ask for any input from us. It is like what we think does not matter. All of our experiences are not important. We need to be able to sit down with them and give them the full picture of our school. I am not saying that their methods are not good. They just need to know the big picture of our school so that adaptations can be made.

Debra: The big issue right now in our district is that the superintendent wants to have community dinners for the parents, students, and business partners. He wants the teachers to serve to show our appreciation. Now, wait a minute -- they have shown no appreciation for us. The District Office, the parents, and the business partners have not spoken out for the teachers in regard to AYP. Now, we are supposed to serve them at a dinner. The voters have never supported a bond or a levy in this district. There is something wrong with this picture. Who appreciates the teachers?

Jill: When the district puts out a statement about the school not achieving AYP, it is very humiliating because of their lack of explanation. They need to very tactfully explain about the low SES and the special needs cells. It could be done in a way that would not harm anyone. No, instead the whole school gets a bad reputation.

One teacher shared that supervisors and other officials had told her that they were only doing what they had been told to do. It appeared to the teacher that those officials just wanted the teachers to do the same thing. Lack of concern for good training sessions was also expressed. The comments were as follows:

Kate: We had a really bad experience the first month of school. We had received all of these directives that we were going to be changing the way 
Running head: EFFECTS OF THE EMPHASIS ON ACHIEVING

we did reading. So, a lady came from the state department and she explained it one way. Then we started trying to implement it in our classrooms. After a few weeks we had another session with someone else and she explained a completely different set of procedures. It was awful. The whole training was wasted. We were all so confused. The worst thing was that no one admitted their mistakes to us. They did not have anything to say to us about all of our time that they wasted. It is as if no one really cares about us.

Maria: I would love to sit down with those people who make up these regulations. Are they trying to assure that some child will always be left behind? I wish they were here on the days that those special needs children are taking a test that is written two grade levels higher than their skills. I want them to look at the frustration and tears on the faces of those students and explain their reason behind doing such a thing. Why don't they come on those days and do a walk-through or observation?

Jan: It is quite evident that they do not really think about us. They keep giving us new programs to implement. Before we, the teachers and students, have time to work the kinks out of a new program, they give us training in another one. We don't even have the schedule working in the new reading tiers and now we are going to be trained in the math interventions and integrate that into the schedule. Superintendents should know better. A person can only do so much and the schedule can only be expanded into so many useful pieces. Too many little chunks can’t be good for instructional purposes.

Diane: Some of our principals, consultants, and district level supervisors tell me to not get upset with them that they are just telling us to do what they have been told. So, I ask if they think these new strategies are good for instruction and they tell me they are just doing as they are told. I told the principal that someone needs to rethink the plan and ask questions. He did not respond to that. I don't think he cares. He can’t understand why we can’t get everything done. 
Running head: EFFECTS OF THE EMPHASIS ON ACHIEVING

\section{Teacher Theme Eleven: Effects of AYP Emphasis on Teachers as Related to}

\section{Training Time on New Programs}

Training time was not taken lightly by these teachers. Most all of them agreed that more training time was needed and that it should be done during the summer, after school, or on Saturdays. It was also agreed that during the school day was not a good option as substitutes in the classroom usually amounted to lost instructional time. The teachers mentioned that "training them on the go" was not a very beneficial method. It was felt that too many different trainings had been given to them at one time and there was not enough time to absorb, assimilate, and teach accordingly. These teachers also emphasized that there was a great need for quality time for the trainings. They expressed the need, "for quality time at the end of the summer to review test results, but not the same time set aside for setting up their classrooms.” This "test result training time” must allow for the study of their last year’s students’ scores and their incoming students' scores. The teachers wanted to study the last year's scores to determine what areas of the CSOs were weak. This showed their acceptance of responsibility for the scores. The teachers felt if they could study those scores then, "They could make a plan for their own instructional improvement.”

Another issue was time for meeting with their grade level peers at the school. These training sessions, according to the teachers, needed to be held after school about once each week. These meetings would allow for time to discuss what's wrong, what's working, what needs changed and to make suggestions to each other. It was also expressed that perhaps occasionally these meetings should be district-wide so information could be shared across grade levels throughout the area. The teachers 
Running head: EFFECTS OF THE EMPHASIS ON ACHIEVING

suggested that, “If the district officials don't trust us, these meetings could be planned and supervised by district level officials.”

Although, the teachers admitted they have had training, they shared that it was "not enough, at the right time, and usually not beneficial.” The training needs to be more "hands-on” and “in a lab situation where all of the computers work.” One teacher expressed, “They give us a lick and a promise and lickety-split we have it all down pat.” The teachers wondered, "Have they ever heard of phasing things in or taking one thing at a time?” Teachers from one school expressed that, “We don’t go against each other. We know if we do; they will divide and conquer us.” These teachers felt it was due to their principals' support that they could move more slowly toward improvement at their school.

\section{Results - from Teachers at all Six Schools in Regard to Effects of AYP Emphasis on Teachers as Related to Training Time on New Programs}

Most of these teachers emphasized a serious need for more appropriate training time. These educators wanted to be trained and felt, if done correctly, it would be beneficial to school improvement. They expressed their concerns as:

Barb: We need time to be trained. They really should have trained us during the summer. They did not plan very well. Now, they are trying to train us as we go. They are implementing too many things. We need time during the summer so that we can get things ready for the beginning of school. We can't do it now. It is so hard for us to learn on the go and try to still teach the children. I think they know that we are fumbling a lot of the time and it doesn't help them.

Jane: At the beginning of the year when the test results come out, we need time to study them. We need to see the test scores of those students who went to the next grade and the scores of our new students. This takes 
time, if they expect us to study them well and see where we were weak on which CSOs. This knowledge helps us to make our plans for the year. We know that we can do better with our students. We are not saying that some of the blame for the scores is not ours, but give us the time to look at the scores and make a plan for improvement.

Kay: The superintendent should allow us to have a day each month or every other month for grade level meetings across the district. They need to appoint certain experienced teachers at each grade level to determine the agenda and to get it approved. Someone from the District Office can supervise each meeting, if they do not trust us to stay on task. We need time to discuss what is working, how other schools are proceeding, to make suggestions to each other, and to check progress on various new programs. I would be glad to set this up for my grade level.

Sharon: We need time at the beginning of the year, quality time - not the same time that we are to be setting up our rooms. We need time to look over the test scores that we were just handed. We need to understand them for the children that left our classrooms in June and the children who we have just received. It takes time to do that. It would be time well spent. We never have the time to do that. We are just so rushed. In that way, we could study individual test results of the incoming students. We could also see where we, the teachers, were weak on certain CSOs during the last school year according to the test results.

Sue: We have had too many days out of the classroom for all of these trainings. Having them in the summer is not bad. Having substitutes in the classroom during the school year, for so many days is not good for anyone, especially for the kids. It is double work on a teacher. We have to really write everything out so that the day won't be lost instructionally. Most of the time it is, anyway. We had reading training during the summer. Now, we are starting the math. So, we will be out of the classroom some more time. 
Running head: EFFECTS OF THE EMPHASIS ON ACHIEVING

Cindy: I can't say that we have not had training, quite honestly, we have not had enough. Especially, when you consider all that they have given us at one time, I just can’t take it all in. We need more time on training -more hands-on training in a lab where everything works and each teacher has a computer. We need this. They just expect to give us a lick and a promise and lickety-split we have it all down pat. It is like they want us to pull a rabbit out of a hat and they keep taking the hat. I don't know. It is too much all at once. Haven't they ever heard of taking one thing at a time and getting that right before adding on more?

Edith: We really need more time at the beginning of the year to do just the test scores. Then during the summer we need time to be trained and re-trained on the new programs. I hope they don't think up something else for us this coming summer. We can't handle one more thing. Anyway, I don't know how I would fit anything else in the schedule. We need training on scheduling apparently. Because according to my calculations, all of the time that we need to spend on each item will not mathematically fit into the length of our day. Yes, we need more training time. Seriously! Martha: We need more training to do the technology things correctly. Like Acuity and Tech Steps, there is so much in those programs and it takes more training than they give us to get a real handle on them. I want to use them correctly and effectively. I just need more training. We are under the gun to use these items. We really have not been trained properly.

Alice: We are given so much information at one workshop and we are supposed to digest it and be able to use it immediately. I have never heard of such a thing. There is no trial period, no learning or assimilation time. We are supposed to integrate it into the classroom and they will be around next week to see how we are doing. Well, that is just too much. We need more time and it is very frustrating. Someone needs to plan for these things. We need training, but do it in the summer so we can get ready for using it in the fall. 
Running head: EFFECTS OF THE EMPHASIS ON ACHIEVING

At a few schools teachers remarked that things had improved and felt it was due to the understanding and support from principals who had recently been teachers. Their remarks were as follows:

Carla: The whole staff is wrapped up right now in implementing the reading interventions and all of the tiers. We meet once a month after school with the consultant and the principal. We all try to follow the directives and do as much as we can. At least the principal understands as she taught here when this first got started. We all pull together and do what we can. We don't go against each other. We know if we do, they will divide and conquer us. With our principal's support, we are moving slowly and getting good training.

Flo: We have our trainings mostly after school and on Saturdays. That is due to our principal. The superintendent and district office supervisors started out with them during the day. Our principal put a stop to that. We will have a big training in the summer for about a week. It will review some of the programs and probably add new ones. We can either get paid or get continuing education credits.

\section{Teacher Theme Twelve: Effects of AYP Emphasis on Teachers as Related to Staff Changes, Transfers, and Retirements}

It was a consensus among these teachers that the staff at most of the schools has remained basically the same over the last two to three years. A few of the schools have had changes in their principals, but the teachers felt it was due to not achieving AYP. Teachers also responded that there had been some retirements, not that many. It was remarked, "It’s hard to consider retiring with the economy so bad.” It was also commented that there have been cuts in special needs and Title I teachers. The teachers agreed in their comments that, "These individuals are needed more and more with all of 
Running head: EFFECTS OF THE EMPHASIS ON ACHIEVING

the inclusion.” It was questioned, “I don’t know how the district figures out who goes and who stays. I think they needed money to hire the consultants.”

\section{Results - from Teachers at all Six Schools in Regard to Effects of AYP Emphasis on Teachers as Related to Staff Changes, Transfers, and Retirements}

The concern about staffing cuts was expressed by most of these teachers. Also, a concern was the results of changing building principals. The comments were as follows:

Ida: Not many teachers have transferred or retired lately. We have had a change in our principal and that has been a positive change. Some teachers want to retire, but they don't. It is hard to consider retiring with the economy so bad.

Carol: Surprisingly, we have not had much change in the teaching staff. We have changed principals over the last few years due to not making AYP. It has been really hard to keep administrators. I guess they have a lot of pressure from the top.

Ruth: That's been one of the biggest things here at this school. Our leadership changes quite often, our staff pretty much stays the same. I think we are on our fifth principal in ten years. Sometimes the district gives us an assistant and sometimes they don’t. Right now we don't have one. I don't think all of these administrative changes are good for a school. The staff just doesn't know how to respond to each new principal. It takes awhile to learn what that person wants and then there is someone new.

Kris: I do not understand it all. Last year we started working on the full inclusion and the special educators were coming around and working in our rooms and co-teaching. They modified for the students and helped us to make accommodations. Then, they had funding cuts. Now, one of our special needs teachers has been cut. It makes a big difference. We needed that teacher and the students needed that teacher. 
Lou: Over the last few years we have lost a couple special educators and at least two Title I teachers. It seems a real shame as we really need those individuals more and more with all of this inclusion. I don't know how they figure out who goes and who stays. I think they needed money to hire the consultants, I don't really know. I don’t think anyone has retired that wasn't ready to do it. Some people want to retire, but just can't afford to do it, yet.

Ina: They have let quite a few of the Title I teachers go and some of the special educators. That is a real shame. We need them more now than ever before. Now, with all of the inclusion and intervention groups, those teachers were the real experts and they could really help us out. We still have a few and they try to get around, this is a big school and the schedule does not allow them to be in our rooms as much as the students need them to be.

\section{Teacher Theme Thirteen: Effects of AYP Emphasis on Teachers as Related to}

\section{Time to Spend Planning with Teachers in the School}

The aspect of time was a shared need throughout the interviews. Several teachers mentioned the need for common planning times. One teacher expressed her disbelief that, "Principals have not recognized our need for common planning time.” Most teachers noted, "There are so many people that we need to share and plan with: Title I, special needs, grade level members, and the consultants.” The teachers admitted to having a regular planning period as required by law, but that all of their duties could not be completed in that short time. It was also shared that one principal had built in some extra planning time. Then the teachers realized, "It was taken up with IEPs, 504s, parent conferences, and most often, consultants.” These teachers mentioned that in order to have a common planning time it would require extra staff members. 
Running head: EFFECTS OF THE EMPHASIS ON ACHIEVING

Even a kindergarten teacher saw the need for this. She felt, "It would be beneficial if she could discuss the weak areas of the upper grades and then she could begin certain strategies at her level.” She remarked, “I feel responsible, for the test scores, also.” It was shared that the common planning time had been asked for, but "No one was addressing it.”

\section{Results - from Teachers at all Six Schools in Regard to Effects of AYP Emphasis on Teachers as Related to Time to Spend Planning with Teachers in the School}

Most of these teachers expressed a need for common planning time. In regard to all of the inclusion, these educators recognized that they needed to regularly meet with each other to make effective plans for their students' needs. They expressed their concerns in these statements:

Page: We need time to get together and plan. We need to be able to talk about the various tiers and interventions. We also need to share the results of the benchmarking. That time is never arranged. Someone needs to work on our schedule. There must be away to do this. We know that other schools do have common planning times. We also need to meet with the special needs teachers. Common planning time has become very important because of all of these new methods and the inclusion.

Becky: I just really can’t believe that our principals have not recognized our need for common planning time. We need to take care of so many things. It is important to talk with Title I teachers, special needs teachers, and the consultants. We can't do all of these things on our regular planning time when the others are not free. We don't have time between classes because everything is so rushed. This needs to be figured out. It is not a luxury! It is a necessity!

Patti: We have lots of meetings with consultants during the day and substitute teachers take over our classrooms. That actually is not a good thing to miss so many days. We need to have time at the end of the day to 
Running head: EFFECTS OF THE EMPHASIS ON ACHIEVING

meet with grade level teachers to see what questions we have and to plan. We need time at the end of another day to meet with all of the teachers who do the tier interventions, special needs teachers, and Title I teachers. We never have time for this. So, we don't know what each one of us is seeing with the different students. This would be helpful as far as I am concerned.

Sandi: We do not have a common planning time and no provisions are being made for that. We have all asked for it. No one is addressing it. We can never get together. I teach kindergarten and I feel responsible for the scores too. If I knew what the weaknesses were, then I could start doing more in kindergarten. If I knew the format of the testing, then I could start getting the kids ready. I really think we all need to meet together and share the test results. I do feel responsible.

Pam: It is hard to do any real planning. I could accomplish a whole lot more if I actually had time to plan. We need to have time to plan together. We don't have time in the schedule for that. We need to plan for differentiated instruction. We all know and want to do that, but when? The things that we need to do take time to put together. We need time to do learning stations.

Ann: We were so excited. The principals built in some extra planning time for us to be together. Then, we found out that most of that time is taken up with IEPs, 504s, parent conferences, and workshops. Those things are all very important. When do we, as teachers, have time to get together to plan for the instruction that we do for these students? Some of us team teach with special educators and we need time to get together. Mary: I have talked to the principal about it several times. We need time to get together to plan and discuss the students' progress. We need team planning. I know teachers in other districts that have a regular planning daily and then a common planning at least once and in some cases twice a week. Once would be nice, if that is all we can get. Well, we have none now. Supposedly, the principal is trying to get copies of schedules from 
Running head: EFFECTS OF THE EMPHASIS ON ACHIEVING

other schools. I believe her, she taught here with us for years before becoming the principal. She knows what I mean. She really does understand our needs.

Cary: They have not figured out yet how to give us a common planning time. The principal knows that it is needed badly. We have all talked about it at faculty meetings. We know some schools in other districts have a regular planning and then they have a common planning. Maybe not every day, but at least once or twice a week. Our principal is getting those schedules to study. We need to spend the time together and that would be a good place to meet with the consultant, not every time. That is not why we want the time together.

Rose: I need more time to meet with the regular classroom teachers to help with modifications and just to go over ideas and IEPs. We need this time to catch up on where individual students are and if anything needs changed. I can't get to each classroom as often as is really needed. Actually, it is very difficult, and quite honestly, I can't always meet the specified minutes on each IEP to spend with each individual child.

These comments concluded the remarks pertaining to the comments in regard to the teacher themes. The comments in regard to the principals' themes are discussed in Chapter Five. At the conclusion of Chapter Five, the results of the two peer reviews of the transcribed interviews have been discussed. The triangulation of the data by the two peer reviewers contributed to the reliability and validity of this study in regard to the themes that were determined by this researcher from the raw interview data. 
Running head: EFFECTS OF THE EMPHASIS ON ACHIEVING

\section{WCHAPTER —}

\section{Results of the Principals’ Interviews}

This chapter is devoted to the themes and comments in regard to the seven (five males and two females) principals’ interviews and the emphasis on achieving adequate yearly progress. The reader is reminded that these comments have been taken from the interviews of real administrators who are presently working under the constraints of NCLB at schools that are trying to achieve adequate yearly progress according to the state and federal regulations.

\section{Principal Theme Fourteen: Effects of a Consultant on Building Principals as} Related to Changes in Principals’ Daily Work Load and Routine

Some of the principals seemed to have a few differences in regard to workload. Four of the five principals that had assistants felt that although the workload was somewhat heavy, "I can get it done.” Another similar comment was, "I enjoy having a lot to do.” The principal at School Five had an assistant, but he was new to administration. She stated that she had kept a number of the duties until, "He had gotten a chance to learn his way.” She also had taught for several years at the school with these teachers and felt the needs of the teachers very personally. In addition to the everyday duties that most of the principals mentioned, she had taken on a task of her own creation, "We need a coach or a consultant that can be here at the school regularly.” She explained that the district had no funds for this, so she was working with the local colleges to get something arranged. She commented, "I may have some good news for these teachers in a few weeks.” The assistant principal at School Two commented that, "I have time to study the new programs and serve as a resource for the 
Running head: EFFECTS OF THE EMPHASIS ON ACHIEVING

teachers.” She expressed that she and the principal were "able to keep everything covered."

\section{Results - from all Administrators in Regard to Effects of a Consultant on Building Principals as Related to Changes in Principals’ Daily Work Loads and Routine}

These administrators felt that they had a great deal of work to do, but most stated they were able to accomplish it. Their remarks included the following statements:

Williams: I don't feel too much more work has been added to my schedule than there was before. I can get it done. Of course, I do have an assistant and that is helpful. I divide the work between myself and my assistant. We share the walk-throughs, lesson plans and various reports. Now, I have to do the observations and the evaluations. I try to be in the classrooms a great deal of the time. I want to see the new programs and strategies in action. Then I try to schedule grade level meetings weekly. I work the special needs, Title I, and planning period teachers into these meetings so that everyone can get to air their views about how things are going. We try to talk about all of the things that we are implementing and what needs changed.

White: I enjoy having a lot to do. The more, the better it is for me. I love to keep busy and we are busy here, even though, I have an assistant. There is a great deal to do all of the time, every day. I can go in and out of the classrooms and do the needed observations and evaluations. I can see the new strategies and how they are going. I manage the attendance and the discipline. Of course, we have many 504 and IEP meetings on a very regular basis. We work very hard to keep all of that up-to-date. I look at the benchmarking and try to keep tabs on where the students are.

Green: I am very busy going to each classroom and checking lesson plans and all of the new programs and software as it is being integrated. I have time to study the programs and serve as a resource for the teachers. If something is not working, then I can call and get someone from the 
district to get over here and take care of it. If they are going to tell us to use these things, then they need to keep them working. I also have time to monitor the consultants as they go in and out of the classrooms. If they are having meetings with the teachers during the day or after school, then I am there also. The principal and I share a lot of duties and keep everything covered.

Brown: This district-wide reading initiative has really added to my work load. Even though the district hired a consultant, she is for all of the schools in the district. So, it is up to me to integrate and implement this program throughout this school. I have all of my other work and I need to be out in the classrooms assisting the teachers with this. I don't mind it. I love to be in the classrooms as much as possible. I am the instructional leader. I am here late every day, just to keep my head above the stacks of paper work. Then when there is a problem or someone in the office, I get called away from the classroom. I just can't be consistent.

Black: I have to be ready to change the schedule on any given day that the district decides to send out a consultant. I also have to do all of the reports for all of the new programs such as the benchmarking, Acuity, Tech Steps, and others. There are also all of the attendance hearings and the letters for that. I have financial statements to deal with and various district meetings. That does not even count walk-throughs, observations, and evaluations.

Jones: Of course, I have all of the everyday principal duties that must be done. I am trying to work with the local colleges since the district has no funding for our school. We need a consultant or coach that can be here regularly -- one for reading and one for math. We have the consultant that the district provides, she comes very sporadically. I am trying to work out a way that someone will come here from the college, maybe twice a week. That person could set up a regular schedule and go through the classrooms and help the teachers to implement these new programs. This has taken a lot of time and it is still not done. I may have some good news for these 
Running head: EFFECTS OF THE EMPHASIS ON ACHIEVING

teachers in a few weeks. We need the help.

Good: In addition to all of the new programs, consultants, attendance reports and letters, disciplinary issues, evaluations, observations, and various principals' meetings called by the district, I have to keep this faculty on track. It is difficult because not only are they frustrated due to not making AYP; many of them just don't get along. They argue over things that should not even be discussed at school. It is just that they are so stressed. It doesn't help that they do not like each other. This is due to things that happened long before I got to this school. I deal with it daily. We are all supposed to be on the same team here. It is difficult to juggle it all.

\section{Principal Theme Fifteen: Effects of a Consultant on Building Principals as Related to Most Difficult Aspects for Principals}

There were common aspects for all of the administrators as to what represented to them the most difficult aspects of the focus on AYP. The items that most of the administrators shared included:

1. Need for a technology specialist --The principals' comments included, “We need someone here who knows what to do when things don't work as they should.”

2. Need for teachers to have more training time --Principals remarked, "Most of the problems stem from the fact that our teachers have not received enough training. It's not their fault.”

3. Need for a common planning time --Most of the principals agreed, "It is difficult to get other teachers to cover classes, but the district won't allocate funds for additional staff or substitutes.

4. Need for help with scheduling --The assistant principal was very vocal 
Running head: EFFECTS OF THE EMPHASIS ON ACHIEVING

when she stated, "We need more time for scheduling the tiers in reading and math.” It appeared that she had really studied the schedule, length of the school day, and the number of available staff members. She surmised, “This really can’t be done.” She told that they needed was a little longer day and a few more staff members. Her comments were repeated by most of the other administrators, as well.

5. Need for improved participation of parents -- One principal had the challenge of trying to get the parents, especially those of the low SES students, to become involved in school activities. He expressed, "Some of the parents are hard-working people, but don’t have the initiative to do any better.” He explained that now the parents, “Don’t even attend when we serve food.” Most of the principals expressed the need for improved parent involvement at the schools.

\section{Results - from all Administrators in Regard to Effects of a Consultant on Building Principals as Related to Most Difficult Aspects for Principals}

It was very apparent that these administrators were very concerned about the five issues listed under Theme Fifteen. Further remarks concerning these topics included the following:

Williams: It is quite difficult to keep all of the computer programs up and running. We need a technology specialist in the building. Someone who knows what to do and is here to do it when things don't work as they should. This person could also help the teachers learn the new software programs and equipment. I know that computers and software don't always work as they should. Most of our problems stem from the fact that our teachers have not received enough training. It's not their fault. They 
are really trying. They have just had too much put on them in such a short time. We really could benefit from a tech specialist.

White: It has been very hard for the teachers to get used to this new teacher reflection writing that our district has required. My assistant and I do walk-throughs, but the teachers must do walk-throughs on their peers. We came up with a schedule for this. This was an idea from the District Office. The teachers do not want to do these. We explained that even the walk-throughs that the administrators do are not really important. They are just three or four minute snapshots of what is happening in the classroom. The teachers are very leery of all of this. They do not write their names on the teacher walk-throughs. There is no name representing who did the walk-through or who received the walk-through, but they know. When you get your peer walk-through back you have to do a reflection on the comments. This has all been very hard on the teachers and I don’t know how beneficial it is. It seems to be adding stress unnecessarily.

Green: It has been very difficult to schedule enough time during the school day to meet the academic times as specified by the state regulations. We need either more teachers or a longer day. I doubt that we get either one. We need more time to schedule the tiers for reading and math. We still have to get in the science and social studies. We need, especially, the time for hands-on science. All of this really can't be done. There actually is not enough time in the day. I have studied it at great length and I have spoken to the district level supervisors about the problem. So far, they haven't come up with a solution for us.

Brown: It is very difficult to take care of all of the reports. I have to do attendance, suspensions, other disciplinary issues, and of course all of the reports that go with the new software programs. It is very difficult to keep up. If I had an assistant, it might not be so bad. I need to also spend time in the classrooms, just to observe the new strategies and programs. In addition, I am required to do the walk-throughs and the regular 
Running head: EFFECTS OF THE EMPHASIS ON ACHIEVING

observations and evaluations.

Black: Scheduling for the consultants and allowing for common teachers' planning meetings is very difficult. The district does not want to allocate funds for substitutes to take over classes every so often to allow common planning to be scheduled. It is difficult to get teachers to cover. It is hard to do all of this and not lose instructional time.

Jones: It is very difficult to change the schedule to accommodate for double reading times and double math times. Really, that is what is needed to place the emphasis where it should be in an attempt to improve the test scores. If we had a few more teachers, it might happen at least on some type of a rotational basis. I also need to be able to schedule the teachers a common planning time in addition to their regular planning time. Again, even if that was just once or twice each week. It would be very helpful to them. It is something that is greatly needed and it would help alleviate some of the stress. It would also be beneficial for the teachers to work together to discuss new strategies and interventions for the tier groupings.

Good: Our challenge here is the low SES group. They come from families that don't have a high value for the education of their kids. They don't see a good education as a means to an end. Some of them are hard working people, but they don't have the initiative to do any better than they are right now. So, they don't encourage their kids to do more. Some don't encourage their kids to do anything. So, how do we get to the kids? It is difficult to get the parents to come into the school for meetings. Sometimes they don’t even come if we tell them we will be serving food. They just don't care.

\section{Principal Theme Sixteen: Effects of a Consultant on Building Principals as}

\section{Related to Noticing Changes in Teachers}

All of the principals shared that they had observed some changes in their teachers. 
Running head: EFFECTS OF THE EMPHASIS ON ACHIEVING

Most of these administrators saw changes in their teachers' professional styles. The principals at School One and School Five saw changes that told them their teachers were learning to "Let the data drive their instructional methods and techniques." The principal at School One said that, “They are learning to use the benchmarks, but it has caused a great deal of frustration.” He also added that he felt, "If the teachers had been given more time to learn the information, it would have been better.” The principal at School Five noticed a change in lesson plans. She responded, "I am impressed with what they have done so far.”

At School Two, the principal noted that the teachers were making great strides using the new software, computers and other equipment. He also added that, "It had been hard to do in such a short amount of time.” The assistant principal at School Two had commented on changes in those teachers who had agreed to serve on the Five Year Strategic Plan Committee. She remarked, "It is one of those required things, I can see they are trying to make it fit our needs.” At School Three, the principal responded that the teachers were changing their teaching styles. She noted all of the extra time that the teachers were spending at the school to make that happen. She explained that without an assistant, she was finding herself at school early, staying late, and coming in on weekends. She added that she was never alone, “The teachers are here, too.” She expressed that she needed help and they did, too.

The principal at School Four had noticed more of a forced change in teaching styles. She felt that the removal of a special needs teacher had caused the regular classroom teachers to learn to make adaptations in an effort to better accommodate those students. She also noticed the burden that this staffing cut had placed on the other 
Running head: EFFECTS OF THE EMPHASIS ON ACHIEVING

special needs staff as they rushed about the building from classroom to classroom to assist students and teachers. The School Six principal observed that some of his teachers were making an attempt to "bury the hatchet and to get along with each other." He said that, "I try to be fair and have the same rules for everyone.” His method was to keep talking to all of them and to hope for change. He added, "I know that it will take time to heal.”

\section{Results - from all Administrators in Regard to Effects of a Consultant on Building Principals as Related to Noticing Changes in Teachers}

Most of these administrators admitted they had noticed changes in the instructional methods of their teachers. Their remarks are represented by these comments:

Williams: I can tell that the teachers are finally learning to let the data drive their instruction. From the state test scores in the fall to the benchmark results throughout the year, they are learning to use them. Yes, it has caused a great deal of frustration. It was something new. The district could have made it better if we would have had more time to learn it all. Also, I still say we need more staff at the buildings to help with all of this. I have to say I see a change in how the teachers are adapting to it. They still complain, but I don’t mind listening.

White: I see that the teachers are really trying to use the new software, the computers, and other equipment. They have really taken great strides in learning how to use the programs and how to integrate it all into the various components of the curriculum. I am very proud of them and I try to tell them that. It has been hard to do in such a short amount of time. Also, our equipment is not the best and I have spoken to the district people about this, but so far no results. When the computers don't work as needed, then that just adds stress to the teachers. I hate that when they try 
Running head: EFFECTS OF THE EMPHASIS ON ACHIEVING

so very hard to do what is expected, then things go wrong that are completely out of their control.

Green: I have been going to the meetings with teachers who agreed to serve on the Five Year Strategic Plan Committee. They get a little extra pay for this, it isn't much. They were all reluctant and were just going through the motions. The longer we work on it, the better it seems to be. I mean they are making it real. They are actually trying to make the document a representation of what we are trying to accomplish here at this school. It is very cumbersome work and I am not sure that it is beneficial. It is one of those required things. I can see that they are trying to make it fit our needs.

Brown: I see that they are changing their teaching styles. I must say they are very tired. I see their cars here in the morning when I come at six and they are here most evenings when I leave after 6:30. It is a real shame. I come down quite often on the Saturdays and Sundays and teachers are here too. It is wearing them out. We need more help. Extra staff members are needed. I know that I need help. My teachers need consultants or coaches, whatever you want to call them; they need to be here daily to actually share the workload. There really is more work on all of us.

Black: We have a consultant, but with the removal of one of our special needs teachers, the faculty has had to learn to really make changes and adaptations for the special students to a greater degree. The special needs students are fully included for the most part. The special staff that remains in the building runs themselves ragged going from classroom to classroom to assist teachers and students. They do a great job. I see all of the staff making a real effort to accommodate these students. The district has no idea what a burden they have placed on the students and the teachers.

Jones: I have really noticed a change in lesson plans. I see references to CSOs due to test scores and benchmarking. The teachers really have taken in what the consultants have been talking about. They are letting the 
data drive their instructional methods and techniques. I am impressed with what they have done so far. It is still early in the school year. We have only had three sessions with the consultant and they are already changing their teaching styles.

Good: I mentioned that this faculty had not gotten along with each other for years. I have noticed that some of them are trying to bury the hatchet and let bygones be bygones, so to speak. I have tried to get along with everyone and to be fair. I hope it is rubbing off. Some of them probably did feel mistreated. I try to be fair to everyone. There are no favorites for me. I play by the rules. It's the same rules for everyone. I think it is getting better. I just keep talking to them and hope for change. I know that it will take time to heal. I think they know it is going to take all of us working together as one team to improve this school and move forward.

\section{Principal Theme Seventeen: Effects of AYP Emphasis on Building Principals as}

\section{Related to Suggestions for Other Districts}

The common theme from all seven administrators was a suggestion that other districts look for ways to add staff to the individual buildings. The principals suggested the following:

1. Hiring data specialists that could be at each building to help with state test results, benchmark results and other testing information.

2. Hiring technology specialists to keep teachers informed of new programs and how to use them. It was suggested that these individuals would also handle the scheduling of the labs and working on the computers in the building.

3. Hiring reading and math specialists to assist in each building and to help in the scheduling and in covering the common planning times. 
Running head: EFFECTS OF THE EMPHASIS ON ACHIEVING

4. Hiring of special educators to assist with inclusion, modifications and adaptations in the regular classroom, as well as, working individually with those students who still needed the extra time and help.

The Assistant Principal actually suggested that the district office should, "Look at their use of their district staff." She seemed to have knowledge of what went on at the district level offices and believed, “They could get by with fewer personnel because of all of the computerization.” This administrator understood the need to have more staff in the buildings for smaller class sizes, to provide more individualization, and to also provide personnel for common planning time. She added, "State and local officials need to study this. It could be done. Things need to change in the district offices, as well as, in the schools. It can no longer be business as usual.”

\section{Results - from Administrators in Regard to Effects of AYP Emphasis on Building Principals as Related to Suggestions for Other Districts}

The four recommendations listed under Theme Seventeen represented a consensus of what was mentioned by all seven administrators at these schools. Further comments are listed as follows:

Williams: There needs to be a district level person or better yet a person at each school who is responsible for reading and interpreting the data from the tests. This would include not only the state test results, but also the Acuity benchmarking. In that way we could be sure that we were interpreting correctly. If we had such an individual who put these things together, then the teachers could spend more time looking at individual scores and this would lead to better results with the tier interventions. As it is now, the teachers do not have enough time to do it all. They are trying. I know that they really try. The district needs to decide to either; 
give the teachers more paid time to do this or hire someone to do it. This person could then meet with us at the beginning of the year, during planning, and teachers' meeting days to help with the data. This needs to be figured out.

White: I would also suggest that the state officials begin looking at individual growth portfolios for students. The benchmarking is a step in the right direction. We need to build on that and get away from basing everything on just one test. Through the growth portfolios we would start each year where the student is and we would monitor every six weeks to see progress. At the end of the year we would note individual improvement in each student on their own level.

Green: It would be so helpful to have more time at the beginning of the school year to look at the test data. We need two full days just for data. The teachers really deserve this. We also need an expert to help us disaggregate it in a manner that will help us to see the problems with the class that just left a teacher and the new class of students coming in to each room. I am sure that there is so much that could be done with the data that would help us in designing the instructional plan for the year, but we need more time. We also need more alternate assessments for the special needs students. This needs to be seriously and quickly addressed. To force a student to try to take a test that is above their reading level is cruel.

Brown: I really believe that the officials at the district need to take a very hard look at the use of their personnel. We need more teachers in these buildings and fewer at the district level. I have worked at all levels and I know that now there is so much of the district level work that is computerized. They can get by with fewer professional personnel. If we had more teachers in the buildings, then classes could be smaller and we could do more individualized work. If we are truly going to do the interventions as it was intended, then we need more teachers. The state needs to study this. I feel sure, that it could be done. Some of the people 
Running head: EFFECTS OF THE EMPHASIS ON ACHIEVING

at the district are going to have to come back into the buildings. Things need to change in the district office as well as in the schools. It can no longer be business as usual. Those days are gone.

Black: Each building needs a reading and/or math specialist that can be used as a resource for the teachers and also serve to help us in our goal to design a schedule where we have a common planning time. This would be so important for the teachers. The district really needs to reevaluate how they handle staffing at their level and see if some individuals can be school-based instead of district-level-based. We need the help out here. Common planning time would be so helpful. We also need a technology specialist here in this building. After all, these new programs are computerized. The teachers can’t be expected to do it all alone. It would add so much to the new aspects of the curriculum to have an expert here. They could at least employ someone until everyone feels comfortable with the programs and has a good understanding of what they do and how to operate them. This is a lot of information to absorb.

Jones: In this school we need one language arts and one math coach. That would be good for any district just going into this. I know that they don't want to hire extra teachers, but I would rather have that instead of the consultants. Of course, schools share the consultants. If the teachers had someone to come around to their classroom consistently it would be a great help. These teachers really want to change, they do need help. The job description would have to be written so that it required about ten years of classroom teaching experience. Most of these consultants have not had much classroom experience and that does not work well. They have a hard time with some of their ideas and the reality of an actual classroom with real students.

Good: It would be nice to have a full time reading consultant on staff. I also liked what I have seen of a brain-based program for really struggling readers. It is difficult to know what to do with severe reading problems. The reading consultant could take these kids into the lab and work with 
Running head: EFFECTS OF THE EMPHASIS ON ACHIEVING

them on certain days. Then, on other days she could help teachers with resources for certain groups of students. It would be someone that the teachers could rely on for information and suggestions about the new reading strategies. This position would require a certain job description. It could not be open to just anyone. The teachers need a person who is an expert in this area. The school needs that, if the district really wants our scores to improve.

Williams: As a principal, I feel that the district office supervisors should allow me to set up my own schedule for the implementation of these new programs in the manner that is best suited for this individual school. Each school is a little different. I have been in the school for awhile and I should be able to work with the district to set-up the schedule. I would do it with recommendations from the teachers. Then they would have some ownership to it. We need to move slowly and implement in a manner that is effective for our school. Also, we should not be forced to do too many new things at one time. I guess it is hard for the district to allow each school to plan slowly, because sometimes, in my opinion, it looks like they don't really have a plan.

\section{Principal Theme Eighteen: Effects of AYP Emphasis on Building Principals as}

\section{Related to Noted Changes in Staff Morales, Feelings, Attitudes, and Motivation}

All of the administrators recognized that low teacher morale was a problem. The principal at School Six said, "Morale is very low and has been for awhile.” He commented that not achieving AYP and all the new programs have caused stress and, to make matters worse, some of the teachers did not speak to each other. "This makes team work difficult” he added. At School One the principal commented that the, "teachers were down on themselves and were taking the blame for not achieving AYP." At School Two, the principal remarked, “The teachers want to teach, however the 
Running head: EFFECTS OF THE EMPHASIS ON ACHIEVING

problem is some of them want to teach the same way they did twenty years ago.” He added that the teachers were not happy about all of the changes. He felt, "It is our job to adapt and improve.” The assistant principal responded, “These teachers love their jobs and are committed to the students. They just need time, resources, and someone to explain all that has been shoved at them so quickly."

The School Three principal suggested that morale was not that bad, "It could be better, though.” This principal tried to show appreciation for the teachers with occasional fresh flowers, coffee, doughnuts, snacks, and various stickers. It was the least that she could do, "Since no one from the district comes to pat them on the back."

Admitted by the School Four principal, "Morale is not good.” She observed that the district got the year off to a bad start by not giving enough time for the data day at the beginning of the school year. She felt that if the district would make these small concessions of extra time that, "They would do a lot to improve the way teachers feel overall.” At School Five, the principal noted that, “The teachers are a very tight knit group.” She stated, "I was one of them and I still am.” She further added, "We are doing the very best that we can.”

\section{Results - from Administrators in Regard to Effects of AYP Emphasis on Building Principals as Related to Noted Changes in Staff Morale, Feelings, Attitudes, and \\ Motivation}

All of these administrators expressed concerns about teacher morale in their comments on this topic. The following statements represented their concerns:

White: The teachers feel a little down on themselves because they take the blame for not making AYP. They do that to themselves. I tell them it is not their fault. They take it to heart. I know we can work through this. 
Running head: EFFECTS OF THE EMPHASIS ON ACHIEVING

We just need adequate training, time and support from the district to get us what we need as we work our way toward improvement. We need more staff members and we need to have understanding about the special needs students and their scores.

Green: These teachers basically want to teach. The problem with some of them, and I did say some of them, is that they want to teach the same way they did twenty years ago. I tell them, you don't drive the same car as you did twenty years ago. So, you have to change. Some of them just aren’t happy about all of these changes, but it is our job to adapt and improve.

Brown: For the most part, these teachers love their jobs and their students. Many are not happy about the changes. They are motivated to do what's best for the students and this school. Most of them have been here a long time and are committed to this school and this area. I believe we can make it. We are in this together. I can work with them and we can become a school that makes AYP. These teachers just need time, resources, and someone to explain all of this that has been shoved at them so very quickly.

Black: As I see it, morale is not that bad. I guess it could be better. So, I try to show them how much I appreciate them. I get them fresh flowers for their desks every once in awhile. Sometimes I have coffee and doughnuts ready for them as they arrive in the morning. I get them snacks for the afternoon or leave treats in the lounge. Just little things, I think they mean a lot. No one from the district comes to pat them on the back. Jones: Morale is not good. Well, the district gets us all off to a bad start by not giving enough time at the beginning of the year for the data day. Then, the teachers never have enough time to set up their rooms. That is no way to start a new school year. I believe that if the district people would find a way to make these small concessions they would do a lot to improve the way teachers feel overall. 
Running head: EFFECTS OF THE EMPHASIS ON ACHIEVING

Good: The teachers at this school are a very tight knit group. I worked here as a teacher for many, many years and they accept me. I was one of them and I still am. Most of us live right here in this area and have for most of our lives, so, we share a lot. We know the students and the families. We are doing the very best that we can. We are trying to learn all of the new programs and techniques. We are trying to improve and achieve AYP. Sometimes teachers get very upset, it is because they care so much.

Williams: Morale is very low here and has been for awhile. It goes way back, as I said, to another administration when the teachers were not treated fairly and equally. I am working hard to overcome this. I talk with them and try to show through my actions that I am treating them all the same. No favorites with me, I don't operate that way. It is bad enough to have so much stress on the teachers due to not achieving AYP and all of these new programs. On top of it all, some of them don't speak to each other and that makes it even harder. They have to work in teams and get over this. I have told them at the district level about this situation, so far they have given me no response.

\section{Principal Theme Nineteen: Effects of AYP Emphasis on Building Principals as}

\section{Related to Empathy from the District Office and/or the State Department of}

\section{Education}

Six of the seven administrators expressed through their statements that the district and state level officials do not show empathy for them through their actions. At School One, the principal commented that, "Everything was helpful - the meetings that he attends, the superintendent, and the people at the Regional Education Service Agency.”

However, none of the other administrators expressed the empathy in quite that manner. At one school, the principal acknowledged that the district sent more and more 
Running head: EFFECTS OF THE EMPHASIS ON ACHIEVING

software programs, but what were really needed were a technology specialist and more up-to-date computers. He commented, “The district needs to step up and really do what is needed.” The assistant principal, due to working with curriculum, admitted to a great need for common planning time for the teachers. She felt that the district office, “needed to prioritize.” She added, “They have regular staff meetings and ought to afford the teachers the same privilege.”

“I don’t think anyone at the district level really understands all of the benchmark testing” commented the principal at School Three. The principal at School Four thought, "The district people need to come to the schools and see what is really happening.” The School Five principal remarked, “I don’t think they feel our pain. They say they want our scores to improve, but they can’t give us more staff members.” The School Six principal wanted the district office officials to understand about the inexperienced building consultants. He expressed that the district needed to figure out a way to post the positions so that veteran teachers would apply. "If they think that these consultants are so important to the improvement of our test scores, then they need to hire people who have the knowledge and the experience to help us.”

\section{Results - from Administrators in Regard to Effects of AYP Emphasis on Building Principals as Related to Empathy from the District Office and/or the State Department of Education}

Most of these administrators' comments reflected their feelings that the district and state officials were not really supplying what was needed to approach school improvement. The following statements expressed more of their concerns: 
Running head: EFFECTS OF THE EMPHASIS ON ACHIEVING

White: Because we are on an improvement plan at my school, I am always going to meetings. These meetings are very helpful. I get a lot of good ideas and names of people to call for help and resources. We are a small district and the superintendent is very helpful. The people at the Regional Education Service Agency are also very helpful. I believe that everyone understands what we are going through and wants to help us.

Green: The district is sending us more and more programs that require computers and various kinds of technical equipment. The computers that we have here in the schools just can't keep up with all of this software. I don't think that the people at the top realize the frustration that this causes. When a teacher plans to do something and the computers are not functioning, then everything is out of whack. I know that we should always have an alternate plan, but the way that curriculum is now; the computers are as viable as the textbooks. They may be even more important as we prepare for the students for the twenty-first century and beyond. I think the district needs to step up and provide what is really needed. We need updated computers and a technology specialist on staff. The curriculum demands these things now.

Brown: The teachers desperately need a common planning time. I have talked with the district level officials, but they say there is no money for staffing. They need to prioritize. They have staff meetings at the district office very regularly. I know. I used to work there. So, why can't the teachers be afforded this same privilege? The district needs to understand how valuable this would be to these teachers - to all teachers. Classroom teachers need this privilege more than ever now.

Black: I don't think that anyone at the district really understands that the students don't really get too geared up for the benchmark testing. The teachers really try, believe me. These teachers realize that the district folks are looking at those benchmark scores and looking at individual teachers. Honestly, it is not fair to the teachers. The students have been tested too much. This benchmarking happens every so many weeks and it 
Running head: EFFECTS OF THE EMPHASIS ON ACHIEVING

is all just too much. We just can't make a big deal out of every one of them. I am afraid that the students won't care about the state test, then what?

Jones: There are some people at the district level who can't handle being told something different from what they think. My main purpose is to do what is best for the students. I have been doing that for more than thirty years. I can look myself in the face in the mirror each morning and I know that I am doing the right thing in my job. Some of the district people are after some kind of power. They need to come to the schools more often and see what is really happening.

Good: They say at the district office that they want the test scores to improve. They can't see their way to giving us math, reading, and special needs teachers. We need these teachers, not only to reduce class sizes, to assist with the full inclusion. It is so needed. I don't think they feel our pain.

Williams: I know that there are rules to follow about job postings, but something has to be done about these consultants. The consultants that have been hired are so very inexperienced. The veteran teachers have no respect for individuals who have not had their own classrooms for at least three years at a minimum. They need to post these jobs with a minimum of at least three years in a regular classroom setting. I guess they will have to guarantee that the job will be there or experienced teachers will not apply. The district says they have no funding for these positions after the AYP money is gone. Well, they need to fund what is really important. If they think that these consultants are so important to our test scores, then they need to get people who have the knowledge and the experience to help at the school level.

\section{Principal Theme Twenty: Effects of AYP Emphasis on Building Principals as}

\section{Related to Staff Changes, Transfers, and Retirements}

The common theme for this issue was that four of the six schools had experienced 
Running head: EFFECTS OF THE EMPHASIS ON ACHIEVING

staffing cuts in at least one special needs position over the last two to three years. Most of the principals also expressed that for the most part there had been no other major changes in their staff. They said that teachers who were ready had retired. They also agreed that more teachers might retire if they weren’t so worried about the economy. The principals acknowledged that they had gotten their positions when the prior administrator had either retired or went to a district level position due to the school's status of not achieving AYP for a few years.

Also, common to all of the administrators was that, they had asked the district office for more personnel. This wish list included more teachers for special needs, math, reading, technology, and data.

\section{Results - from Administrators in Regard to Effects of AYP Emphasis on Building Principals as Related to Staff Changes, Transfers, and Retirement}

The common concerns of these seven administrators are further expressed by these comments:

White: The position of Assistant Principal was posted as a Dean of Students. I understand that has been done in numerous districts around the state. It is done so that a lower salary can be paid. Some teachers have retired, but only those who wanted to or had to due to illness. Some of the others would like to retire, however they can't afford it or are afraid of the economy.

Brown: The principal's and the assistant principal's positions at this school were posted after so many years of not achieving AYP. The previous individuals were either taken to the district or they retired. The rest of the faculty has stayed pretty much the same for many years. The economy is bad here and it is too far to drive to another district to work. So, most people just stay right here till they can retire. 
Running head: EFFECTS OF THE EMPHASIS ON ACHIEVING

Green: This position as the assistant is now more focused on curriculum than it was in the past. That was due to the principal's suggestion. He knew what he wanted for this position and the district let him and his committee members do the selection. I work very closely with all of the new programs and their implementation. I also do a great deal with the data and work closely to help the teachers learn to use the data to drive their instruction.

Jones: The principal that was here took a job at the district level, and then I bid and got this job. They cut a special needs teacher a few years ago, but nothing else. We haven't had any retirements for awhile either. There will be a teacher retiring during the break. She says that she is ready and she is going. I think the start of this year was just too much for her.

Black: One special education teaching position was removed from this school about two or three years ago and maybe a few Title I positions over the last few years. That has made it very hard on the entire faculty. I told the district last spring that we needed the special teacher back and that we needed another math and reading teacher. They said the numbers did not warrant those positions. I explained that I had talked to administrators at the three small private schools in our area. These individuals had shared with me that they felt a number of their students were going to return to public school in the fall. Of course, the district paid no attention to me and my numbers. Now, we are way over crowded. They assure me that they understand our problems.

Good: I came from a classroom here in this building to the principal's job a few years ago. Now, this year they gave me a brand new assistant. He is a great help and will be a great administrator one day. We were cut a special needs teacher a few years ago. No other cuts have occurred for a long while. I need more teachers for smaller classes and common planning times. It won’t happen, I can keep asking and I will. No one has retired or indicated that they were going to in the near future. 
Running head: EFFECTS OF THE EMPHASIS ON ACHIEVING

Williams: Well, I have been a principal for a long while. I have been here only a few years. We have had retirements over the last two years and no cuts or transfers except the one in special needs. I'd like to add staff to get common planning, tech specialists, special needs, and to help with smaller class size. That would be the ultimate. Then, we could really move forward.

These comments concluded the remarks in regard to the results of the principals' themes and associated comments. This researcher hoped that the reader gained an understanding of the experiences expressed by these administrators and through this interpretation can find usefulness in similar situations.

The peer review results of the transcribed interviews are discussed in the next section of this chapter. These reviewers read the transcripts of the raw data and determined the most significant themes.

\section{Results of Peer Review of the Transcribed Interviews}

The results of the two peer reviewers showed that the themes deduced by this researcher were the same significant themes that both analysts determined separately. These analysts read the raw data, that is, the transcribed interviews of the fifty participants. Both analysts determined that the most significant themes drawn from the teacher interviews were: changes in daily teaching activities/work load and staff morale. These were in agreement with the two most significant themes of this researcher. The review of the analysts also showed agreement with this researcher on the principals’ themes. Some disagreement of the order of significance of themes was pointed out.

It was felt by this researcher that this peer review triangulation of the data contributed to this study's level of reliability and validity in regard to the themes that were determined by this researcher. It was hoped that the analysts would determine that the themes obtained from the raw data by this researcher were comparable to what 


\section{Running head: EFFECTS OF THE EMPHASIS ON ACHIEVING}

others would deduce from their reading of the raw data. This researcher believed that the difference in the significance of the themes as measured by the peer reviewers was attributed to the fact that this researcher used the NVIVO8 software that kept an accurate count of how the statements were totaled under each theme. The reviewers, of course, did not have access to that software and analyzed the data by hand. In addition, the personal objectivity involved in placing certain statements under certain themes could also account for some disagreement in the significance of the themes between the peer reviewers and this researcher.

The themes are listed below in the order of significance as determined by this researcher. The number in parentheses shows the placement in order of significance as rated by analyst one and by analyst two for each theme.

A. Effects of a consultant on teachers were as follow:

1. Daily teaching activities and work load (Analyst $1=1$; Analyst 2=1)

2. Class management and teaching styles (Analyst 1=2; Analyst 2=2)

3. Changes in yourself (Analyst $1=4$; Analyst 2=3)

4. Most difficult aspects to integrate (Analyst 1=3; Analyst 2=5)

5. Empathy from District Office and/or State (Analyst 1=5; Analyst 2=4)

6. Time to spend with individual students (Analyst 1=6; Analyst 2=6)

7. Parent involvement/students' home life (Analyst 1=7; Analyst 2=7)

B. Effects of AYP emphasis on teachers were as follows:

1. Staff morale, attitudes, and motivation (Analyst 1=1; Analyst 2=1)

2. Suggestion for other Districts (Analyst 1=2; Analyst 2=2)

3. Empathy from District Office and/or State (Analyst 1=4; Analyst 2=5) 
Running head: EFFECTS OF THE EMPHASIS ON ACHIEVING

4. Training time on new programs (Analyst 1=3; Analyst 2=3)

5. Staff changes, transfers, and retirements (Analyst 1=5; Analyst 2=4)

6. Time to spend planning with teachers (Analyst 1=6; Analyst 2=6)

C. Effects of a consultant on building principals

1. Principals' daily work load and routine (Analyst 1=3; Analyst 2=2)

2. Most difficult aspects for principals (Analyst $1=1$; Analyst 2=1)

3. Noted changes in teachers (Analyst 1=2; Analyst 2=3)

D. Effects of AYP emphasis on building principals

1. Suggestions for other districts (Analyst $1=1$; Analyst $2=1$ )

2. Noted changes in staff morale (Analyst 1=3; Analyst 2=3)

3. Empathy from District Office and/or State (Analyst 1=2; Analyst 2=2)

4. Staff changes, transfers, and retirements (Analyst 1=4; Analyst 2=4)

In the next chapter this researcher has provided a summary of the findings in regard to the research questions. A description of the limitations, significance of the findings, and implications for future research as indicated by the findings of this study are also discussed in Chapter Six. 
Running head: EFFECTS OF THE EMPHASIS ON ACHIEVING

\section{TCHAPTER [}

\section{Summary of Findings}

In this chapter this researcher has attempted to provide an overall "essence of the life experiences” (Moustakis, 1994, p. 35) by providing a combination of the textural and structural descriptions of the experience phenomenon blended with this researcher's personal experiences and various themes from the literature on the topic. In doing so, this researcher hoped to create for the readers an understanding of what it was like for these educators to live through these experiences.

The purpose of this study was to determine how teachers and principals working at schools that had not achieved Adequate Yearly Progress were affected by consultants and the emphasis placed on achieving AYP according to the constraints of NCLB. This study used qualitative methods of phenomenology and hermeneutics to interview fifty educators who worked at schools that had not achieved AYP. In this chapter, this researcher attempted to let the reader know what this researcher learned from participating in the interviews, studying the transcripts of the data, coding the themes, and organizing the information, “(Dilley, 2004, p. 128). These interviews have allowed the investigation of the participants' expression of their experiences. This researcher has tried to give meaning and understanding to the facts and information that these educators conveyed. Hopefully, this researcher's approach to making sense of the interview data, applied a combination of learning and comprehension that will give each reader a small understanding of what these educators have experienced in their schools. This researcher also endeavored to clarify for the readers how these particular interpretations were concluded in regard to this set of data. The amount of data 
Running head: EFFECTS OF THE EMPHASIS ON ACHIEVING

contained in this document was provided to allow each reader to also determine if their situations matched or were comparable to these recorded experiences. In this way, this researcher trusted that perhaps the findings of this study could be usefully transferred to the related situations experienced by the readers.

The two research questions that guided this study and that were used in labeling and organizing the concluding themes and findings were as follows:

1. What are the effects of a consultant's work at schools that did not achieve AYP on the following:

(A): teachers’ instructional techniques, daily work load, and teaching strategies used with students (B): administrators' daily work load and leadership styles?

2. What effects does the emphasis on achieving AYP at schools that do not meet the required proficiency level on the NCLB mandated annual state tests have on the following:
(A): teachers
(B): administrators? 
Running head: EFFECTS OF THE EMPHASIS ON ACHIEVING

In regard to research question $1 \mathrm{~A}$, the most significant findings that appeared to this researcher were as follows:

1. Changes in Teaching Activities, Work Load, Class Management, and Teaching Styles

2. Changes in the Teachers Themselves

3. Most Difficult Aspects to Handle and Empathy Received from Local and State Officials

4. Individual Time to Spend with Students

\section{Research Question 1A -- Changes in Teaching Activities, Work Load, Class Management, and Teaching Styles}

These teachers shared the feeling of being overwhelmed by all of the various tasks that faced them on a daily and even moment to moment basis. The teacher that expressed the frustration as comparable to that of the game where the "mole kept coming up through a hole and was continually punched back down” spoke volumes to this researcher. That teacher's description was similar to those described by teachers at the school where this researcher worked. As administrator, quite often, this researcher observed those looks of anxiety and frustration as the teachers tried desperately to fulfill all of their regular daily tasks in addition to the extra ones prescribed by the consultants.

These teachers mentioned trying to implement new programs with their students, but not feeling that they had enough knowledge of the new techniques to be comfortable in presenting it to the students. This was related to what Darling-Hammond (2010, p. 226), referred to as, "ineffective one-shot workshops that emphasize abstract discussions of teaching." She added that teachers needed professional development that 
Running head: EFFECTS OF THE EMPHASIS ON ACHIEVING

"focused on concrete tasks of teaching, assessment, observation and reflection about student learning” (p .226). In addition, “teachers judge professional development to be most valuable in authentic settings with hands-on work that builds on local context” (p. 227).

Another feeling described was the frustration of having, "so many jobs besides teaching - we are nurses, counselors, parents, and special educators.” This was supported by Max Van Manen (1990, p.2) when he wrote, "Pedagogy is the activity of teaching, parenting, educating and generally living with children.”

The teachers also expressed that their "voices had not been heard - there had been no brainstorming or input from the teachers in the plan for improvement.” In addition, teachers added that, “the human element was removed.” Teachers wanted to be a part of the "makeover" instead for them it was a "takeover." This researcher on hearing this statement and continually reading it in the data recognized that the teachers were asking to be a part of the improvement plan. A good principal would have done this by involving teachers in the process. "Teachers are the key to successful change and principals must build cultures of mutual support for everyone’s continuous improvement” (Tewel, 1995, p. 212).

This researcher heard the teachers state the need for "time to learn new programs, schedule students, do lesson plans, and learn to use new technology.” The teachers also asked the question, “Are we really improving student learning?” This led this researcher to consider these new techniques and programs, which are touted as research-based, however according to Borkowski and Sneed (2006, p. 507), “are not based on any clear scientific consensus or convincing educational research.” 
Running head: EFFECTS OF THE EMPHASIS ON ACHIEVING

When these dedicated teachers remarked that they “couldn’t find their way through all that they were being faced with” it brought back to mind the experiences at this researcher's school that caused many teachers to leave each day overcome by tears. It appeared to this researcher that these teachers who were so willing to talk did indeed want to share their feelings and situations in the hope of somehow making it better for others. Although, the problems facing these teachers could not compare in the slightest to those faced by the participants in Troubling the Angels, by Lather and Smithies (1997, pp. 154-155), it still reminded this researcher of the need expressed by even the most ill women who wanted to, “contribute” so that perhaps others might benefit and "be empowered.”

These teachers had accepted what they had learned years ago that their "instruction must be data driven” but what they regretted now was that it was no longer also "student-centered.” These teach to the test mandates had certainly, according to this group of educators, narrowed the curriculum focus. By narrowing the curriculum and pigeonholing the subjects these teachers felt that they were actually giving less to their students. "Facts are torn away from the original place in experience and rearranged with reference to some general principle” (Dewey, 1938, p. 5). According to Dewey (1938, p. 84), "the most elementary experiences of the young are filled with cases of the means-consequences relationship.” These teachers, like Dewey (1938, p. 84) agreed, "the trouble with education is the failure to utilize the situations so that the learner can grasp the relation to a purpose.” All of this teaching in "isolation” without “association” did not represent "life skills" and "long term learning” for the students of these teachers. 
Running head: EFFECTS OF THE EMPHASIS ON ACHIEVING

Some of the teachers were trying to put "fun and creativity" into their daily activities, but felt the need to "look over their shoulders to see who was coming through the doorway." The feelings caused by this type of anxiety led teachers to feelings of self-doubt and insecurity. These teachers knew the usefulness of, "activities in school” (Dewey, 1938, p.84) however, they were faced with the feelings of being watched and being caught doing the wrong things. These teachers who continued to change the prescribed activities by interjecting experiences that were more interesting to their students represented what Freire (2007, p. 179) termed, “cultural action with the objective of transforming” their classrooms in spite of their supervisors. A teacher sadly remarked, "Everything has to fit the mold, but I sneak in some fun.” According to Kozol (2005, p. 287) these teachers knew that, “they must work within the 'the box' of demographics and inequities; in their moral disposition they stand 'outside the box' and use the gifts they have to make school good, whole, and beautiful for children.”

\section{Research Question 1A -- Changes in Teachers Themselves}

This researcher was very concerned as teachers expressed their acceptance of the blame for the test scores of their students. As teachers further commented on their feelings of anxiety, one even remarked, "I feel like a gerbil in a round wheel; running faster and getting nowhere.” This researcher understood this type of frustration having experienced it while working in a school with inadequate test scores. Also, when the teachers expressed the feelings of being in a "whirlwind from which there was no escape” this researcher recalled the massive amounts of conflicting information that was constantly dispersed to the teachers from the consultants and the district officials. It seemed apparent to this researcher that all of the information from the consultants was 


\section{Running head: EFFECTS OF THE EMPHASIS ON ACHIEVING}

what Elliott Eisner (1998, p. 172) termed the, “intended curriculum.” These consultants had a plan, materials and goals. However, they did not have the time or know-how to successfully blend this intended curriculum with the “operational curriculum” (Eisner, 1998, p. 172). The operational curriculum is what actually happens, "in the context of classroom life.” Eisner (1998, p. 172) further pointed out that, “no intended curriculum can be scripted as the classroom is too uncertain for that.” Eisner (1998, p. 172) further stated that a true professional teacher "uses the curriculum only as a resource to amplify his abilities.”

The teachers also stated the guilt they felt about the home lives of their students. These teachers tried to "make-up the difference" and make school the best part of their students' day. In addition, the teachers tried to make sure that, "the basic needs of the children were satisfied before they made any attempt at the "basic skills.” In trying to do these things, these educators knew what Eisner (1998, p. 168) believed, "It is a mistake to assume that all good teaching has identical characteristics, that one size fits all.” These educators recognized that the needs of each students differed and in response to that their teaching needed to change to accommodate each child. Wagner (2008, p. 200) wrote, "Understanding these conditions is required for motivating real learning and productive engagement in classrooms is essential if we want to close the global achievement gap and help all students.” This gap is mostly about, "race and class, however it can be defined as the gap between students who are driven to succeed - the Overachievers - and those who have very little hope of success - the Unengaged” (Wagner, 2005, p. 200).

Not only were these teachers concerned about the survival of their students, most 
Running head: EFFECTS OF THE EMPHASIS ON ACHIEVING

of them were concerned about their own survival. They commented on "early mornings, late evenings, and long weekends” at the school. Also of concern to this researcher was the statement, “I don’t want my daughter to teach; I don’t want her to feel this way each day.” This researcher had been guilty of this same reaction in regard to young family members contemplating careers in education.

One very significant statement made was, “All of the joy has been taken out of the job.” And, another teacher admitted to this researcher, "I feel negligent and sad because I am leaving some students in the dust as I race to keep on schedule.” This researcher was more than able to internalize both of these remarks from reflecting on past personal experiences as a teacher and as an administrator. Debbie Miller, teacher and author, reminded in her book, Teaching with Intention, (2008, p. 136) that, “Teaching is magical, so slow it down and keep the joyfulness, the accomplishment, and the inspiration. Teaching is a place that never ends, but gets us to another place to learn.”

\section{Research Question 1A -- Most Difficult Aspects for Teachers to Handle and} Empathy Teachers Received from Local and State Officials

These two issues seemed to blend themselves together as this researcher worked through the findings of the teacher interview data. Teachers mentioned that they felt not appreciated and not listened to in regard to the changes in strategies and programs. Teachers suggested that, "It is very important to embrace the people involved in the change and give them their voice.” As Freire (2007, p. 92) wrote, “Only dialogue, which requires critical thinking, is capable of generating critical thinking.” These teachers acknowledged that if they were able to communicate their feelings, voice and knowledge into the plan then it could possibly represent their views of education. 


\section{Running head: EFFECTS OF THE EMPHASIS ON ACHIEVING}

Freire (2007, p. 94) further noted, "Many educational plans have failed because their authors designed them according to their own personal views without taking into account those in the situation.”

It was also suggested that the "test results in the fall might be different if they talked to the teachers about assessment and benchmarking progress throughout the school year.” These teachers also remarked about the problem of not being able to have time to study the test scores of the same students over a period of time. They recognized that, "scores should be comparable to those used at a preceding date so that one can see whether change is taking place and if educational progress is happening” (Tyler, 1949, p. 121).

The effects of parents and students' home lives were also believed to be a factor that warranted attention by local, state, and federal officials according to these teachers. These teachers recognized the importance of the involvement and effects that factors outside of the school had on children. As Robert Murphy (2003, p. 39) wrote, "We need to roll up our sleeves and get involved in the nasty business of influencing political discussions that have an impact on our ability to do our work as educators.”

Teachers also expressed that the district should make accommodations for better computers and give teachers more time to learn the software before trying to have the teachers implement the programs. Teachers also stated that, “Consultants often admitted to them that they had just learned the programs and wanted the teachers to be considerate of that.” These same teachers remarked, “They received no consideration when they stated their needs.” This researcher was encouraged by the comment of a teacher that stated, "I chose to be a teacher and I take my job seriously. I see the looks 
Running head: EFFECTS OF THE EMPHASIS ON ACHIEVING

in the students' eyes and I'm not getting to do the things that I became a teacher to do.” Just as Theobald, (1997, p. 134) stated, “Education is a serious business.” These teachers recognized this fact. They wanted to do more for their students than simply teach to the test. They wanted to engage them in an education that reflected real life and gave the child information about community, justice, and society. This researcher believed these teachers wanted to do something similar to what Callejo Perez (2006, p. 106) referred to when he wrote, “...to cut across boundaries of self-discovery to live out the ideas of diversity within society, and...search for hope in education.” The concern for computers and technology by these teachers was not made to imply taking away teachers for computers. These teachers realized, “That teaching is a human endeavor” (Theobald, 1997, p. 129). These teachers expressed the forced need of using the computers themselves as a way of handling the massive amounts of test data given to them by their officials. Of course, they understood that, "they are the best delivery system” (Theobald, 1997, p. 130) for their students, but they wanted their students to engage in the use of technology as a "tool for research" (Theobald, 1997, p. 130) and for gaining further knowledge.

\section{Research Question 1A -- Teachers in Regard to Individual Time to Spend with}

\section{Students}

These teachers showed concern for students at both ends of the academic spectrum. They felt compelled to help the special needs students and those students that were "falling through the cracks." The teachers felt that all of the emphasis on full inclusion had "removed the individualization of special education." Even a special educator expressed that both she and her students "spend time running in and out of classrooms 


\section{Running head: EFFECTS OF THE EMPHASIS ON ACHIEVING}

and can’t get back to their room to get caught up.” As educators, they realized that time to focus on a task was very important for all students. Even for good students, "the mind wanders after about twenty minutes” (Erlauer, 2003, p. 76). That doesn’t mean that the, “lesson's topic should change every twenty minutes, but the way the students are working should change” (Erlauer, 2003, p. 76). Teachers expressed an understanding of this concept when they commented on the need for common planning time. It requires more time to plan activities that use the brain in different ways during one lesson and throughout the day. These changes in activities or instructional techniques allow the students to still concentrate, but in a different way.

The loss of a "chance to establish one-on-one rapport with a certain teacher or classmate: had been taken away according to these educators. Marzano (2007, p. 149) wrote that, “Arguably, the quality of teacher-student relationships are the key, even the entirety of teaching. Teachers have a personal stake in the success of each student.”

The children who could benefit from enrichment and those who are falling through the cracks are left behind were comments made by several teachers at the six schools. Teachers also lamented that they can "no longer give extra points for extra effort." These teachers in making these statements showed that they were, "attuned to the lifeexperience of the classroom, and knew that assessment situations hold the power to affect student lives” (Robertson, 2005, p. 35). Linda Darling-Hammond (2009, p. 194) wrote, "We need to focus our curriculum on standards that evaluate how people can think, problem-solve, invent, create, and use knowledge in new ways and continue to learn independently. That means we have to change the assessments that we use.” As far as parent involvement and student home life, teachers remarked that the 


\section{Running head: EFFECTS OF THE EMPHASIS ON ACHIEVING}

same students, who needed, but are no longer getting the benefits of one-on-one relationships, are also the ones who are affected by the lack of parental support and poor conditions at home. The teachers reflected that, "Parents did not even come to the school when prizes and food were offered.” It was apparent to these teachers that the factors of lack of parental support and poor home life were out of control, but the teachers felt that they were held accountable for them according to the test results. Here again, the teachers commented on satisfying the basic needs of the students as being their top priority. The problem shown by these teachers' comments on not being able to get parents involved in the schools had been growing for years. It goes back to the late 1800s and early 1900s when the government, through early consolidation, tried to show rural communities and their members the importance of progress. "These individuals would not allow this invisible hand to take control over their lives and place it into the hands of someone all too willing to use it for personal gain” (Theobald, 1997, p. 19). Teachers are still left to overcome this long established pattern of distrust. Along this same line, David Tyack (1974, p. 270) wrote about the American school system being held accountable for, "the problems of the 1950s due to its being too soft to sustain a conflict with Russia and the problems of the 1960s in the war on poverty.” It appears that still today, “in order to continue to divert the public’s attention away from the real issues of America's crisis such as: poverty, lack of jobs, and health care; the focus is on education as a solution” (Hursh, 2007, p. 295). 
Running head: EFFECTS OF THE EMPHASIS ON ACHIEVING

The most significant findings for this researcher in regard to research question 1B were as follows:

1. Daily Work Load and Most Difficult Aspects to Handle

2. Recognized Changes in Teachers

\section{Research Question 1B -- Principals’ Daily Work Load and Most Difficult Aspects}

\section{to Handle}

Most of the administrators felt that they could "get their work done" and they “enjoyed having a lot to do.” There were only two administrators who admitted to being very busy. One had no assistant and the other had recently been a teacher at her school for many years prior to becoming the principal. She said that she "had been one of them and still was.” It appeared to this researcher that these two principals had an entirely different understanding of the teachers' experiences than the other administrators who had assistants and who had not worked at their schools as teachers. It was hard to determine from the interviews, but this researcher deduced that this teacher - turned principal had gained this understanding from having worked closely with her colleagues and continuing to do so when she became their leader. This principal used the terms, "We are a team” to describe her relationship with her teachers. She had taken on the extra task of finding a coach or consultant to be at the school on a regular basis. She expressed hopefully that, "She might have some good news for her teachers in a few weeks.” This showed her concern for their feelings and frustrations and her desire to get what was needed for her school. This principal exemplified what Douglas Reeves (2006, p. 29) stated, “Leadership is neither a unitary skill set nor a solitary activity. No single leader possesses every dimension of leadership, but the 
Running head: EFFECTS OF THE EMPHASIS ON ACHIEVING

team will. “This principal apparently recognized this fact and used it to complement her work at the school.

All of these seven administrators seemed to agree on five items that were the most difficult for them to handle. These included the following:

1. Need for a technology specialist.

2. Need for teachers to have more training time.

3. Need for more common planning time.

4. Need or help with scheduling.

5. Need for parent participation.

This researcher noted that all of these items overlapped with items that the teachers had also emphasized. Even though, all but two of the principals stated that they could get their work done, it appeared to this researcher that these five items would enable the principals to truly be able to get their jobs done in a much more efficient and effective manner for their students, their teachers and their schools. All of the items mentioned would enable a school to run more efficiently and would add to the overall instructional enhancement.

\section{Research Question 1B -- Principals’ Recognition of Changes in Teachers}

All of the administrators had observed changes in their teachers, but some of the principals felt these were only changes in their professional styles and not in personal morale levels. However, one principal admitted that learning to use the new programs did cause a great deal of frustration for the teachers. The principals were at least aware that the changes had been difficult to implement in such a short period of time. Only one principal recognized the hours of extra work that the teachers had spent before and 


\section{Running head: EFFECTS OF THE EMPHASIS ON ACHIEVING}

after school and on weekends to make the changes happen. She knew this because she had been at school also. One principal noted the extra burden placed on some staff members due to a staffing cut of one special needs teacher. Alfie Kohn (1990, p. 186) wrote, "It is difficult for teachers to dispense with textbooks, directed lessons, and to let students play an active role in their quest.” However, good teachers know that is what it takes to provide students with an environment in which they, "think and learn for themselves” (Kohn, 1990, p. 187). Even though most of the new programs were structured toward the state tests and actually narrowed the curriculum, these teachers tried to integrate strategies that were best for their students’ learning experiences.

In regard to research question $2 \mathrm{~A}$, the most significant findings or themes that appeared to this researcher were as follows:

1. Staff Morale, Attitudes, and Motivation

2. More Time for Training and Common Planning

3. Suggestions for Other Districts, Empathy, and Staffing Changes

\section{Research Question 2A -- Teachers in Regard to Staff Morale, Attitudes, and}

\section{Motivation}

Not only was teacher morale low according to the responses of these educators, but in the eyes of this researcher, even worse was that there was a general acceptance of these feelings. It appeared that the feelings of stress, frustration, and anxiety were to be expected. The teachers expressed that the “feeling of pressure was not good and didn't know how long they could take it.” As if dealing with all of their daily teaching responsibilities was not enough stress, these teachers were also anxious about the benefits of the constantly changing research-based programs. Many teachers felt that 
Running head: EFFECTS OF THE EMPHASIS ON ACHIEVING

the programs hadn't really been tested and believed that their classrooms were serving as the testing sites. It was commented that, “The programs changed from year to year because the test scores did not improve.”

From the remarks of the teachers, it was easy for this researcher to see that the need to talk with their peers was a means of stress-relief. Some of the teachers mentioned meeting in the copy room after school some evenings and that had turned into a night out for teachers and their spouses at local restaurants. These teachers were also frustrated because the "professionalism and art of teaching had been taken away." They expressed feeling very responsible for not achieving AYP, but didn’t know “what to do.” For some, the answer was to retire, but they didn't like the idea of letting the system define "when they were ready” for them. Some of the teachers remarked that they had to see therapists, take medication, or just take a day off in order to deal with the situations they were experiencing.

Younger teachers expressed that since they could not remember teaching in any other type of conditions that they had learned to deal with it by "going with the flow." These individuals expressed that they tried to help their older colleagues. Most of the teachers responded that they wanted to make "school a nice place in spite of AYP.” One group expressed that their morale was pretty good and added that it was, "because they all stuck together and got along.” Harris (2004, pp. 15-24) suggested, “A good principal could lighten the load through supportive actions, and be sensitive to what is happening in the school and personally to the teachers. The principal can be supportive by being available, communicating, listening, encouraging, mentoring and recognizing teacher needs.” 
Running head: EFFECTS OF THE EMPHASIS ON ACHIEVING

\section{Research Question 2A -- Teachers Need for More Time for Training and Common Planning Time}

It was found by this researcher that most of the teachers placed a great emphasis on the need for time. Time for training and time to plan with their colleagues were of utmost importance to these teachers and apparently would have satisfied many of their needs. The issue with training time expressed to this researcher was that the teachers had accepted the programs, but needed time to study, learn and practice with them before implementing in the classrooms with their students. This "training on the go" as termed by some of the teachers was not seen as beneficial. Nor, did the teachers like the idea of trainings during the school day and leaving substitutes in the classrooms. In regard to this, the teachers commented again about time -- wasted instructional time in having a substitute with their students and wasted personal time as the teachers spent extra time preparing for the substitutes. Kozol (2005, p. 329) believed and agreed with this thinking when he wrote, "When guidelines given to teachers are transmuted into lists of state-mandated jargon that are given iconic status in the classroom; we're not saving time for instruction. We're stealing time from anything that contributes to a child's education.”

The time when the workshop training was held was also a major concern. It appeared that most of the teachers were very receptive to training during the summer. In that way, they would have time to absorb the information and prepare for the fall when the students returned to school. Darling-Hammond (2010, p. 239) wrote that, "The kinds of changes needed are not a mystery. Schools have higher achievement levels when they create smaller units in which teachers plan and work together around 
Running head: EFFECTS OF THE EMPHASIS ON ACHIEVING

shared groups of students and curriculum.”

The need for a common planning time throughout the school year was also expressed as a significant issue. The teachers expressed that there were many staff members who needed to plan together. One teacher expressed that she couldn't believe that the principals had not recognized their need for this time.

Teachers were also overwhelmed by the rush of so many trainings on so many different programs, one after the other. They felt that throughout all of this turmoil it had been very important that they had "stuck together" and "had not gone against each other.” As Richard Elmore (2003, p. 11) wrote, “There is no instrumental relationship between any change in practice and any change in student performance. We are attracted and drawn to these things because they are visible and are easier to do than make the hard changes in instructional practice.” Elmore (2003, p. 15) stated, “Grab people by their practice and their hearts and minds will follow.” These teachers realized that, “generic advice disconnected from content does not have much impact” (Elmore, 2003, p. 15) on teachers’ instruction or student performance.

\section{Research Question 2A -- Teachers' Suggestions for Other Districts, Empathy, and Staffing Changes}

For this researcher these three themes seemed to naturally blend together into this finding because if the officials from the local and state levels would have shown empathy to the teachers by listening to their suggestions then perhaps, the reasons for so many staffing changes would have been eliminated. In studying the interview comments, this researcher realized that the teachers who were living through these experiences had come to an understanding of what had happened and was still 
Running head: EFFECTS OF THE EMPHASIS ON ACHIEVING

happening to them. In this realization, they now wanted to make suggestions to others in perhaps similar situations about ways to avoid the feelings and repercussions that they had experienced. The teachers suggested that in starting on this journey to school improvement there needed to be an organized plan. The plan needed to have input from the teachers who were at the "heart of the problem" and who knew their students and their needs. The teachers needed to have their "voices heard and their input needed to be acknowledged. This need for dialogue seemed to this researcher to represent what Freire (2007, p. 17) called, “dialogical practice.” Freire (2007, p. 17) wrote that, "Dialogue characterizes a relationship. It is a way of knowing and learning, not a mere tactic of involvement.” That is what these teachers were yearning for to be really involved not just placated.

The proper use of assessments and the time to study and use them was also a major suggestion. These teachers saw the importance of both formative and summative assessments. They expressed a great need for the "time to use the data to drive the instruction in a student-centered” manner. Stuart S. Yeh (2006, p. 495) of the University of Minnesota wrote an article for Education Policy in which he stated, "The use of a single level of difficulty testing causes harmful student stress and provides poor quality measurement.” In his study he found that according to teachers, "adaptive tests that provide quick diagnostic student information are very useful” (Yeh, 2006, p. 517). This type of testing would, “measure longitudinal growth for individual students and could demonstrate growth in achievement” (Yeh, 2006, p. 517). This type of testing could be used at the beginning, end, and throughout the school year. Yeh (2006, p. 518) believed that, "these computerized-adaptive tests could be used to determine how 
Running head: EFFECTS OF THE EMPHASIS ON ACHIEVING

students perform relative to each other.” At present NCLB prohibits the, "use of adaptive tests for reporting purposes” (Yeh, 2006, p. 518). Yeh’s study recommended that the U.S. Department of Education lift this prohibition.

This need for time was also expressed in the suggestion made to look into a little longer school day, so that scheduling would not have to be so rushed. The comment that the "transitions from subject to subject and room to room were more important than what happened before and after” was a serious problem for these teachers. The teachers wanted to be able to focus on the "whole child" and satisfy the child's basic need before attempting to focus on the basic skills. These educators suggested that this should be done "through the schools in conjunction with other agencies.” In Chapter Six of the book, The $21^{\text {st }}$ Century Principal, Gil G. Noam (2003, p. 72) wrote that, “Good afterschool programs focus on homework, sports and physical activity, and project-based learning.” His suggestions included that adding these to the school day in conjunction with assistance from other agencies would help students to feel better about themselves and to improve academic achievement. He expressed that, "The programs must be carefully designed, focused, monitored and evaluated to achieve success for students” (Noam, 2003, p. 73). Catherine Gewertz (2009, p. 127) wrote, “Also, refueling the rethinking of time was the expansion of the Twenty-First Century Community Learning Centers, which seek to use after-school time for a blend of academics and enrichment.”

The need for smaller class sizes and more reading, math, special needs, and other specialty teachers such as data and technology was also addressed by these teachers. These staffing needs would help to avoid the early retirements of teachers who really weren’t "ready.” These changes would also improve instruction and get back to 
Running head: EFFECTS OF THE EMPHASIS ON ACHIEVING

individualization and spending more time with students including the special needs, the advanced, and those who had been "falling through the cracks.” As a suggestion to adding more staff members, these teachers mentioned that the district needed to not hire consultants that had little or no classroom experience and who had not worked much with the programs that they were presenting.

These teachers also suggested the need for more positive communication among the teachers, principals, and district and state officials. The teachers wanted their supervisors to listen to them and to have input in the changes being made in the schools. On test days, the teachers wanted the supervisors to come to the classrooms and see the "tears of frustration of students trying to read a test that was written two grade levels above the students' skill level.” These educators knew that the fear of failure negatively affected learning. Therefore, according to Robertson (2005, p. 43), “Teachers are very uncomfortable about putting children in testing situations that cause them to attempt materials without support or assistance.”

The most significant findings for this researcher in regard to research question 2B were as follows:

1. Suggestions for Other Districts and Empathy from Local and State Supervisors

2. Staff Morale, Attitudes, and Staff Changes

\section{Research Question 2B -- Principals' Suggestions for Other Districts and Empathy from Local and State Supervisors}

The findings for this topic were common to all seven administrators. This researcher found that if the local and state officials had empathy for their administrators and teachers they would have provided more staff members at the schools. The staff 
Running head: EFFECTS OF THE EMPHASIS ON ACHIEVING

members that the principals suggested that other districts needed in starting a journey toward the achievement of AYP were as follows:

1. Hiring technology specialists.

2. Hiring data specialists. (It was suggested that the tech and data specialists could be one position.)

3. Hiring reading and/or math specialists depending on the needs of the school.

4. Hiring and not removing special needs teachers.

These positions suggested by the principals coincided directly with those positions suggested by the teachers. As a former teacher of twenty-seven years and an administrator for five years at a school that had not achieved AYP, this researcher had asked for these same positions. As the reader can see, no principal or teacher asked for or suggested that the district hire a consultant. In agreement with these educators, this researcher also believed that with the proper staff, time, and resources AYP could be achieved without the consultants. As one administrator expressed, "If the district officials think that the test scores can be improved then they need to hire the people who have the knowledge and experience to help us.” Thomas Hehir (2005, p. 122) reminded that, "schools with inadequate special needs staff are clustering numbers of special needs students together in one regular classroom.” Hehir (2005, p. 123) pointed out, "Without adequate support, students with disabilities could not effectively access the general curriculum in a regular classroom.” These items must be remembered when principals approach their district officials each spring concerning staffing issues. This researcher is reminded, as one teacher stated, "It is not business as usual." 
Running head: EFFECTS OF THE EMPHASIS ON ACHIEVING

\section{Research Question 2B -- Principals in Regard to Staff Morale, Attitudes, and Staff}

\section{Changes}

Four of the six schools had experienced staffing cuts of at least one special needs teacher over the last few years. It appeared that these losses caused the teachers, according to most of the principals, to have to adapt and change their methods even more in an effort to accommodate the special needs students. This caused even more frustration and anxiety for the already overwhelmed teachers. All of the principals recognized that morale was low. At some schools, the principals expressed that they felt it was "not as bad as it could be.” The principal of the school where she had taught for several years seemed to feel their pain and recognized, "We are doing the best that we can.” One principal admitted trying to show appreciation to the teachers by leaving small gifts of fresh flowers, or snacks for them from time to time. It was her way of giving them a "pat on the back. This researcher remembered providing similar gestures of appreciation for the teachers, while serving as an administrator.

\section{Limitations}

One of the overwhelming constraints of this study was the eighty-eight teachers who wrote on their participant response sheets that they had chosen not to participate and the reason why. These teachers did not sign their names, but they wrote that due to the fear that if confidentiality were somehow violated, that their supervisors might retaliate, if it was disclosed that they had made negative comments during the interviews. These eighty-eight individuals could have chosen to just not respond and not even return their participant sheets. However, not only did they return them; they chose to make a comment. In so doing, this researcher felt it was as if they were 
Running head: EFFECTS OF THE EMPHASIS ON ACHIEVING

sending out a smoke signal or waving a white flag that said something is wrong, please help us. Perhaps, this researcher read too much into those responses; however it appeared that this fear to participate should be addressed perhaps, in some type of a future study. Do these educators feel so oppressed that they will not even allow themselves to participate in a one-on-one interview for the sake of research? If these individuals had not indicated their reason for not participating, this researcher would probably not have wondered so much about it. After all, there were nineteen individuals that did not return their sheets at all. One hundred twelve sheets were returned with no name and just a check mark indicating - will not participate. Those responses did not bear much burden on this researcher. They had chosen not to participate due to all kinds of reasons unknown to this researcher. These individuals who did not participate due to fear caused this researcher to wonder if the responses given by those who did participate may have been tempered by that same fear. Either way, this aspect of fear of retaliation by supervisors was a concern that this researcher felt should be mentioned and perhaps addressed in a future study.

The remarks of those non-participants were perhaps more astounding to this researcher because as an educator in the public school system for thirty-two years that same fear was often felt at different times. However, this researcher usually found the courage to speak out. When this researcher began interviewing for principal's positions it took more than twenty-five interviews to be hired as a principal in the district where this researcher had always lived and worked. This researcher often wondered if that was the district's way of retaliation. It was felt that this fear of retaliation was only limited to the personal experiences of this researcher. On the other hand, from the 
Running head: EFFECTS OF THE EMPHASIS ON ACHIEVING

statements made by the eighty-eighty non-participants, apparently other educators had felt similarly.

\section{Significance of Findings}

These findings are not only important, but in the opinion of this researcher, they are of an urgent nature for schools, especially those that have not achieved AYP. The low morale experienced by these forty-three teachers is something that should not be overlooked or neglected. Realizing that these feelings can only be hypothetically generalized to other teachers at other schools, it is important to suggest that low morale is a factor in the public schools. The findings though indicate that the teachers and the administrators have good solid suggestions about what to do in an effort to improve the schools. The need to have their voices heard and to be a part of the process toward improvement is a positive suggestion to allow schools to move forward. Research shows that teachers do much better work when they feel a part of the improvement plan is theirs. These educators stated that they were performing numerous jobs in addition to their classroom teaching duties. They were serving as nurses, counselors, parents and special educators. The importance of hiring staff members in the areas of special needs, reading, math, data, and technology are very relevant to school improvement. These factors serve to answer two purposes as they would allow for smaller class sizes, and more individualization of student instruction. The addition of more staff members would allow for the time to reintroduce one-on-one student-teacher relationships into the classroom situations. The addition of more special educators would alleviate the classroom teachers' concerns about those students who were falling through the cracks of the system and those special needs students who need more attention from the 
Running head: EFFECTS OF THE EMPHASIS ON ACHIEVING

specially trained teachers.

Also, with more staff members the schools could offer more scheduling of common planning times, so that teachers could meet, organize, study data, and make plans for improved instruction. The implementation of this finding would also serve to address staff morale in a positive manner. The implementation of common planning time would enable teachers to begin to feel that professionalism and the art and soul of teaching were being brought back to the forefront of their chosen career. When teachers are able to meet, plan, organize, and work together their activities and duties becomes more satisfying and meaningful to them. By the addition of these characteristics, the 'factory model of education' can be removed and professionalism begins to return to the career.

The suggestions of these educators about the need for more training time to study new programs and data is a concern that should be addressed at once by district and state officials. These educators suggested that training be held during the summer so that preparation could be made before the opening of school. As district officials look at their budgets in early spring, they should consider these suggestions and make the necessary staff and budgetary changes. As these educators suggested, the priorities of the district and state offices "need to change” it can, "no longer be business as usual." Positive channels of communication must be opened between all individuals involved: teachers, parents, and principals as well as, local, state and federal supervisors. In this way, teachers' voices will be heard, suggestions will be made, and changes will occur for the benefit of all involved.

There is also urgency for these districts to acquire computers that work efficiently to keep up with the many new software programs and the massive amounts of testing 


\section{Running head: EFFECTS OF THE EMPHASIS ON ACHIEVING}

data. These computers would perhaps enable teachers to better use the assessment data in an effort to drive their student-centered instructional strategies. These teachers wanted to use the data, but needed more quality time. The teachers in this study stated many times that they accepted the blame for the test scores of their students. They asked for adequate and quality time to study the data and implement the new programs. It must be noted again by this researcher that these teachers were very receptive to quality training done at the right time, by an experienced and knowledgeable presenter and in an organized and unrushed manner. The districts need to urgently address this issue, in that way, they would show true concern for school improvement and empathy for the teachers’ voices and input. Empathy shown by state and district supervisors would begin to open the door to more positive communication between teachers, principals, district, and state level administrators. Also, the suggestion by the teachers to use the formative benchmark assessments in a practical manner throughout the school year is also an issue worth noting for this researcher. If districts, of course with state and federal permission, could engage in these formative assessments in a more effective way perhaps, the scores at the end of the year would be improved and achievement of AYP could be approached. Teachers suggested that one way to begin to allow time for the studying of the data would be to slightly change the length of the school day. These teachers are making creative suggestions and it is 'time' that someone listened to their voices and communicated with the teachers in an attempt to change the public school system in ways that truly benefit children.

Finally, the suggestion of some sort of a combined effort of the schools and various state and federal agencies together addressing the basic needs of their students and 
Running head: EFFECTS OF THE EMPHASIS ON ACHIEVING

families must be focused on in a swift manner. If this suggestion would be implemented, it quite possibly could serve to help not only the students and their families, but it could also alleviate some of the concerns that teachers expressed about the home lives of their students. If classroom teachers truly felt that their students’ basic needs were being dealt with, perhaps some of the teachers' sadness and anxiety due to these issues might be eliminated. This need would help students by giving their parents a method of becoming involved in the lives of their children and information could be available to the parents in an attempt to answer their needs in regard to jobs, income, health care, and other issues. If this suggestion could be worked out expeditiously, the schools would be relieved of a burden which is out of their control, but for which they feel responsible and are held accountable for through the various student population cells as required by No Child Left Behind.

\section{Implications for Future Study}

This researcher felt that many of the feelings encountered throughout her career were only the results of her personal experiences. These fifty interviews have shown that, at least, in these instances that is not true. As a result, this researcher felt compelled to suggest that future studies should occur that look at ways to incorporate the suggestions made by this group of educators. This researcher proposes that not just research be done in these areas, but actual pilot studies that involve the incorporation of the suggestions of the fifty educators that participated in this study. This needs to be done in a form of action research because the urgency of the problem in the public schools at this time is affecting the children who need to prepare for the twenty-first century and beyond. Suggestions must be made to those officials at the federal level 
Running head: EFFECTS OF THE EMPHASIS ON ACHIEVING

who are providing the funding for the government's new “Race to the Top” grants.

Perhaps, programs implementing the suggestions made as a result of this research study

could be funded instead of, or at least in addition to the other methods recommended by the government. The students, the teachers, and the parents need assistance now.

Surely, enough test results from previous years of NCLB testing have been collected to verify that in many school systems across the nation, the plan of No Child Left Behind is not working or at least is not working quickly enough for the children who have the least and who stand to lose the most.

The educators who voluntarily participated in these interviews have indicated that more special education teachers are needed in the schools to work both in the regular classrooms with teachers and also in special areas with those students who require extra assistance as indicated on their IEPs (individualized educational plans). Studies should be done to compare the improvement of special needs students who are able to spend various amounts of time with special educators both in the regular classroom and in the self-contained situations. These studies could also show a comparison of the time that a regular educator would spend with other students when a special educator was also in the regular classroom and when fewer special needs students were in the regular classroom situation. It appeared to this researcher that many comparisons could be done in this area to enable educators to learn what situations are most beneficial to meet the needs of all of the individual students.

These interview results also implied a need for studies involving the comparison of teaching styles and stress responses or accommodations of younger teachers as compared to those educators who have been in the classroom for more than eight years. 


\section{Running head: EFFECTS OF THE EMPHASIS ON ACHIEVING}

It appeared from the interview comments that younger teachers have acquired different methods of responding to the pressures of the classroom teaching environment and the various mandates associated with emphasis on achieving AYP and other federal guidelines. Studies comparing these two generations of educators might yield useful results for future school/staff structuring and organization.

Along these same lines, studies comparing the approaches of male and female educators might produce useful results for managing and determining the staffing of schools. In this study, all of the forty-three teachers who volunteered to be interviewed were females. This researcher can only wonder how the results would have differed if male teachers had volunteered to participate in the sampling.

All of the schools in this study had not achieved AYP and all had a high concentration of students from low socio-economic backgrounds. Some studies should be conducted to see if this trend is common in other areas and if there are other conditions associated with not achieving AYP. It appeared to this researcher that many implications for further study and research would be of interest and significance in the relationship of AYP and students from low socio-economic levels.

Certainly, others have done or are doing studies similar to this one, which only spoke to a small sample of educators. It is time for "change" and it needs to come quickly, but the problem is that change takes time. A step by step plan for change and improvement does not exist at this time. It is a long and slow process as research has shown. The process towards change and improvement needs to involve the teachers who have accepted the blame and are at the "heart of the problem.” These teachers who participated in this study wanted to do what their profession required - teach in 


\section{Running head: EFFECTS OF THE EMPHASIS ON ACHIEVING}

response to the needs their students. These teachers need help now and they do need to feel they are a part of the solution. In response to the suggestions of these educators, a follow-up study could be done to see if actually changing instructional methods and teaching styles in response to the needs of the individual students, as indicated by all of their various test data, could really make a significant change in individual students' test results. This would be a study that required the cooperation of individuals from the federal, state, and local levels. It would take the cooperation of everyone involved, but it might yield results that would truly be beneficial to the students of the twenty-first century.

\section{Hope for Change}

This change will require the attention, dedication and concern of all educators and policy makers from all levels - local, state, and federal -- working together as a team. Just as one of the administrators in this study commented, "We will have to speak up and out to those individuals at the local, state, and federal levels who have the authority to begin the change process.” It is time for all of the supervisors and policy makers in positions of authority to stop talking. They need to listen and to learn from the dedicated and concerned teachers who work daily with the students and have a true understanding of the problems and concerns of the public education system of today. The teachers though, need to step out of their "fears" and proceed to tell the political agents and others in positions of authority what needs to be done to 'change' the public education system in time to benefit the students of the twenty-first century. Yes, these educators have suggested that it is time for change, now. But, these teachers and others like them, who are currently working in the public school system, can't do it alone. The 
Running head: EFFECTS OF THE EMPHASIS ON ACHIEVING

principals out there who truly understand must also continue to speak out and not let "fear" stifle them from doing the right thing. By working together as individuals who truly believe in the significance of their students, this goal can be achieved and perhaps then the public schools of this country can be set in a positive evolving position to carry this nation and its children into a time that we cannot even imagine. 
Running head: EFFECTS OF THE EMPHASIS ON ACHIEVING

\section{REFERENCES}

Aronowitz, S. \& Giroux, H.A. (1993). Education Still Under Siege. Westport, CT:

Bergin \& Garvey.

Behar, R. (1993). Translated Woman. Boston, MA: Beacon Press.

Black, S.(2001, January). When Teachers Feel Good About Their Work, Research Shows Student Achievement Rises. The American School Journal , pp. 1 - 7. Retrieved on April 18, 2007 from: http://www.asbj.com/2001/01/0101research.html

Borkowski, J.W. \& Sneed, M. (2006). Will NCLB Improve or Harm Public Education: Harvard Educational Review, 76 (4), pp. 503-525.

Burke, R. (2010, February 5). Associate Professor of Teacher Education at Miami University of Ohio. Response to email from C. Fisher.

Burke, R. (2006). Enhancing No Child Left Behind - School Mental Health Connections. Journal of School Health, 76 (9), pp. 446 - 451. doi: 10.111/j.17461561.20 06.00142.x.

Burkhardt, H. F. (1990). The Dynamics of Curriculum Change, Developments in School Mathematics Education around the World: Proceedings of the UCSMP International Conference on Mathematics Education. Vol. 2, pp. 3 - 29. National Council of Teachers of Mathematics. Retrieved on January 19, 2010 from: http://www.worldcat.org/isbn/08735330X?

Callejo Perez, D., Fain, S., \& Slater, J. (2007). Educating for Democracy in a Changing World, New York, NY: Peter Lang Publishing.

Capito, S. (2010, January 28). Rep. to the U.S. House of Representative from West Virginia. Response to email from C. Fisher.

Cornell University Law School. (1972, March 21). Legal Information Institute, Supreme Court Collection No. 71-1332, pp. 1-2. Retrieved on May 28, 2009, from: http://www.law.cornel.edu/supct/html/historics/USSC_CR_0411_0001_ZS.html

Creswell, J. (2007). Qualitative Inquiry \& Research Design. Thousand Oaks, CA: Sage Publications.

Creswell, J.W. \& Plano Clark, V.L. (2008). The Mixed Methods Reader. Thousand Oaks, CA: Sage Publications. 
Running head: EFFECTS OF THE EMPHASIS ON ACHIEVING

Darling-Hammond, L. (2010). The Flat World and Education, New York, NY: Teachers College.

Darling-Hammond, L. (2009). Advice for the President (Chapter 9). In The Obama Education Plan. Jossey-Bass (Ed.), pp. 193-210. San Francisco, CA: Jossey-Bass. Dewey, J. (1938). Experience \& Education. New York, NY: Touchstone

Dewey, J. (2009). The School and Society \& The Child and The Curriculum. Lexington, KY: Feather Trail Press.

Dilley, P. (2004). Interviews and the Philosophy of Qualitative Research. The Journal of Higher Education, 75 (1) Jan. /Feb. pp. 127-132.

Duncan, A. (2009, February 16). U.S. Secretary of Education. Educate Our Way To A Better Economy. (M. Block, Interviewer) National Public Radio. pp.1 - 4. Retrieved on February 16, 2007 from: http://www.npr.org/templates/story/story.php?storyId100249947

Eisner, E. (1998). The Kind of Schools We Need. Portsmouth, NH: Heinemann.

Elmore, R. (2003). The Limits of Change. In The $21^{\text {st }}$ Century Principal. (Pierce \& Stapleton - Editors). Cambridge, MA: Harvard Education Press.

Erlauer, L. (2003). The Brain Compatible Classroom .Alexandria, VA: Association for Supervision and Curriculum Development.

Gewertz, C. (2009). Building Consensus on Learning Time (Chapter 6). In The Obama Education Plan. Jossey-Bass (Ed.), pp. 120-137. San Francisco, CA; Josser-Bass.

Fitzgerald, J. \& Shah, P. (2008). No Child Left Behind: The Teachers' Voice. St. Paul, MN pp1 - 25. Retrieved on April 14, 2009 from: http://www.MN2020.org

Flattau, P., Bracken, J., VanAtta, R., Bandeh-Ahmadi, A., de la Cruz, R., \& Sullivan, K. (2006, March). The National Defense Education Act of 1958: Selected Outcomes, Retrieved on January 15, 2009, from Science \& Technology Policy Institute: www.ida.org/stpi/pages/D3306/FINAL.pdf

Flinders, D. \& Mills, G.E.,(1993). Theory and Concepts in Qualitative Research: Perspectives from the Field. New York, NY: Teachers College Press.

Flynn, P. (1995). Global Competition and Education: Another Sputnik? Social Studies, 86 (2), pp. 1 - 4. Retrieved on January 14, 2010 from: Education Research Complete Database. 
Fraser, J. (2001). The School in the United States A Documentary History. New York, NY: McGraw-Hill.

Freire, P. (2007). Pedagogy of the Oppressed. New York, NY: Continuum International Publishing Group.

Gerla, J., Gilliam, B., \& Wright, G. (2006, Winter). Project Summit: A Cooperative Effort to Effect Teacher Change. Education, 127 (2), pp. 280-286. Retrieved on April 21, 2007 from: Education Research Complete Database.

Goldman, L. (1983). The Hidden Agenda of the Report on Excellence. Educational Leadership , 41 (2), pp. 24 -26. Retrieved on January 27, 2010 from Education Research Complete Database.

Hahn, L. E. (Ed.). (1997). The Philosophy of Hans-Georg Gadamer. Chicago, IL: Open Court Publishing Company.

Hale, J. (2010, January 28). President of the West Virginia American Federation of Teachers. Response to email from C. Fisher.

Halperin, S. (1979). ESEA Comes of Age: Some Historical Reflections. Educational Leadership , 36 (5), pp. 349 - 353. Retrieved on August 6, 2009 from Education Research Complete Database.

Harris, S. (2004). Bravo Principal! Building Relationships with Actions that Value Others. Larchmont, NY: Eye on Education.

Hehir, T. (2005). New Directions in Special Education. Cambridge, MA: Harvard Education Press.

Hoy, W. \& Woolfolk, A. (1993). Teachers' Sense of Efficacy and the Organizational Health of Schools. The Elementary School Journal, 93 (4), pp. 355 - 372. Retrieved on January 27, 2010 from Education Research Complete Database.

Hursh, D. (2007, September). Exacerbating Inequality: The Failed Promise of the No Child Left Behind Act. Race, Ethnicity and Education , 10 (3), pp. 295-308. Retrieved on January 27, 2010 from DOI: 10.1080/13613320701503264

Iannone, R. \& Obenauf, P. (1999). Toward Spirituality in Curriculum and Teaching. Journal of Education, 119 (4), pp.737 - 743.

Joffres, C. \& Haughey, M. (2001). Elementary Teachers' Commitment Declines: Antecedents, Process, and Outcomes. The Qualitative Report, 6 (1), pp. 1 - 20. Retrieved on January 27, 2010 from Education Research Complete Database. 
Running head: EFFECTS OF THE EMPHASIS ON ACHIEVING

Jones, S. (May 8, 2008). Creative Leadership under NCLB. pp. 1 - 7. Atlanta, GA: International Reading Association. Retrieved on November 12, 2008 from: http://engagedintellectual.wordpress.com/2008/05/09/ira-talk-for-literacy-coachescreative-lea...

Jorgensen, M. \& Hoffmann, J. (August, 2003). History of the No Child Left Behind Act of 2001 (NCLB). San Antonio, TX: Pearson Education, Inc. Retrieved from: http: //www.pearsonassess.com

Kantor, H. \& Lowe, R. (Winter, 2006). From New Deal to No Deal: No Child Left Behind and the Devolution of Responsibility for Equal Opportunity. Harvard Educational Review, 76 (4), pp. 474 - 502.

Kohn, A. (1999). The Schools Our Children Deserve. New York, NY: Houghton Mifflin Company.

Kozol, J. (2005). The Shame of the Nation, New York, NY: Three Rivers Press.

Labaree, D. F. (1997). How to Succeed in School Without Really Learning. New Haven, CT: Yale University Press.

Labaree, D. F. (2004). The Trouble with Ed Schools. New Haven , CT: Yale University Press.

Lather, P. \& Smithies, C. (1997). Troubling the Angels. Boulder, CO: Westview Press.

Lewis, A. (2002). The Will to Leave No Child Behind? Phi Delta Kappan, 83 (5), pp. 343 - 344. Retrieved on January 26, 2010 from: Education Research Complete Database.

Lincoln, Y.S. \& Guba (1985). Naturalistic Inquiry. Beverly Hills, CA: Sage Publications.

Lumsden, L. (1998). Teacher Morale. Educational Resources Information Center, ERIC Digest, Number 120. Eugene, OR: ERIC Clearinghouse. Retrieved on November 12, 2008 from: www.eric.ed.gov

Maehr, M.L., Midgley, C., \& Urdan, T. (August, 1992). School Leader as Motivator. Occasional Papers: School Leadership and Education Reform, OP\#9. Educational Administration Quarterly, 18 (3), pp. 1 - 32. Retrieved on January 15, 2010 from: http://www.eric.ed.gov/ERICWebPortal/custom?portlets/recordDetails/detailmini.jsp?_ nfpb=tru... 
Running head: EFFECTS OF THE EMPHASIS ON ACHIEVING

Marzano, R.J. (2007). The Art and Science of Teaching. Alexandria, VA: Association for Supervision and Curriculum Development.

McElroy, E. (July, 20, 2006). NCLB "Not Making the Grade". AFT Keynote Address, pp. 1 - 2. Retrieved on November 12, 2008 from:

http://www.aft.org/presscenter/releases/2006/072006a.htm

McKenzie, J. (September, 2006). Killing NCLB in 2007: 17 Reasons Why NCLB Must Go. NoChildLeft.Com, 4 (8) pp. 1-9. Retrieved on November 12, 2008, from: http://nochildleft.com/2006/sept06killing.html

Meir, D. (2000). Will Standards Save Public Education? Boston, MS: Beacon Press.

Miller, D. (2008). Teaching with Intention. Portland, Maine: Stenhouse Publishers.

Million, J. (May, 2005). Nurturing Teachers in the Famine of NCLB. Education Digest, 70 (9), pp. 16 - 18. Retrieved on November 12, 2008 from: Education Research Complete Database.

Moody, R. \& Barrett, J. (April, 2009). Stress Levels of School Administrators and Teachers in November and January. Academic Leadership: The Online Journal , 7 (2), pp. 1 - 10. Retrieved on May 7, 2009 from:

http: www.academicleadership.org/emprical_research/618.shtml

Moustakis, C. (1994). Phenomenological Research Methods. Thousand Oaks, CA: Sage Publications.

Murphy, R. (2003). The Challenge of a Changing Nation. In The $21^{\text {st }}$ Century Principal. (Pierce \& Stapleton - Editors). Cambridge, MA: Harvard Education Press.

National Council of Teachers of English (NCTE). (September 6, 2006). Literacy Educators and the Public Deeply Concerned about NCLB. The Council Chronicle Online. pp. 1-4. (NCTE, Ed.) Urbana, IL. Retrieved on November 11, 2008 from: http://www.ncte.org/pubs/chron/highlights/125383.htm

Nichols, S. (May, 2006). Low Pay, Lack of Respect and NCLB Create Crisis in Teacher Morale. Education Matters: California Schools and Public Education . pp. 1 - 2.

Retrieved on November 12, 2008 from: http://www.tellingthetruth.com/education_matters?ESSAYS_06/sandra_0506.html Noam, G. (2003). Using After School Programs to Raise Achievement. In The $21^{\text {st }}$ Century Principal. (Pierce \& Stapleton - Editors). Cambridge, MA: Harvard Education Press.

NVIVO8 (2007). QSR International Ltd., Australia: Doncaster, Victoria 3108. 
Running head: EFFECTS OF THE EMPHASIS ON ACHIEVING

Paine, S. (2010, January 28). West Virginia State Superintendent of Schools. Response to email from C. Fisher.

Patton, M. (2002). Qualitative Research \& Evaluation Methods (Third Ed.). Thousand Oaks, CA: Sage Publications, Inc.

Phillips, D.C. (1990). Subjectivity and Objectivity: An Objective Inquiry. In Eisner, E.W. \& Peshkin, A. (Ed.), Qualitative Inquiry In Education: The Continuing Debate . pp. 19 - 37. New York, NY: Teachers College Press.

Pinar, W. R. (2004). Understanding Curriculum. NewYork, NY: Peter Lang Publishing, Inc.

Ravitch, D. (June 8, 2009). Time to Kill "No Child Left Behind". Education Week , 28 (33). pp. 30 - 36. Retrieved on June 11, 2009 from:

http://www.edweek.org/ew/articles/2009/06/04/33ravitch_ep.h28.html?tkn=RVNFwrW cPvzqC...

Reese, W. J. (2005). America's Public Schools from the Common Schools to "No Child Left Behind". Baltimore, MD: Johns Hopkins University Press.

Reeves, D.B. (2006). The Learning Leader, Alexandria, VA: Association for Supervision and Curriculum Development.

Robertson, D. (2005). Enhancing Learning and Teaching. Queensland, Australia: Post Pressed.

Smith, D. (1991). Hermeneutic Inquiry: The Hermeneutic Imagination and the Pedagogic Text. In Forms of Curriculum Inquiry. Short, E.C. (Ed.), pp. 187 - 209. Albany, NY: State University of New York Press.

Spring, J. (1986). The American School 1642-1985. White Plains, NY: Longman Inc.

Sunderman, G. T. (September, 2004). Listening to Teachers: Classroom Realities and No Child Left Behind. pp. 2 - 47. Cambridge, MA: Harvard University Press.

Retrieved on January 15, 2010 from: http://www.eric.ed.gov/ERICWebPortal?Home.portal?_nfpb=true\&ERICExtSearch_Se archValu...

Tewel, K. (1995). New Schools for a New Century. Delray Beach, FL; St. Lucie Press.

Thattai, D. (2001). A History of Public Education in the United States. pp. 1 - 4.

Retrieved on May 28, 2009 from: http://www.servintfree.net/ aidmn-

ejournal/publications/2001-11/PublicEducationInTheUnited... 
Running head: EFFECTS OF THE EMPHASIS ON ACHIEVING

Theobald,P. (1997). Teaching the Commons - Place, Pride, and the Renewal of Community. Boulder, CO: Westview Press.

Tyack, D. B. (1974). The One Best System A History of American Urban Education. Cambridge, MA: Harvard University Press.

Tyler, R. (1969). Basic Principles of Curriculum and Instruction. Chicago, IL: University of Chicago Press.

U. S. Department of Education. (2004). A Guide to Education and No Child Left Behind. Washington, D.C.: U. S. Department of Education. Retrieved on April 4, 2009 from: http:/www.ed.gov/print/nclb/overview/intro/guide/guide.html

Van Manen, M. (1990). Researching Lived Experiences: Human Science for an Action Sensitive Pedagogy. Albany, NY: State University of New York Press.

Wagner, T. (2008). The Global Achievement Gap, New York, NY: Basic Books.

Wallin, J. (Fall, 2006). Under an Owl Moon: Topos and Abundance in Jardine's Ecopedagogy. Journal of Curriculum Theorizing , 22 (3), pp. 81 - 94. Retrieved on January 15, 2010 from Education Research Complete Database.

Wideman, R. (2002, September 23). Using Action Research and Provincial Test Results to Improve Student Learning. International Electronic Journal for Leadership in Learning, 6 (20) pp. 1 -13. Calgary, Ontario, Canada: University of Calgary Press. Retrieved on February 16, 2009 from:

http://www.ucalgary.ca/ iejll/volume6/wideman.html

Yeh, S. (2006). Reforming Federal Testing Policy to Support Teaching and Learning. Educational Policy, 20 (3), July, pp. 495-524. Retrieved on January 13, 2010 from DOI: $10.1177 / 0895904805284119$

Zellmer, M. (2006). What Are NCLB's Instructional Costs? Educational Leadership, 64 (3), pp. 43 - 46. Retrieved on April 7, 2008 from Education Research Complete Database. 


\section{Appendix I}

\section{Permission Letter to Superintendents}

Cathr $A_{\text {nn }}$ Fisher $_{\text {ishor }}$

94 Cimarron Road

Nutter Fort, WV 26301

Telephone: 304-623-3454 Cell Phone: 304- 476-2294

email: cathydanf@aol.com

August 15, 2009

Dear Superintendent:

I am Cathy Fisher, a Doctoral Student in Curriculum and Instruction at WVU under the supervision of Dr. Patricia Obenauf, a Professor in the College of Human Resources at West Virginia University. The intent of this letter is to ask your permission to interview from 6 to 10 teachers and the principal/s at the school/s listed at the bottom of this letter. The purpose of my research study is to investigate the effects of intervention strategies, the use of consultants, and the stress of the demands of meeting adequate yearly progress due to the requirements of No Child Left Behind. The interviews will take about 50 minutes and will be conducted by me with your teachers and administrators after the regular school day. No names will be used in any part of the study. There will be audio taping of the interviews, no names will be mentioned. All tapes will be kept secured during the study and destroyed at the conclusion of the study. The interviewees will be able to end the interview at any time and they do not need to answer every question. The audio tapes will allow me to transcribe the information in a very accurate manner. All participation is voluntary, confidential, and anonymous. Strict confidentiality will be maintained and none of the information will lead back to your staff members, your county or you. No identifiers will be used in the study. This study will have the acknowledgement of the West Virginia University Institutional Review Board (IRB).

I hope that you will allow the teachers and administrators from your county to participate in this study. Their participation will enable me to complete my study and perhaps to gain some information that will enable educators at the state and perhaps national level to further benefit students. Thank you very much for your time. If you have any questions about this research study, please contact me at 304-623-3454 (home) or 304-476-2294 (cell). You can also reach me by email at cathydanf@aol.com.

Please return this letter to me at the email address above after you have filled in the lines below. Again, thank you for your time and if you have questions, please call me at your convenience.

Respectfully,

Cathy A. Fisher

I am Superintendent of County.

(Please place an $\mathrm{X}$ on your choice below.)

I will allow the teachers and administrators of this county to participate.

I do not want the teachers and administrators to participate. 
Running head: EFFECTS OF THE EMPHASIS ON ACHIEVING

\section{Appendix II}

\section{Permission to Conduct Interviews}

\section{West Virginia University Internal Review Board \\ We West VirginiaUniversity.}

Office of Research Compliance

\section{Expedited-IRB Protocol-Exemption}

To: Obenauf, Patricia

From: $\quad$ WVU Office of Research Compliance

Date: $\quad$ Thursday, October 22, 2009

Subject: Exemption Acknowledgement

Tracking \#: $\mathrm{H}-21954$

Title: $\quad$ Effects of the Emphasis on Achieving Adequate Yearly Progress on Teachers and Administrators at Schools under the Constraints of No Child Left Behind

The above-referenced study was reviewed by the West Virginia University Institutional Review Board (IRB) and was granted exemption in accordance with 45 CFR 46.101(2).

This protocol was reviewed using the following:

Exemption Checklist (210r)

This research study was granted an exemption in accordance with Research that involves educational tests, survey procedures, interview procedures or observation of public behavior [45 CFR 46.101(2)].

The following documents have been acknowledged for use in this study and are available in the BRAAN system:

Miscellaneous Attachments Attachments

participant agreement wvu updated.doc (cover letter) This attachment is the updated and approved version of the particpants cover letter.

Thank you.

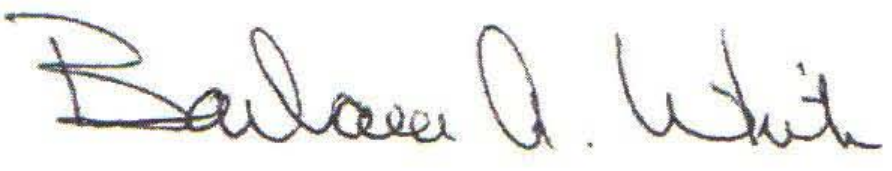




\title{
Appendix III
}

\section{Introductory Letter to Teachers}

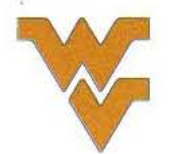

\section{Department of Curriculum \& Instruction/Literacy Studies WestVirginiaUniversity.}

\author{
College of Human Resources and Education
}

October 13, 2009

Dear Volunteer Participant:

This letter is a request for you to take part in a research project designed to assess the Effects of the Emphasis on Achieving Adequate Yearly Progress on Teachers and Administrators at Schools under the Constraints of No Child Left Behind. Your superintendent has given permission for this study to be conducted in your county. I am conducting this research project as a Doctoral Student in Curriculum and Instruction at WVU under the supervision of Dr. Patricia Obenauf, a professor in Human Resources and Education. Your participation in this project will be greatly appreciated and the interview will take approximately fifty minutes.

Your involvement in this project will be kept confidential and anonymous. All data will be reported in the aggregate. Your name will not be attached to any data. You must be at least eighteen years of age to participate. I will not ask for any information that would lead back to your identity as a participant. Your participation is completely voluntary. You may skip any question that you do not wish to answer and you may stop the interview at any time. Your employment status will not be affected if you decide either not to participate or to withdraw. No one will have that information. West Virginia University's Institutional Review Board's acknowledgment of this project is on file.

I hope that you will participate in this research project, as it could be beneficial in understanding the impact of Emphasis on Adequate Yearly Progress on educators in West Virginia. Thank you very much for your time. Should you have any questions about this letter or the research project, please feel free to contact me, Cathy Fisher at 304-623-3454 or by email at cathydanf@aol.com .

Thank you for your time and consideration of this project.

Respectfully,

Cathy Ann Burnett Fisher

If you agree to participate we will set-up the interview after school at your convenience any day before Thanksgiving break. I will return to your school to pick-up these forms on

Your Name Your School

Please check below:

Yes, I agree to be interviewed.

I want to do the interview on

No, I do not want to participate.

Day of Week October or November Date Time
after school.

\section{(PLEASE LEAVE THIS WITH YOUR SCHOOL SECRETARY.)}

602 Allen Hall PO Box 6122 Morgantown, WV 26506-6122

Phone: 304-293-3441 Fax: 304-293-3802

Equal Opportunity / Affirmative Action Institution 
Running head: EFFECTS OF THE EMPHASIS ON ACHIEVING

\section{Appendix IV}

\section{Information about School Administrators}

\begin{tabular}{|c|l|l|c|c|c|}
\hline School & \multicolumn{1}{|c|}{ Title } & $\begin{array}{c}\text { Total Years } \\
\text { Taught Prior } \\
\text { to } \\
\text { Administration }\end{array}$ & $\begin{array}{c}\text { Total Years at } \\
\text { this School as } \\
\text { an } \\
\text { Administrator }\end{array}$ & $\begin{array}{c}\text { Total Years } \\
\text { as an } \\
\text { Administrator }\end{array}$ & $\begin{array}{c}\text { Degree Level } \\
\text { and Field }\end{array}$ \\
\hline 1 & Principal & 9 & 5 & 5 & Master's +45 \\
\hline 2 & Principal & 8 & 1 & 30 & Master's +60 \\
\hline 2 & Ast. Principal & 19 & 14 & 14 & Master's +45 \\
\hline 3 & Principal & 21 & 3 & 3 & Master's +45 \\
\hline 4 & Principal & 16 & 16 & 16 & Master's +60 \\
\hline 5 & Principal & 17 & 5 & 5 & Master's +45 \\
\hline 6 & Principal & 24 & 6 & 7 & Master's +60 \\
\hline (totals) & Administrator & 114 & 50 & 80 & Master's +51 \\
\hline (averages) & Administrator & 16.3 & 7.1 & 11.4 & \\
\hline
\end{tabular}


Running head: EFFECTS OF THE EMPHASIS ON ACHIEVING

\section{Appendix V}

\section{Information About All Participating Schools}

\begin{tabular}{|c|c|c|c|c|c|c|}
\hline $\begin{array}{l}\text { School } \\
\text { Number }\end{array}$ & $\begin{array}{l}\text { Grade } \\
\text { Levels }\end{array}$ & $\begin{array}{l}\text { Number } \\
\text { of } \\
\text { Students }\end{array}$ & $\begin{array}{l}\text { Number } \\
\text { of } \\
\text { Teachers }\end{array}$ & $\begin{array}{l}\text { Number of } \\
\text { Administrators }\end{array}$ & $\begin{array}{l}\text { Years Not } \\
\text { Achieving } \\
\text { AYP }\end{array}$ & \begin{tabular}{|l} 
Student \\
Cells Not \\
Achieving \\
AYP/ and \\
Subject
\end{tabular} \\
\hline 1 & PK-5 & 460 & 40 & $\begin{array}{l}1 \text { Principal } \\
1 \text { Assistant Principal }\end{array}$ & 2 & $\begin{array}{l}\text { All/Reading } \\
\text { Low SES/ } \\
\text { Math } \\
\end{array}$ \\
\hline 2 & PK-5 & 580 & 50 & $\begin{array}{l}1 \text { Principal } \\
1 \text { Assistant Principal }\end{array}$ & 1 & \begin{tabular}{|l} 
Special \\
Needs \& \\
Low SES/ \\
Reading \& \\
Math
\end{tabular} \\
\hline 3 & PK-5 & 417 & 31 & 1 Principal & 2 & \begin{tabular}{|l} 
Special \\
Needs \& \\
Low SES/ \\
Reading \& \\
Math
\end{tabular} \\
\hline 4 & $5-8$ & 725 & 56 & $\begin{array}{l}1 \text { Principal } \\
2 \text { Assistant Principals }\end{array}$ & 4 & $\begin{array}{l}\text { Special } \\
\text { Needs \& } \\
\text { Low SES/ } \\
\text { Reading \& } \\
\text { Math }\end{array}$ \\
\hline 5 & $5-8$ & 714 & 55 & $\begin{array}{l}1 \text { Principal } \\
1 \text { Assistant Principal }\end{array}$ & 5 & \begin{tabular}{|l} 
Special \\
Needs \& \\
Low SES/ \\
Reading \& \\
Math
\end{tabular} \\
\hline 6 & $5-8$ & 260 & 30 & $\begin{array}{l}1 \text { Principal } \\
1 \text { Assistant Principal }\end{array}$ & 4 & \begin{tabular}{|l} 
Special \\
Needs \& \\
Low SES/ \\
Reading \& \\
Math
\end{tabular} \\
\hline (Totals) & PK -8 & 3,156 & 262 & 12 Administrators & 18 & \\
\hline
\end{tabular}


Running head: EFFECTS OF THE EMPHASIS ON ACHIEVING

\section{Appendix VI}

\section{School One}

\begin{tabular}{|c|c|c|c|}
\hline Teacher & $\begin{array}{c}\text { Total } \\
\text { Years } \\
\text { Taught }\end{array}$ & $\begin{array}{c}\text { Total Years } \\
\text { at This } \\
\text { School }\end{array}$ & $\begin{array}{c}\text { Degree } \\
\text { Level and } \\
\text { Field }\end{array}$ \\
\hline 1 & 35 & 7 & $\mathrm{M}+45$ \\
\hline 2 & 19 & 7 & $\mathrm{M}+45$ \\
\hline 3 & 3 & 3 & $\mathrm{~B}+15$ \\
\hline 4 & 30 & 7 & $\mathrm{M}+30$ \\
\hline 5 & 37 & 7 & $\mathrm{M}+45$ \\
\hline 6 & 35 & 7 & $\mathrm{~B}+15$ \\
\hline 7 & 29 & 7 & $\mathrm{M}+45$ \\
\hline 8 & 20 & 5 & $\mathrm{~B}+15$ \\
\hline 9 & 11 & 7 & $\mathrm{~B}+15$ \\
\hline & & & \\
\hline (Range) & $3-37$ & $3-7$ & \\
\hline (Average) & 24.3 & 6.3 & \\
\hline
\end{tabular}


Running head: EFFECTS OF THE EMPHASIS ON ACHIEVING

\section{Appendix VII}

\section{School Two}

\begin{tabular}{|c|c|c|l|}
\hline Teacher & $\begin{array}{c}\text { Total } \\
\text { Years } \\
\text { Taught }\end{array}$ & $\begin{array}{c}\text { Total Years } \\
\text { at This } \\
\text { School }\end{array}$ & $\begin{array}{c}\text { Degree } \\
\text { Level and } \\
\text { Field }\end{array}$ \\
\hline 1 & 32 & 30 & $\mathrm{M}$ \\
\hline 2 & 32 & 32 & $\mathrm{M}+45$ \\
\hline 3 & 33 & 14 & $\mathrm{M}+45$ \\
\hline 4 & 9 & 2 & $\mathrm{M}$ \\
\hline 5 & 22 & 11 & $\mathrm{M}+30$ \\
\hline 6 & 29 & 4 & $\mathrm{~B}+15$ \\
\hline 7 & 6 & 5 & $\mathrm{M}$ \\
\hline 8 & 42 & 19 & $\mathrm{M}+45$ \\
\hline 9 & 25 & 22 & $\mathrm{~B}+15$ \\
\hline 10 & 27 & 13 & $\mathrm{M}+45$ \\
\hline (Range) & $6-42$ & $2-32$ & \\
\hline (Average) & 25.7 & 15.2 & \\
\hline
\end{tabular}


Running head: EFFECTS OF THE EMPHASIS ON ACHIEVING

\section{Appendix VIII}

School Three

\begin{tabular}{|c|c|c|c|}
\hline Teacher & $\begin{array}{c}\text { Total } \\
\text { Years } \\
\text { Taught }\end{array}$ & $\begin{array}{c}\text { Total Years } \\
\text { at This } \\
\text { School }\end{array}$ & $\begin{array}{c}\text { Degree } \\
\text { Level and } \\
\text { Field }\end{array}$ \\
\hline 1 & 27 & 27 & $\mathrm{~B}$ \\
\hline 2 & 15 & 3 & $\mathrm{M}+30$ \\
\hline (Range) & $15-27$ & $3-27$ & \\
\hline (Average) & 21 & 15 & \\
\hline
\end{tabular}


Running head: EFFECTS OF THE EMPHASIS ON ACHIEVING

\section{Appendix IX}

\section{School Four}

\begin{tabular}{|c|c|c|l|}
\hline Teacher & $\begin{array}{c}\text { Total } \\
\text { Years } \\
\text { Taught }\end{array}$ & $\begin{array}{c}\text { Total Years } \\
\text { at This } \\
\text { School }\end{array}$ & $\begin{array}{c}\text { Degree } \\
\text { Level and } \\
\text { Field }\end{array}$ \\
\hline 1 & 35 & 18 & $\mathrm{M}+60$ \\
\hline 2 & 13 & 11 & $\mathrm{M}+45$ \\
\hline 3 & 30 & 5 & $\mathrm{M}+36$ \\
\hline 4 & 2 & 1 & $\mathrm{M}+45$ \\
\hline 5 & 36 & 36 & $\mathrm{~B}$ \\
\hline 6 & 21 & 18 & $\mathrm{~B}$ \\
\hline 7 & 2 & 2 & $\mathrm{M}+30$ \\
\hline 8 & 7 & 2 & $\mathrm{~B}+15$ \\
\hline 9 & 34 & 21 & $\mathrm{~B}+15$ \\
\hline 10 & 34 & 21 & $\mathrm{M}+45$ \\
\hline (Range) & $2-36$ & $1-36$ & \\
\hline (Average) & 21.4 & 13.5 & \\
\hline
\end{tabular}


Running head: EFFECTS OF THE EMPHASIS ON ACHIEVING

\section{Appendix $X$}

\section{School Five}

\begin{tabular}{|c|c|c|c|}
\hline Teacher & $\begin{array}{c}\text { Total } \\
\text { Years } \\
\text { Taught }\end{array}$ & $\begin{array}{c}\text { Total Years } \\
\text { at This } \\
\text { School }\end{array}$ & $\begin{array}{c}\text { Degree } \\
\text { Level and } \\
\text { Field }\end{array}$ \\
\hline 1 & 23 & 12 & $\mathrm{M}+30$ \\
\hline 2 & 18 & 10 & $\mathrm{M}$ \\
\hline (Range) & $18-23$ & $10-12$ & \\
\hline (Average) & 20.5 & 11 & \\
\hline
\end{tabular}


Running head: EFFECTS OF THE EMPHASIS ON ACHIEVING

\section{Appendix XI}

\section{School Six}

\begin{tabular}{|c|c|c|l|}
\hline Teacher & $\begin{array}{c}\text { Total } \\
\text { Years } \\
\text { Taught }\end{array}$ & $\begin{array}{c}\text { Total Years } \\
\text { at This } \\
\text { School }\end{array}$ & $\begin{array}{c}\text { Degree } \\
\text { Level and } \\
\text { Field }\end{array}$ \\
\hline 1 & 32 & 30 & $\mathrm{M}$ \\
\hline 2 & 27 & 12 & $\mathrm{~B}$ \\
\hline 3 & 9 & 3 & $\mathrm{M}$ \\
\hline 4 & 33 & 21 & $\mathrm{M}$ \\
\hline 5 & 22 & 16 & $\mathrm{M}+3$ \\
\hline 6 & 3 & 1 & $\mathrm{~B}+15$ \\
\hline 7 & 18 & 11 & $\mathrm{~B}+15$ \\
\hline 8 & 3 & 3 & $\mathrm{~B}$ \\
\hline 9 & 2 & 2 & $\mathrm{~B}$ \\
\hline 10 & 32 & 25 & $\mathrm{M}+60$ \\
& & & $\mathrm{NBC}$ \\
\hline (Range) & $2-33$ & $1-30$ & \\
\hline (Average) & 18.1 & 12.4 & \\
\hline
\end{tabular}


Running head: EFFECTS OF THE EMPHASIS ON ACHIEVING

\section{Appendix XII}

\section{Introductory Script to Begin Each Interview}

Hello and thank you for participating in this research study. I am Cathy Fisher, a student in the Doctoral Program in Curriculum and Instruction at West Virginia University. The purpose of this study is to explore the ways the mandated strategies of No Child Left Behind have affected your daily work load and activities at this school. I will be taking notes and also audio taping during the interview.

Before we begin I want to make sure you understand the following:

1. Your responses will be kept confidential; at no time will your name be revealed during the reporting of the information.

2. Your name will not be attached to either the tape or the notes from this interview, or to the transcribed data.

3. Your participation is entirely voluntary; you can choose to stop the interview at any time.

4. Your job status will not be affected by your refusal to participate or to withdraw from the study.

Thank you again for participating in this study. I will do my best to accurately report all of the information that you give to me.

We will begin now; please tell me about your experiences with trying to achieve AYP, consultants, workshops, new programs and teaching strategies, and any other aspects of dealing with the mandates of No Child Left Behind. 
Running head: EFFECTS OF THE EMPHASIS ON ACHIEVING

\section{Appendix XIII}

\section{Interview Questions (only used as a guide - never given to interviewees)}

\section{Research Question I:}

What are the effects of a consultant's work at schools that did not achieve AYP on:

(A): teachers' instructional techniques, daily work load, and teaching strategies used

with students and (B): administrators’ daily work load and leadership styles?

\section{Interview Questions that relate to Research Question I:}

1. As a result of working in a school that has mandated intervention strategies, such as a consultant, how have your teaching style, work load, and habits that guide your daily classroom management changed?

2. How effective do you think this method of "using a consultant" with substitutes in and out of your classroom has been to you, your students, and the school?

3. What do you do now in your daily teaching regimen that you did not do before this program and its objectives were introduced to you and this school?

4. What aspects of this program have been the most difficult to implement and integrate into your daily classroom routine?

5. What aspects were the easiest to implement and integrate into your daily classroom routine?

\section{Research Question II:}

What effects does the emphasis on achieving AYP at schools that do not meet the

required proficiency level on the NCLB mandated annual state tests have on:

(A): teachers and (B): administrators?

\section{Interview Questions that relate to Research Question II:}

6. What do you wish would have been done differently at the onset of this program at the school?

7. What kinds of staff changes have occurred at the school since the implementation of this program? (possible prompts - a: staff relationships, collegiality; b: staff morale; c: staff transferring out of the school; d: staff taking early retirement; e: new teachers transferring into the school; f: other types of changes)

8. What or how has the program caused you to change in regard to your feelings, motivation, and/or attitude when you come to work each day?

9. Suppose you were asked by the superintendent from another district for your ideas about ways to help the administration and teachers to improve test scores at a school that had not achieved AYP - what would you suggest?

10. What else would you like to add about this school since the emphasis was placed on achieving AYP? 
Running head: EFFECTS OF THE EMPHASIS ON ACHIEVING

\title{
Appendix XIV
}

\author{
Sample Interview Transcript
}

File 25 -- Interview

\begin{abstract}
After reading the Introductory Script as shown in Appendix XII, the interview would begin. The interviewees were not given the Research Questions. Those questions were only used by this researcher as a way to check off what had been commented on by the interviewee. If a topic had not been covered then, a comment was interjected by this researcher in an attempt to get information about it from the interviewee.
\end{abstract}

I have been a teacher for twenty-one and a half years. I have been at this school for eighteen years. I have a Masters plus thirty hours and I teach fifth grade. I teach reading this year, in the past it has been Reading Language Arts and History. My undergraduate degree is all subjects -- kindergarten through sixth grade. I have a Masters in Special Education - Learning Disabilities and Mildly Impaired kindergarten through twelfth grade.

The last two years for me being a regular education teacher with mainstreamed special needs students, I feel constant stress to the point where I can't sleep. I am to the point where I am up through the night sometimes two and a half three hours a night before I can go back to sleep.

I think it is inclusion that is one thing that stresses me out. It just depends on who is teaching with me. I would have ideas for the special needs students, I don't have any control. I would have to run ideas by that teacher first. And, then even when I have a concern about kids, there's not a lot she can control. If their modifications are being met it's like I still can't meet them without contacting administration if that teacher doesn't want me to do something. As far as other stress, I have noticed stress just about things I can't control. Like if I need something fixed in my classroom or a password for something, or results to something I can't get my hands on. It's like pulling teeth to get information. I'm not stressed about anything I can control. I am not stressed about working with the kids or planning lessons. It's more about what the consultants and supervisors are demanding.

It's all state mandated. We have no control over that. I was happiest when my classroom was fully contained and there were not students coming in and out all the time. Even though they mandated state CSOs. You still had more say than you do now in your own regular education room. When they put the special need students in your room and say - teach them. You can't reach them all, you can try, you can modify, you can accommodate, you can make it interesting, you can make it fun, there is only so much you can do and that's what keeps you up at night. 
Running head: EFFECTS OF THE EMPHASIS ON ACHIEVING

\section{Appendix XIV -- Continued}

\section{Sample Interview Transcript}

\section{File 25 - Interview Continued}

We didn’t make it -- our test scores didn’t make it because of our special education population. We can't help that the special population is so large here. They are here to stay. We are doing our job and identifying our students and it appears that we are penalized for that. We do a good job here identifying them. Then we are penalized because they are here. So it is a catch twenty-two.

I don't think that the general public has an understanding when the scores come back and when the school didn't achieve AYP again. It isn't said that it's the special needs area that did not make the score and that the other areas did achieve the score.

I didn't know where the low scores were until the day in late August when we had our workshop and they told us. So, I know that is not what was put in the newspaper. I do not think that most of the parents of our students know. And, I do not know if they would understand if you explained it to them. And, what does that matter?

So now we have all of these new programs to implement - Acuity, Tech Steps, DIBELS, RTI and many others. Last year we did other programs and other trainings and now we are getting rid of some of those and adding others.

It is good that they took some things away, they put some things in and before you could get any results they take them away?

I wasn't sure how I felt about DIBELS. We did it one year and it seemed to me it was more about how fast they could read. To me it should be more about do they comprehend. And, maybe that's my special education background.

I don't understand that and a lot of our teachers do not understand either. There are no comprehension scores and yet comprehension is very important to us as teachers. The DIBELS wanted to know if the student is slow and correct or fast and incorrect, and all these ratings, where's the comprehension? Are they putting things in and taking them out for a reason? I feel overwhelmed with these different programs. And I feel that the special needs students are not being served very well.

I have heard many other teachers say they are overwhelmed with all these tests the kids are taking. I think the tests cut out a lot of instruction time. I feel overwhelmed that we have so many CSOs to meet in a certain time period and we are constantly having classes pulled out to take this test or we have to go watch this in the auditorium. It is like instruction time is always interrupted. 
Running head: EFFECTS OF THE EMPHASIS ON ACHIEVING

\section{Appendix XIV -- Continued}

\section{Sample Interview Transcript}

\section{File 25 - Interview Continued}

Anyway when we do all of these different assessments we do not have much real time to actually look at those individual scores and set-up the instruction around the needs of the students as indicated by the results.

If I want to fit the instruction to the assessment, then I have to do that on my own time either here after school or at home. We are all doing so many things at home. If you really care you are doing things at home. And once you do that and you look at your children as a group and think how am I going to teach them, and you back up and say this one was missed the most so I had better teach this. It's just old fashioned teaching. There's absolutely nothing new about that. So you go with what is missed the most. That is what you do.

You try to figure out a new way to teach it, to make it more interesting for the students. They may have missed it because you did something wrong as a teacher, I think that is what the test tries to portray. Maybe you weren't entertaining enough that day. I feel like when I do my lesson plans for certain classes, I have heard other teachers say oh I can just do them real fast, it takes me hours because I am researching this stuff. Where can I find a power point, where can I find a song? I am only planning for two or three classes a week, it takes me a long time and I don't hear other teachers saying that. I don't know how much this even helps.

I am still in the stage where I am just going with the flow. I will do whatever you ask me to do. I think if something needs to be changed I will try to say it in the nicest way possible because I don't feel like I have much authority. It does stress me out, the number of hours I put in outside of school. I am looking at test scores. I am really trying and it might be because I am an inclusive teacher a lot of the time. I really want to impress the teacher I am working with so they will let me teach.

Daily I teach with at least four different teachers in and out of my room. It is two different grade levels and four different teachers. I have one class that I don't teach with anyone else so it's just me. I have $6^{\text {th }}$ grade reading, $6^{\text {th }}$ grade math, $5^{\text {th }}$ grade math, $5^{\text {th }}$ grade reading, and $5^{\text {th }}$ grade language arts. Also, when I work with the $5^{\text {th }}$ grade math I am with two different teachers and they are doing totally different things in two totally different ways. Last year I was with one teacher all day. It was a senior teacher and they didn't let me do a lot because they were getting ready to retire so that part was worse the part that was better was that I got a chance to know them and work together. Now it's just like some of the classes might be an hour and a half and I'm only in there for forty-five minutes and some of the classes are only forty-five minutes long. So, it's kind of like peeking your head in seeing how your special needs students are doing and what you can help them with. 
Running head: EFFECTS OF THE EMPHASIS ON ACHIEVING

\section{Appendix XIV -- Continued}

\section{Sample Interview Transcript}

\section{File 25 - Interview Continued}

At the most I have had nine special needs students in the regular classroom at one time, at the least there were probably five. It has to be 30\%. There are usually at least four to five. And usually I might only have one or two that need a lot of help the other ones just need to make sure their modifications are being met.

I think the idea of measuring and assessing each student is great. Not every teacher wants to be on board with this. They are from the day when you sent your special needs students out. And now here you come with your group of special needs students in their $r$ room and we have to make sure these modifications are being met. These modifications are just not being met on a weekly basis these are every day. When you go home every night you have to modify your plan for every one of your students. You have to constantly work with other teachers and you don't get a lot of time to plan with other teachers. And, if one teacher is not meeting the modification it's my job as a special needs teacher to tell them that we're not and that we are going to because it is the law. And, how do you think they feel about me coming in their classroom after I have said that to them? I am a new teacher here and, how am I am going to tell a veteran teacher how to modify for a child. As far as meeting modifications, it was easier when I was with one teacher.

I still love my job. I have only been here for a year so I am still happy. They have just been here so long and I haven’t seen many changes yet.

I am actually teaching an RTI class, sixth grade reading. I've only done it for a week so far. I love the group of kids. We are starting and developing the program at the same time. Here I believe the state test scores determined the tiers this year. Who was lacking in comprehension on the state test? We'll put all of them in a group together and we will work on that skill with them. And in fluency, we will work on that skill with that group.

The administration did the grouping of the students this first year, but in the future if they think someone will need tested for special services then they'll put them in RTI and we will actually see if that benefits them. I don't know. I love my job, I'm not that stressed out. I do get overwhelmed with the fact that you don't have time at work to get your job done, I knew that was coming, that it was part of teaching. It is stressful to go home and do work for a couple of hours. 
Running head: EFFECTS OF THE EMPHASIS ON ACHIEVING

\section{Appendix XIV -- Continued}

\section{Sample Interview Transcript}

\section{File 25 - Interview Continued}

That is just the way it is. The way it was explained to me when I was first hired, other people work from eight to five, you work at school from 7:30 a.m. to 3:00 p.m. and then your other two hours are either spent at school or you take it home. That is how professionals do it. Anything else you get involved in to be helpful to your school which the school needs these things, then you are going to be working all weekend. You are volunteering, still it takes extra time. And the more you do the more people expect. I find that certain people do the extra and certain other people don't. I volunteered to do it. So I am not complaining about it. If you want the kids to have things then you have to go above and beyond to help them out. 
Running head: EFFECTS OF THE EMPHASIS ON ACHIEVING

\section{Appendix XV}

\section{Background Information of Readers/Peer Reviewers}

\begin{tabular}{|c|c|c|c|c|}
\hline Reader & Profession & $\begin{array}{l}\text { Number } \\
\text { of Years } \\
\text { Teaching }\end{array}$ & $\begin{array}{l}\text { Subject/Grade Taught at } \\
\text { Present Time }\end{array}$ & Degree Level \\
\hline Reader 1 & $\begin{array}{l}\text { Retired } \\
\text { Teacher }\end{array}$ & 36 & $\begin{array}{l}\text { Special Needs - K - } 12- \\
\text { All subjects } \\
\text { Also was a High School } \\
\text { Business/Computer } \\
\text { Teacher }\end{array}$ & $\begin{array}{l}\text { Masters + } 45 \text { Special Education } \\
\text { - Learning Disabilities and } \\
\text { Mentally Impaired }\end{array}$ \\
\hline Reader 2 & $\begin{array}{l}\text { Speech } \\
\text { Pathologist } \\
\text { and } \\
\text { Regular } \\
\text { Classroom } \\
\text { Teacher }\end{array}$ & 21 & Speech Pathology K - 6 & $\begin{array}{l}\text { Masters + } 65 \text { Speech Pathology } \\
\text { Also holds degrees in Special } \\
\text { Education - Mildly Impaired K- } \\
12 \text { and Regular Education K - } 6\end{array}$ \\
\hline
\end{tabular}


Running head: EFFECTS OF THE EMPHASIS ON ACHIEVING

\section{Appendix XVI}

Development of Themes

\section{Research Question 1A - Effects of Consultant's Work on Teachers' Strategies}

Transcribed Interviews

Themes

Findings

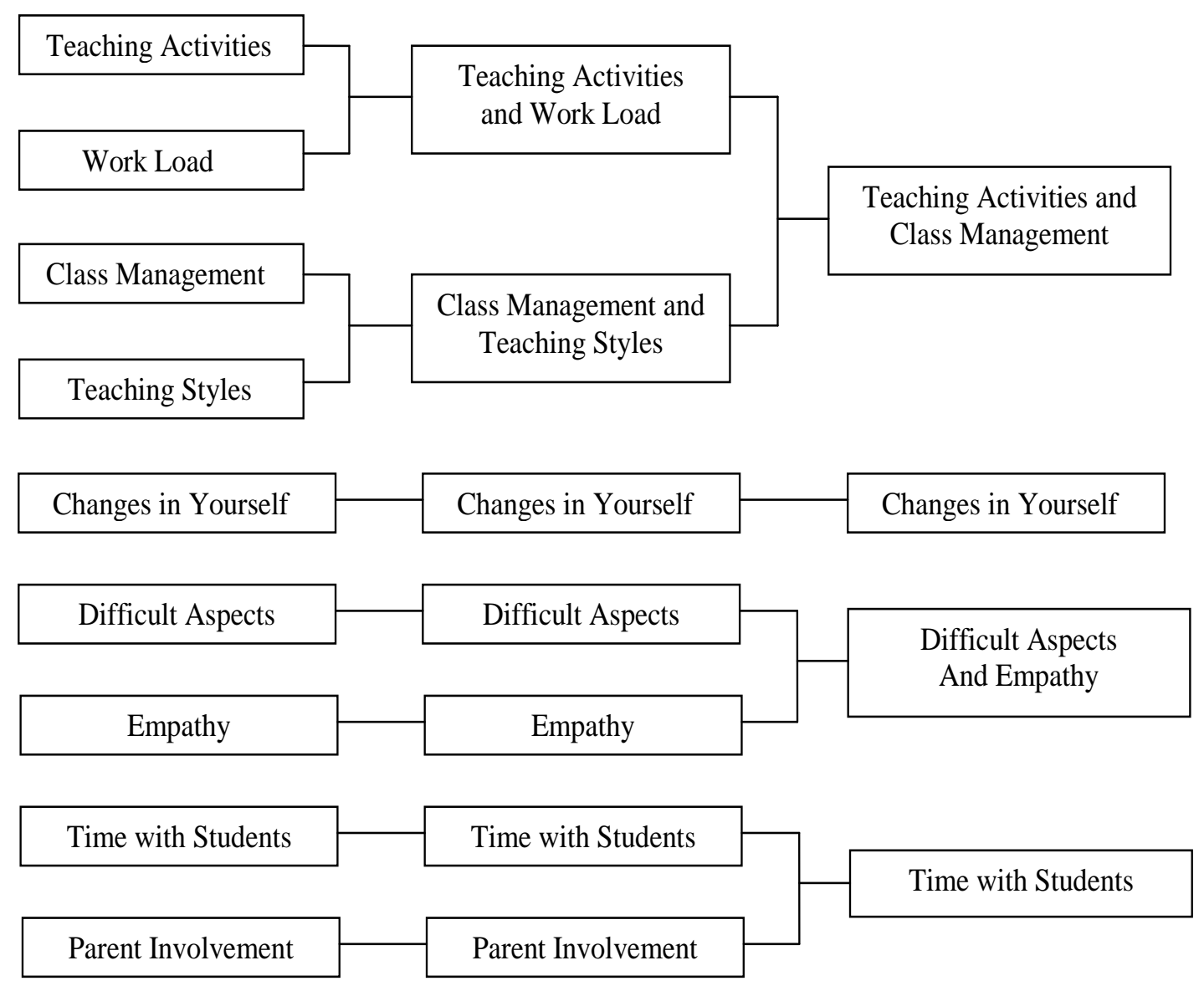

Teacher Comments

Changes in Students

Changes in the School

Insignificant

Comments

Easiest Aspects 
Running head: EFFECTS OF THE EMPHASIS ON ACHIEVING

\section{Appendix XVI -- Continued}

Development of Themes

Research Question 1B - Effects of Consultant's Work on Administrators' Work Load

Findings
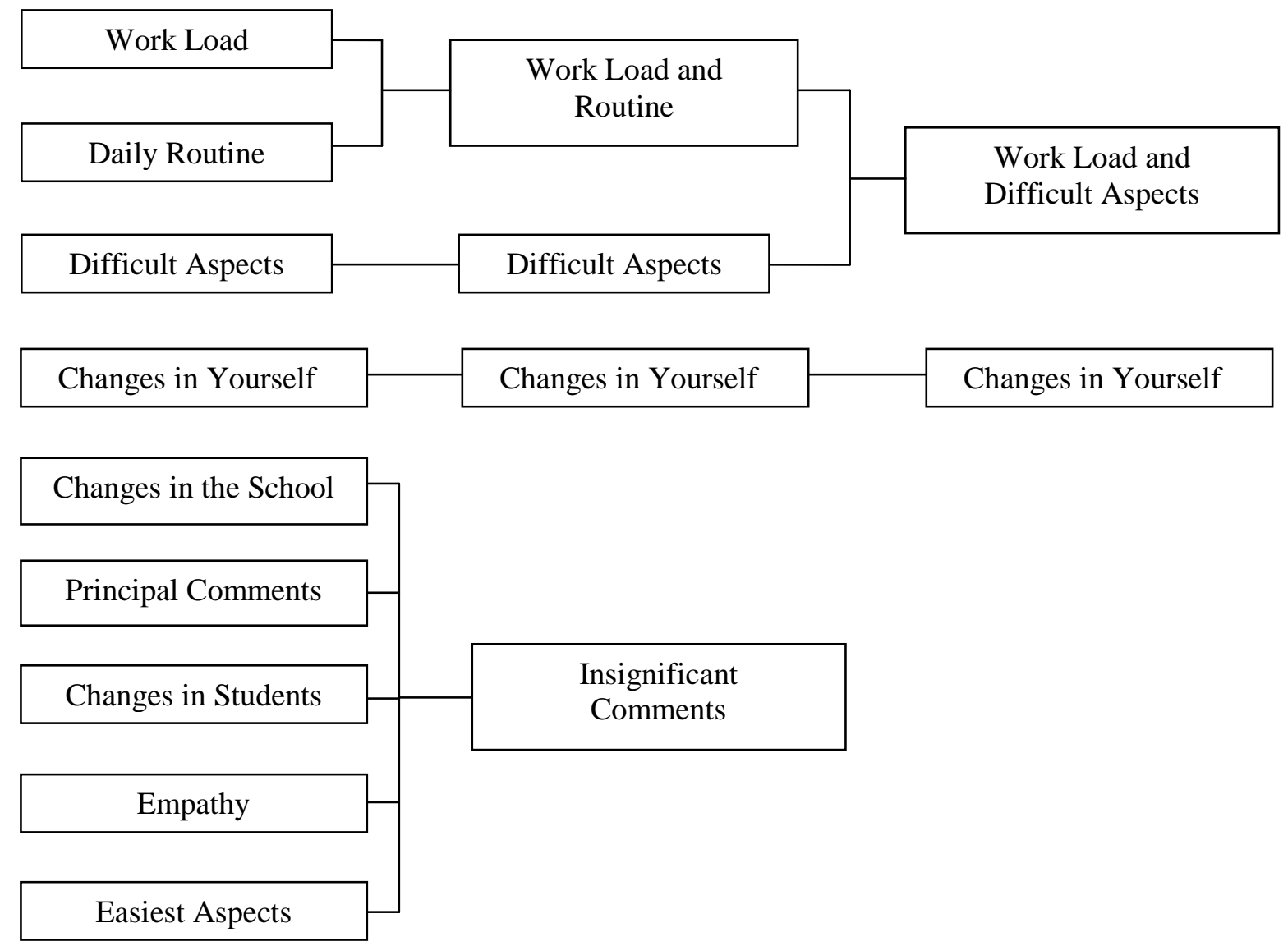
Running head: EFFECTS OF THE EMPHASIS ON ACHIEVING

\section{Appendix XVI -- Continued \\ Development of Themes}

Research Question 2A - Effects of AYP Emphasis on Teachers

Transcribed Interviews

Themes

Findings
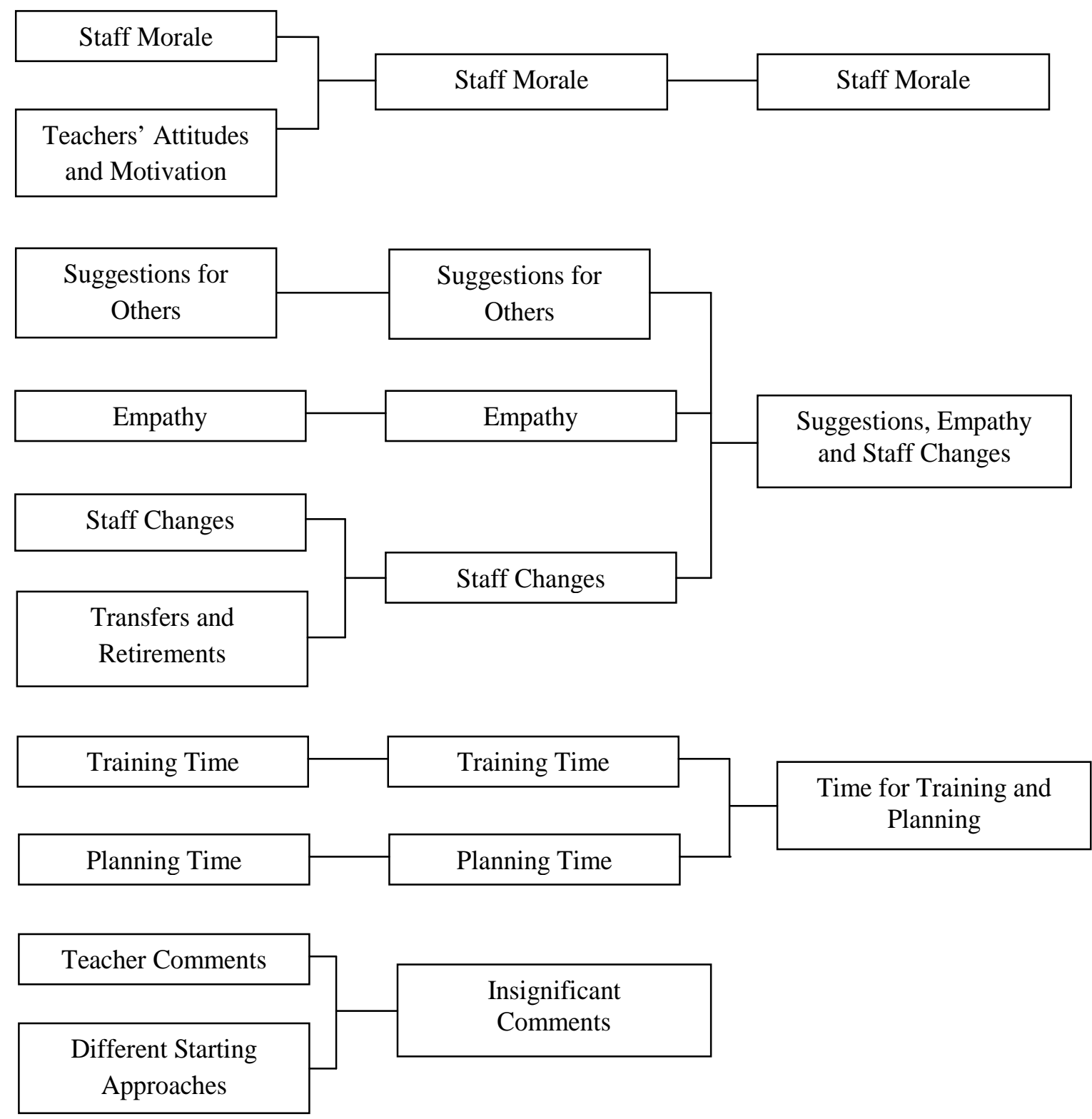
Running head: EFFECTS OF THE EMPHASIS ON ACHIEVING

\section{Appendix XVI -- Continued}

\section{Development of Themes}

Research Question 2B - Effects of AYP Emphasis on Administrators

Transcribed Interviews

Themes

Findings

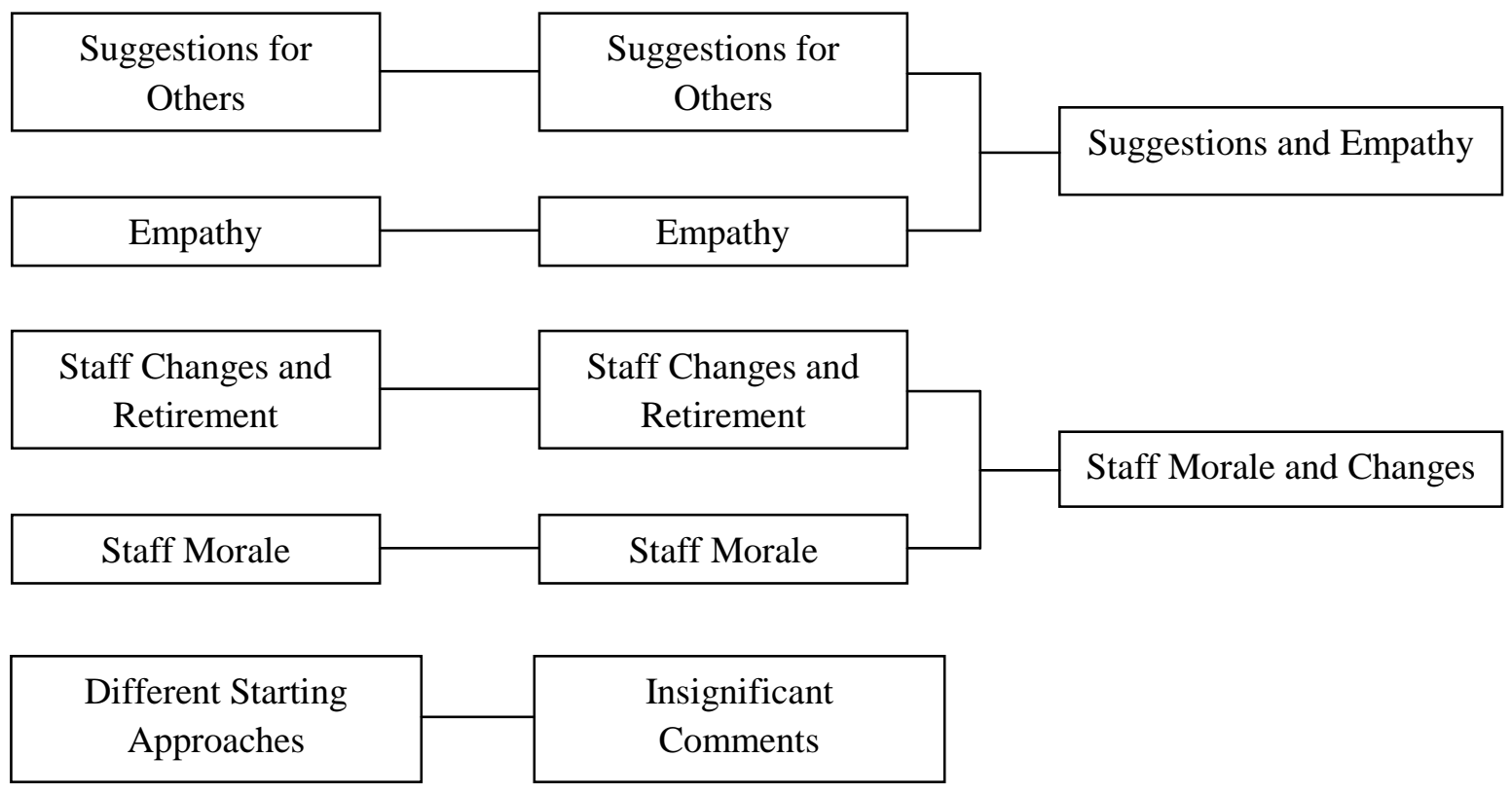

